\title{
The role of inflammasomes in vascular cognitive impairment
}

\author{
Luting Poh', Wei Liang Sim, Dong-Gyu Jo², Quynh Nhu Dinh ${ }^{3}$, Grant R. Drummond ${ }^{3}$, Christopher G. Sobey ${ }^{3}$, \\ Christopher Li-Hsian Chen ${ }^{4,5}$, Mitchell K. P. Lai ${ }^{4}$, David Y. Fann ${ }^{1,6,7,8^{*}}$ and Thiruma V. Arumugam ${ }^{2,3^{*}}$ (D)
}

\begin{abstract}
There is an increasing prevalence of Vascular Cognitive Impairment ( $\mathrm{VCl}$ ) worldwide, and several studies have suggested that Chronic Cerebral Hypoperfusion (CCH) plays a critical role in disease onset and progression. However, there is a limited understanding of the underlying pathophysiology of $\mathrm{VCl}$, especially in relation to $\mathrm{CCH}$. Neuroinflammation is a significant contributor in the progression of $\mathrm{VCl}$ as increased systemic levels of the proinflammatory cytokine interleukin-1 $\beta$ (IL-1 $\beta$ ) has been extensively reported in VCl patients. Recently it has been established that CCH can activate the inflammasome signaling pathways, involving NLRP3 and AIM2 inflammasomes that critically regulate IL-1 $\beta$ production. Given that neuroinflammation is an early event in $\mathrm{VCl}$, it is important that we understand its molecular and cellular mechanisms to enable development of disease-modifying treatments to reduce the structural brain damage and cognitive deficits that are observed clinically in the elderly. Hence, this review aims to provide a comprehensive insight into the molecular and cellular mechanisms involved in the pathogenesis of $\mathrm{CCH}$-induced inflammasome signaling in $\mathrm{VCl}$.
\end{abstract}

Keywords: Inflammasome, Inflammation, Chronic cerebral Hypoperfusion, Vascular cognitive impairment, Vascular dementia

\section{Dementia: a focus on vascular cognitive impairment}

Dementia describes a set of symptoms that occur when the brain is damaged by injury or disease. These commonly include progressive deterioration in memory, thinking and behavior, and ultimately the ability to perform everyday activities [1]. Dementia can be caused by many neurological disorders including Alzheimer's disease (AD), frontotemporal dementia, Lewy body dementia and vascular dementia $(\mathrm{VaD})$. An estimated 35.6 million people worldwide were diagnosed with dementia in 2010, with these numbers expected to double every 20 years [2]. In particular, the proportion of $\mathrm{VaD}$

\footnotetext{
* Correspondence: bchfywd@nus.edu.sg; g.arumugam@latrobe.edu.au 'Department of Physiology, Yong Loo Lin School of Medicine, National University of Singapore, Singapore, Singapore

${ }^{2}$ School of Pharmacy, Sungkyunkwan University, Suwon, Republic of Korea Full list of author information is available at the end of the article
}

patients among the entire dementia population is reported to be approximately $15-20 \%$ in North America and Europe $[3,4]$, and $30 \%$ in Asia and developing countries [5-7].

In recent decades, increasing evidence has shown vascular diseases contributing to cognitive impairment and memory deficits, with an underlying vascular component in the etiology of most forms of dementia $[8,9]$. Several studies have shown that with the inclusion of dementia arising from mixed neuropathologies, the percentage of the demented population with a contributing vascular cause may be up to $70 \%[10,11]$. To effectively target cognitive impairment due to vascular injury or diseases, the term Vascular Cognitive Impairment (VCI) was introduced to encapsulate the whole spectrum of disease, ranging from subjective cognitive impairment, mild cognitive impairment to dementia associated with underlying cerebrovascular disease burden [12, 13]. 
VCI arises from heterogeneous cerebrovascular pathologies with diverse vascular etiologies. From the perspective of vascular injury, the origin and type of vascular occlusion, hemorrhage, distribution of arterial territories, and vessel size are the common causes of the types of vascular pathologies due to large vessel diseases, small vessel diseases, ischemic-hypoperfusive and hemorrhagic diseases [14]. The underlying vascular etiologies for VCI have been extensively reviewed in the statement released by the International Society for Vascular Behavioral and Cognitive Disorders (VASCOG) [15].

\section{Chronic Cerebral Hypoperfusion (CCH): a primary driver of $\mathrm{VCl}$}

Pre-clinical vascular diseases are difficult to detect until vascular lesions are formed and affect cognitive functions [16]. While numerous lines of evidence have identified risk factors associated with pre-clinical vascular diseases and $\mathrm{VCI}$, the mechanisms by which these risk factors contribute to VCI pathologies resulting in cognitive impairment remain to be fully established [17-19]. Emerging evidence suggests that chronic cerebral hypoperfusion $(\mathrm{CCH})$, as a result of vascular disease, could play a critical role in the pathophysiology of VCI [2022]. $\mathrm{CCH}$ refers to a condition whereby cerebral blood flow (CBF) supply to the brain is reduced by 20 to $40 \%$ over a prolonged period. It can occur either to the whole brain or within specific brain regions [23, 24]. $\mathrm{CCH}$ is involved in the development of $\mathrm{VCI}$ as it is closelyassociated with a number of major physiological vascular risk factors, VCI pathologies and cognitive decline [20, $25,26]$. It is well established $\mathrm{CCH}$ precedes white matter lesion (WML) formation and the presence of cerebral hypoperfusion together with white matter lesions, further exacerbates the decline in executive function and memory in VCI patients with dementia [27, 28].

Understanding the effect of $\mathrm{CCH}$ on cerebral function may explain its role in VCI. A continuous CBF plays an essential role in maintaining the brain's structural and functional integrity [29]. At the neurovascular level, continuous blood supply to the brain parenchyma is necessary for essential functions such as neuronal activity, blood-brain barrier function and immune cell surveillance [8]. Disruption of blood flow to the brain is associated with a number of neurovascular dysfunctions such as endothelial dysfunction, glial activation, demyelination and blood-brain barrier breakdown as observed in VCI patients [30-32]. These observations warrant mechanistic investigations of $\mathrm{VCI}$ pathogenesis from the perspective of $\mathrm{CCH}$. Various animal models have been developed to mimic a state of cerebral hypoperfusion as observed in VCI patients [33, 34]. By experimentally inducing $\mathrm{CCH}$, these animal models provide a useful platform for understanding the underlying pathophysiology of VCI.

\section{Pathogenic molecular mechanisms of $\mathrm{CCH}$}

Disruptions to CBF directly results in reduced glucose and oxygen supply, leading to immediate bioenergetic impairment and ionic imbalance, and development of excitotoxicity, oxidative stress and inflammation (Fig. 1).

\section{Bioenergetic impairment and ionic imbalance}

Bioenergetic impairment refers to the disruption of cellular energy metabolism. Inadequate blood supply due to $\mathrm{CCH}$ is likely to result in bioenergetic impairments as neurons are unable to produce sufficient adenosine triphosphate (ATP) for normal cellular functions [35, 36]. Reduction in ATP production leads to compromised function of ATP-dependent ion channels such as the $\mathrm{Na}^{+} / \mathrm{K}^{+}$and $\mathrm{Ca}^{2+}$ pump. The ion channels' inability to maintain an ionic balance results in a net $\mathrm{Na}^{+}$and $\mathrm{Ca}^{2+}$ influx, and $\mathrm{K}^{+}$efflux across the plasma membrane. Consequently, this increases the resting membrane potential to threshold, leading to unregulated depolarizations known as anoxic depolarization in neurons [37, 38].

Studies have provided evidence suggesting bioenergetic impairment and ionic imbalance caused by $\mathrm{CCH}$ [39-41]. Mitochondrial dysfunction has been reported to be evident in VCI, whereby the expression and activity of mitochondrial enzymes that are vital for ATP production and cellular bioenergetics are reduced in a $\mathrm{CCH}$ rodent model of VCI [39]. Several energy metabolites including ATP were significantly reduced upon $\mathrm{CCH}$ [40]. Impairment in $\mathrm{Na}^{+} / \mathrm{K}^{+}$homeostasis has also been observed with $\mathrm{CCH}$, with reduced blood flow leading to increased intracellular $\mathrm{Na}^{+}$concentration and decreased in intracellular $\mathrm{K}^{+}$concentration [35]. Pharmacological inhibition of $\mathrm{Ca}^{2+}$ influx offers neuroprotective effects on hippocampal neurons under $\mathrm{CCH}$, demonstrating the significance of $\mathrm{Ca}^{2+}$ influx in mediating $\mathrm{CCH}$-induced injuries [42].

\section{Excitotoxicity}

Excitotoxicity is the damage or death of neurons from the uncontrolled stimulation of excitatory glutamate receptors and is prevalent during $\mathrm{CCH}$. As neurons undergo anoxic depolarization during cerebral hypoperfusion, there is a resulting influx of $\mathrm{Ca}^{2+}$ ions into the presynaptic neuronal terminals, culminating in a massive release of the excitatory neurotransmitter glutamate into the synaptic cleft $[35,43]$. Consequently, postsynaptic glutamate receptors on surrounding neurons become overstimulated, causing a large influx of $\mathrm{Na}^{+}$and $\mathrm{Ca}^{2+}$ ions that trigger the propagation of an uncontrolled downstream cytotoxic cascade. Accumulation of intracellular $\mathrm{Na}^{+}$creates an osmotic pressure for water to enter the neuron, leading to cytotoxic swelling and lysis 


\section{Possible Pathological Mechanisms of $\mathrm{CCH}-$ Induced VCI}

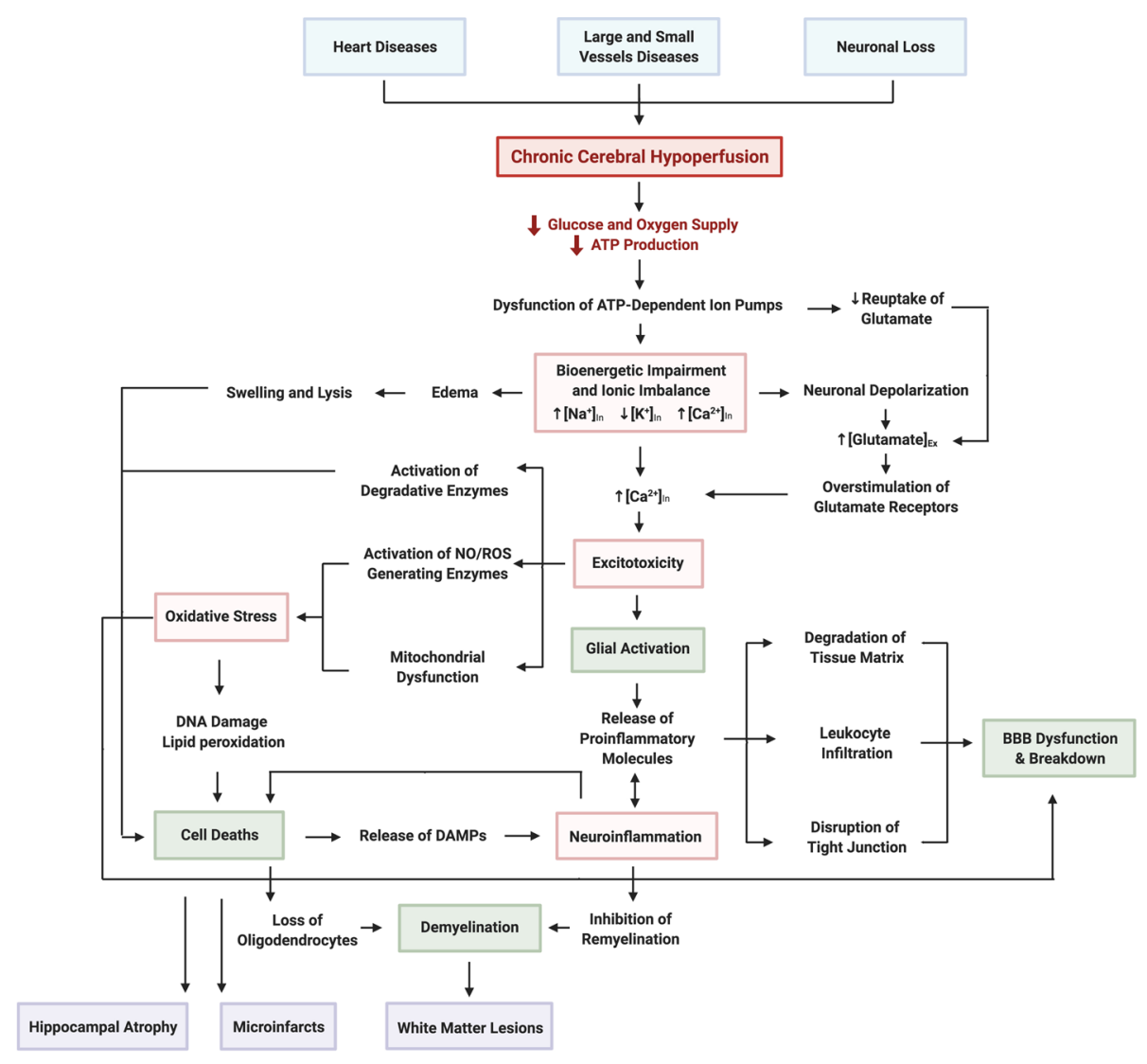

Fig. 1 A schematic diagram illustrating the possible pathological mechanisms of VCl. Cardiovascular disease is major contributor to early cerebral blood flow reduction in the disease progression of $\mathrm{VCl}$. These conditions include heart disease (i.e. coronary artery disease and arrhythmias) that impairs the ejection of blood into the blood circulation; and small and large vessel diseases (i.e. atherosclerosis and arteriosclerosis), which narrow the vascular lumen and impede blood flow. Neuronal loss results in reduced production of angiogenesis regulators, leading to neurovascular unit uncoupling. These conditions converge to cause chronic cerebral hypoperfusion that reduces delivery of glucose and oxygen to the brain leading to decreased energy (i.e. ATP) production, resulting in bioenergetic impairment. Reduced ATP levels initiate a series of pathogenic molecular and cellular mechanisms. Firstly, the function of ATP-dependent transporters (i.e. $\mathrm{Na}^{+} / \mathrm{K}^{+}$ATPase) are impaired leading to ionic imbalance (i.e. $\mathrm{Na}^{+}$and $\mathrm{Ca}^{2+}$ influx, and $\mathrm{K}^{+}$efflux) across the plasma membrane resulting in anoxic depolarization within neurons causing excitotoxicity. Moreover, increased levels of intracellular $\mathrm{Ca}^{2+}$ activate a wide variety of calcium-dependent ROS generating pathways in the mitochondria and cytosol contributing to oxidative stress. Finally, neuroinflammation is activated as stressed or injured cells release DAMPs that bind to PRRs to induce an inflammatory response. Under $\mathrm{CCH}$, these molecular mechanisms influence each other within different cell types that result in the following pathogenic cellular mechanisms: glial activation, BBB dysfunction, cell death and demyelination. As pathogenic cellular mechanisms accumulate, they synergistically drive further damage eventually causing structural damage such as white matter lesions,

microinfarcts and hippocampal atrophy. Each of these structural changes cause disruption to the neuronal network and functional connectivity that eventually leads to cognitive decline. Abbreviations: VCl, vascular cognitive impairment; ATP, adenosine triphosphate; ROS, reactive oxygen species; DAMPs, damage-associated molecular patterns; $\mathrm{CCH}$, chronic cerebral hypoperfusion; BBB, blood brain barrier

[35, 44, 45]. High levels of intracellular $\mathrm{Ca}^{2+}$ activate downstream catabolic enzymes such as endonuclease and calpain, which degrade key cellular components such as nuclear DNA and the extracellular matrix, respectively, potentially resulting in either apoptosis and necrosis depending on $\mathrm{CCH}$ severity $[38,46]$. Studies have shown the therapeutic potential of interventions targeting excitotoxicity, including memantine, glutamate receptor antagonist and calcium channel blockers, in ameliorating VCI for both patients and rodent models of $\mathrm{VaD}[47-50]$.

\section{Oxidative stress}

Oxidative stress occurs when the balance of reactive oxygen species (ROS) and antioxidants disrupted and is increasingly implicated in $\mathrm{VaD}$. Upon disruption of $\mathrm{CBF}$, the mitochondrial electron transport chain is disturbed, electron leakage occurs and reaction with oxygen produces a ROS called superoxide $\left(\mathrm{O}_{2}^{-}\right)[38,51,52]$. Disruption of calcium homeostasis during $\mathrm{CCH}$-induced excitotoxicity can also trigger ROS overproduction through depolarization of the mitochondrial membrane and activation of downstream ROS-generating enzymes 
such as NADPH (nicotinamide adenine dinucleotide phosphate) oxidases and xanthine oxidase [53, 54]. It was recently suggested that a major source of ROS production in the cytosol was activated NADPH oxidase in VCI, with enzyme inhibition capable of ameliorating cognitive impairment in a $\mathrm{CCH}$ rodent model [55]. Moreover, $\mathrm{O}_{2}{ }^{-}$can spontaneously undergo a series of dismutation reactions to form other types of ROS such as hydrogen peroxide $\left(\mathrm{H}_{2} \mathrm{O}_{2}\right)$ and hydroxyl radical $\left(\mathrm{OH}^{-}\right)[56,57]$.

Oxidative stress can cause DNA damage and induce oxidation of lipids and proteins that eventually results in apoptotic death [58]. Elevated hydrogen peroxide levels were observed in isolated mitochondria from the brain of rodent models of VCI, with an increase proportionate to the duration of $\mathrm{CCH}$ [39]. Several markers of oxidative stress are elevated in VCI patients, such as lipid peroxidation and oxidized DNA, coupled with reduced antioxidant levels in the plasma [59-61].

\section{Neuroinflammation}

Neuroinflammation is characterized by an increased production of proinflammatory cytokines and chemokines by resident brain cells such as microglia and astrocytes, together with infiltration of peripheral immune cells into the CNS $[62,63]$. This is usually in response to pathogens or to a variety of pathophysiological mechanisms such as bioenergetic imbalance, excitotoxity, mitochondrial dysfunction and oxidative stress causing stress or injury to neurons, glial and vascular endothelial cells during $\mathrm{CCH}$. Consequently, danger signals such as damage-associated molecular patterns (DAMPs) that are released into the extracellular environment are able to initiate local and systemic inflammation $[62,63]$.

The presence of chronic inflammation has been reported in VCI patients during pre-clinical, clinical and severe stages of $\mathrm{VaD}$ [64-67]. These studies reported elevated levels of classic inflammatory mediators such as interleukin-1 beta (IL-1 $\beta$ ), interleukin-6 (IL-6), TNF $\alpha$ and $\mathrm{C}$-reactive protein (CRP) that propagate inflammation, leading to degradation of the tissue matrix and infiltration of peripheral immune cells causing various forms of cell death [64-67]. Studies in animal models suggest that $\mathrm{CCH}$ can induce both acute and chronic neuroinflammation that damage the myelin sheath, blood-brain barrier (BBB) and grey matter via oligodendrocyte loss, endothelial cell dysfunction, and apoptotic and necrotic cell death of the neurovascular unit [68-71]. Furthermore, the complement system may also be involved in driving late stage neuroinflammatory processes via complement factor $5 \mathrm{a}$ (C5a), as elimination of C5a in a VCI mouse model exerts a protective effect against $\mathrm{CCH}$-induced injury [72].

\section{Pathogenic cellular mechanisms of $\mathrm{CCH}$}

The aforementioned molecular mechanisms initiated by $\mathrm{CCH}$ are critical drivers of subsequent pathogenic cellular mechanisms in VCI such as glial activation, bloodbrain barrier dysfunction, cell death and demyelination (Fig. 1).

\section{Glial activation}

Glial activation occurs when resident immune cells switch from a resting state to an activated state to initiate a series of changes in glial function following cellular stress and injury in the brain. In general, microglia and astrocytes are considered the main resident immuneassociated cell types in the brain that respond readily to microenvironmental disturbances. $\mathrm{CCH}$ can trigger glial activation through ionic imbalance, oxidative stress and neuroinflammation [23, 73, 74] .

Several studies of brains from VCI have shown the presence of reactive astrocytes and microglia in the areas surrounding lesions, alongside markers of oxidative stress and inflammation [75-77]. These activated glial cells are likely to be involved in the pathophysiology of VCI via several mechanisms. Firstly, they initiate and facilitate neuroinflammation, leading to cellular injury and leukocyte infiltration into the brain $[78,79]$. Secondly, inflammation suppresses the pro-survival action of endothelial cells on neurons by reducing neurotrophic signaling leading to endothelial cell atrophy and microvascular rarefaction [80, 81]. Thirdly, activated microglia release proinflammatory cytokines and chemokines that disrupt $\mathrm{BBB}$ integrity by redistributing tight junction proteins and reorganizing the actin cytoskeleton in microvascular endothelial cells in the brain $[82,83]$. Finally, glial activation contributes to demyelination by impeding remyelination, as reactive astrocytes and microglia surrounding the white matter lesion release IL- $1 \beta$ and hyaluronan to inhibit maturation of oligodendrocytes during $\mathrm{CCH}[69$, 84].

\section{Blood-Brain barrier dysfunction and breakdown}

Blood-brain barrier (BBB) dysfunction is when the integrity of the highly selective semipermeable border surrounding the brain parenchyma is compromised. BBB function involves coordinated interactions between endothelial cells and pericytes regulating the selective diffusion of substances into the brain parenchyma. In particular, it is regulated by tight junction proteins (TJPs) located between endothelial cells, with the support of pericytes attached $[85,86]$. Disruption of TJP arrangement or distribution loosens the interaction between adjacent endothelial cells, compromising the physical barrier and increasing its permeability to foreign substances [87, 88]. CCH-induced oxidative stress and inflammation contribute significantly to BBB dysfunction 
by reducing the density of TJPs on the endothelial membrane [89-91]. Inflammation can also upregulate cell adhesion molecules (i.e. Intercellular Adhesion Molecule (ICAM) and Vascular Cell Adhesion Molecule (VCAM) to facilitate the infiltration of peripheral immune cells across the BBB to release additional ROS and proinflammatory cytokines [90, 92, 93]. Finally, proinflammatory cytokines can upregulate gene expression of matrix metalloproteinases, MMP2 and MMP9, that can also degrade the extracellular matrix contributing to $\mathrm{BBB}$ dysfunction [94, 95].

Dysfunction of the BBB is increasingly implicated in VCI $[96,97]$. In multiple mouse models of $\mathrm{CCH}$, impairment of the BBB is observed through increased vascular permeability of intravascular Evans blue dye and horseradish peroxidase (HRP) into the brain parenchyma [91, $98,99]$. Several studies have also shown that $\mathrm{CCH}$ reduced pericyte coverage on capillaries, contributing to BBB dysfunction via endothelial transcytosis [91, 100, 101]. Moreover, the cerebrospinal fluid/plasma albumin ratio, another indicator of $\mathrm{BBB}$ damage, has also been reported to be elevated in VCI patients relative to healthy controls, with the severity of BBB damage corresponding to white matter lesions [102]. While the nature and extent of BBB disruption in the pathogenesis of $\mathrm{VCI}$ remains to be fully elucidated, it is currently thought to be mediated by oxidative stress and neuroinflammation $[103,104]$.

\section{Cell death: necrosis and apoptosis}

The aforementioned pathogenic molecular mechanisms caused by $\mathrm{CCH}$, including bioenergetic imbalance, excitotoxicity, oxidative stress and inflammation, can disrupt the integrity of the neurovascular unit leading to programmed neuronal and glial death $[38,58,105]$. In particular, accumulation of $\mathrm{Ca}^{2+}$ in the cytosol from excitotoxicity can activate catabolic enzymes that cleave DNA and hydrolyze cellular cytoskeletal proteins to cause apoptosis $[46,106,107]$. Similarly, $\mathrm{CCH}$-induced oxidative stress and neuroinflammation can also activate cell death pathways. For example, $\mathrm{H}_{2} \mathrm{O}_{2}$ can trigger necrosis and apoptosis via the modulation of activator protein-1 (AP-1) and B-cell lymphoma-2 (Bcl-2) family proteins, respectively [108, 109]. The proinflammatory cytokine, TNF- $\alpha$, is a critical ligand for death receptors that can activate pro-apoptotic caspase- 8 and -3 in the extrinsic apoptotic pathway during $\mathrm{CCH}$ [110].

Necrosis and apoptosis are two types of cell death that have been established to occur clinically in VCI. In VCI, necrotic cell death can be observed within lacunar infarcts formed when the brain tissue is exposed to total or partial reduction of blood flow [111, 112]. Apoptosis is a highly conserved cell death pathway involving the family of cysteine-dependent aspartate specific proteases
(Caspases), which induces DNA fragmentation and phagocytic signaling $[113,114]$. Apoptosis has also been observed in cerebral autosomal dominant arteriopathy with CADASIL patients and various mouse models of VCI [115-117]. In addition to necrosis and apoptosis, recent studies have demonstrated inflammasome mediated necroptotic and pyroptotic forms of cell death during $\mathrm{CCH}$, suggesting its potential involvement in $\mathrm{VCI}$ $[66,71,118,119]$.

\section{Demyelination}

Demyelination refers to a condition where the protective myelin sheath that surrounds neuronal axons is damaged and degraded. It is commonly observed within the deep white matter in patients with small vessel disease, leading to cognitive decline in the aged brain $[120,121]$.

$\mathrm{CCH}$ can result in demyelination induced by a hypoxic-ischemic environment and inflammation [121, 122]. Hypoxic conditions trigger the activation of the hypoxia-inducible factor-1 (HIF-1) regulatory pathway leading to inflammation and apoptotic cell death [76, 123]. Inflammation activates glial cells to release inflammatory mediators such as TNF- $\alpha$, matrix metalloproteinases (MMPs) and serine proteases that damage the myelin sheath [77, 124, 125]. Active proteases (i.e. MMP-1, MMP-2, MMP-3, MMP-7, MMP-9 and Calpain) induced by $\mathrm{CBF}$ disruption degrade myelin basic protein (MPB), and disrupt the polymeric network within the myelin sheath [95, 124, 126]. Moreover, $\mathrm{CCH}$-induced inflammation can initiate activation of apoptosis and pyroptosis in oligodendrocytes, that may attenuate myelin synthesis and repair, and exacerbate demyelination [71].

\section{Pathological Structural features and cognitive impairment from $\mathrm{CCH}$}

Several structural pathological features are observed in the brain during VCI. Advances in neuroimaging have allowed detection of white matter lesions, lacunes, microinfarcts, microbleeds and enlarged periventricular spaces, which are now considered standard diagnostic features of VCI [15, 127, 128]. In this section, several key pathogenic structural damages and cognitive impairment associated with $\mathrm{CCH}$ will be discussed (Fig. 1).

\section{White matter Lesions}

White matter lesions (WMLs) are regions in the brain parenchyma with demyelination in the white matter that appear as hyperintensities (without cavitation) on T2weighted MRI images [128]. WMLs are primarily formed from axonal demyelination that is usually produced from the loss of oligodendrocytes [129, 130], and accompanied by both glial activation [131, 132] and loss of axonglial integrity [133]. These features are a reflection of the 
underlying mechanisms of $\mathrm{CCH}$-induced WML formation. As discussed above, $\mathrm{CCH}$ triggers molecular mechanisms that contribute to glial activation, cell death and demyelination. As cerebral hypoperfusion persists, these injuries accumulate at the cellular level, especially in oligodendrocytes within the white matter region and surrounding glial cells.

WMLs are a significant contributor to cognitive decline and are a prominent feature of VCI [134-136]. WMLs disrupt the functional connections between the cortical and subcortical regions, affecting cognitive function and emotions $[137,138]$. WMLs also reflect loss of cholinergic neurons, compromising the neurotransmitter system, eventually leading to cognitive decline in VCI patients $[134,139]$. The main mechanisms underlying the formation of WMLs in humans are critical stenosis and hypoperfusion of medullary arterioles in small vessel disease (i.e. arteriolosclerosis) and hypotensive episodes [140-142]. White matter regions with lower CBF developed into WMLs in a longitudinal study [143]. The positive association between $\mathrm{CCH}$ and a decline in cognitive function is particularly profound in patients with severe WMLs [28]. In mouse models, $\mathrm{CCH}$ resulted in similar white matter rarefaction and lesion formation together with cognitive impairment, further emphasizing the common role of WMLs in VCI [71].

\section{Microinfarcts}

Microinfarcts are small fluid-filled spaces/lesions that appear in large numbers within the cortical and subcortical brain regions. The formation of microinfarcts is usually caused by the activation of necrotic and programmed cell death pathways in neurons and glial cells, and commonly associated with neuronal loss, gliosis and axonal damage [144-146]. This process is often accompanied by the migration of glial and peripheral immune cells, such as macrophages, to the necrotic site of injury. Immune cells phagocytose damaged cells, and astrocytes proliferate and undergo gliosis to form a barrier around the lesion to limit the spread of necrosis [145-147].

Microinfarcts are more prominent in VCI than in other demented patients [148]. In VCI, microinfarcts are associated with cerebral amyloid angiopathy and reduced cerebral perfusion $[22,120]$. Several post-mortem studies have demonstrated that hypoperfusion initiates and promotes the progression of microinfarct formation in brain areas vulnerable to hypoperfusion (i.e. watershed cortical region) $[149,150]$. Microinfarcts affect the brain structural network, leading to impaired performance in various cognitive domains [151, 152]. Microinfarcts also cause primary disruption to local tissue function, secondary inflammation and axonal disorganization to the white matter tracts, further exacerbating damage to brain circuits and function [153-155].

\section{Hippocampal atrophy}

Hippocampal atrophy refers to the loss of neurons and neuronal volume in the hippocampus. It is a classic marker for $\mathrm{AD}$, but can also be observed in VCI patients. The degree of atrophy has been estimated to be $16.6 \%$ in $\mathrm{AD}$ and $11.6 \%$ in VCI [156-158]. The hippocampus is a complex brain region that is highly sensitive and vulnerable to insults caused by reduced cerebral perfusion or hypoxia, which stimulate a number of pathogenic mechanisms such as excitotoxicity, oxidative stress, and inflammation to activate cell death pathways [159, 160], leading to hippocampal atrophy. Animal studies have shown that with $\mathrm{CCH}$, the hippocampus displays acute neuronal damage and cell death originating from the CA4 area, to CA2 and CA3, with the CA1 area being the last zone affected [71, 161, 162]. Decline in memory performance, spatial navigation and visuospatial functions have been observed in patients with hippocampal atrophy $[163,164]$. While the direct mechanistic explanation for these associations in VCI has not been established, it is suggested that reduced neuronal capacity in the hippocampal area lowers its connectivity with other brain regions [163-165]. Decreased levels of the synaptic protein synaptophysin has been reported in VCI patients compared to healthy subjects, suggesting a potential deficit in synaptic transmission upon hippocampal atrophy $[144,166]$.

\section{Cognitive dysfunction in VCl}

VCI encompasses a broad spectrum of cognitive dysfunctions ranging from subjective cognitive impairment, mild cognitive impairment to dementia $(\mathrm{VaD})[8,13]$. The underlying pathophysiological mechanisms responsible for $\mathrm{CCH}$-induced cognitive impairment may be extensive and severe. $\mathrm{CCH}$ initiates several cellular mechanisms - glial activation, BBB dysfunction, cell death and demyelination, via the activation of numerous pathogenic molecular mechanisms, including bioenergetic impairment and ionic imbalance, excitotoxicity, oxidative stress and neuroinflammation in different types of brain cells. These mechanisms all contribute to structural damage such as WMLs, microinfarcts and hippocampal atrophy. The influence of these structural damages on cognitive function was discussed previously.

Several guidelines have proposed that VCI is a syndrome with evidence of either clinical stroke or subclinical vascular brain injury, and cognitive impairment affecting at least one cognitive domain $[8,15,167]$. The cognitive domains involved in diagnosing $\mathrm{VCI}$ are executive/attention, memory, language, and visuospatial function [8]. Executive dysfunction is a well characterized neurological feature of $\mathrm{VaD}$ and can be present in $\mathrm{VCI}$ patients who are not demented [168, 169]. Impairments to executive functions are heavily associated with lesions 
and damage within the frontal lobes or downstream frontal-subcortical circuits of $\mathrm{VCI} / \mathrm{VaD}$ patients [170, 171]. Memory impairment is a key feature of $A D$ and is also important in $\mathrm{VaD}$. Studies have shown that $\mathrm{VaD}$ patients experienced greater impairment in semantic memory than $\mathrm{AD}$ patients, possibly due to the inability to retrieve information from short and long-term memory [172-174]. Impairments in language and visuospatial functions can also be observed in VCI. When presented with a picture description task, $\mathrm{VaD}$ patients exhibit lower semantic content production while maintaining a fluency comparable to healthy patients [175]. VaD patients show impairments in most of the tests associated with visuospatial tasks, indicating a deficit in constructional and visuoperceptual ability $[174,176]$.

\section{Inflammation - a critical molecular mechanism and a bridge between $\mathrm{CCH}$ and various cellular mechanisms}

Several key events have been identified in the pathophysiology of VCI, as briefly summarized above. However, whether these events are causative or merely consequential to the progression of $\mathrm{VCI}$ has yet to be conclusively validated. A comprehensive understanding on the pathogenesis of VCI will not only pave the way for development of interventions, but allow us to target VCI with maximum efficacy [8]. In addition, interventions targeting an early temporal event in the pathogenesis of VCI would better attenuate other repercussions elicited by the many late temporal events in the pathogenesis of VCI. Hence, there is an increasing focus on exploring the temporal profile of events in the pathogenesis of VCI. The current notion regarding VCI remains that the underlying root cause is the initial disruption to CBF, with a cascade of events leading to cognitive impairments [20-22, 26, 177]. Specifically, several lines of evidence have highlighted a plausible causative role of neuroinflammation as an early temporal event that then influences other mechanisms in contributing to the pathogenesis of VCI [64-67, 77].

Neuroinflammation has been implicated in dementia, and is associated with a decline in cognitive functions and functional connectivity in demented patients [178, 179]. Elevated levels of inflammatory markers, including the highly sensitive CRP and IL- 6 , IL- 8 and IL- $1 \beta$, were found in brain tissues and peripheral samples of demented patients $[65,66,180-182]$. Some of them (e.g. IL-6 and CRP) were even associated with an increased risk of dementia, including $\mathrm{VaD}[181,182]$. However, a few studies demonstrated lower levels of inflammatory mediators in patients with dementia. For example, Chen et al. and Mulugeta et al. showed that normal controls had significantly higher levels of IL-6 and IL-8 in different parts of the brain when compared to $\mathrm{AD}$, mixed dementia or $\mathrm{VaD}$ patients $[183,184]$. It was also observed that IL- 6 and IL-8 levels were lower in the cerebrospinal fluid and plasma of patients with AD [185, 186]. While the results are controversial, it is essential to consider the following points. Firstly, the profile of cytokines may depend on the stage and progression of the disease $[187,188]$. Secondly, some of these inflammatory cytokines, such as IL- 6 and TNF- $\alpha$, may exhibit pleiotropic actions with known pro- or anti-inflammatory effects [187, 188], which adds more complexity to the interpretation of these studies. Lastly, heterogeneity of post-mortem samples and difficult application of the detection methods for proinflammatory mediators in the brain and peripheral samples may account for the contradictory conclusions of some studies [189-191]. Despite these variable results, inflammation is still considered one of the critical underlying mechanisms of dementia. More importantly, the levels of these proinflammatory mediators were shown to be elevated even before the clinical onset of $\mathrm{VaD}$ [67] suggesting that neuroinflammation may be involved in both early and late stages of $\mathrm{VCI}$ disease progression.

The associations between neuroinflammation and impairments in cognitive function may stem from its involvement in several key events in the pathogenesis of VCI, such as glial activation, BBB dysfunction, cell death, demyelination and WML formation. The influence of neuroinflammation on these events through the action of the inflammasome signaling pathway will be discussed in the following section.

\section{Inflammasome signaling pathway: linking IL-1 to VCI}

Among the numerous inflammatory mediators implicated in VCI, one group of proinflammatory cytokines is prominent: the interleukin-1 (IL-1) family. Amongst the IL- 1 family members, both IL- $1 \beta$ and IL- 18 are increasingly implicated in the progression of VCI. Elevated levels of both IL-1 $\beta$ and IL-18 have been reported in the serum of $\mathrm{VaD}$ patients [64, 65, 192]. While there could be an involvement of systemic inflammation in the studies of serum samples, postmortem studies of different brain tissues showed that the level of IL-1 $\beta$ was higher in the frontal cortex and hippocampus of $\mathrm{VaD}$ patients in comparison to controls $[66,193]$ indicating that IL-1 $\beta$ may be strongly involved in the process of neuroinflammation during VCI. The production and maturation of both IL- $1 \beta$ and IL- 18 is primarily driven from a major arm of the innate immune system termed the inflammasome signaling pathway [194]. As such, this pathway is likely to serve as a critical point in regulating production of IL-1 family cytokines during the pathogenesis of VCI. 


\section{Overview of the Inflammasome signaling pathway}

Inflammasomes are macromolecular protein complexes that are essential signaling platforms capable of detecting pathogenic signals via pathogen-associated molecular patterns (PAMPs) and endogenous sterile stressors via damage-associated molecular patterns (DAMPs) [38]. Upon detection of PAMPs or DAMPs, the inflammasome complex is activated to trigger downstream inflammatory cascades such as the production of inflammatory cytokines. Given its sterile nature, neuroinflammation in VCI can be considered exclusively driven by DAMPs. The two main characterized inflammasome signaling pathways are the canonical and non-canonical pathways, each of which involves two steps to achieve inflammasome signaling: priming and activation $[38,195,196]$.

The canonical inflammasome signaling pathway typically leads to the activation of caspase- 1 and -8 (Fig. 2). The priming step (i.e. Signal 1) is initiated by the presence of DAMPs (e.g. HMGB1, IL- $1 \alpha$ ), which can activate various extracellular PRRs including toll-like receptors (TLR; TLR2, TLR4), receptor for advanced glycation end-products (RAGE) and interleukin-1 receptor 1 (IL1R1) $[195,197]$, leading to downstream activation of NF-кB, MAPK, p53 and JAK-STAT pathways [38, 195, 198]. The main purpose of priming is to increase gene expression of key inflammasome components (i.e. receptor/sensor, adaptor and effector) and precursors of IL- $1 \beta$ and IL-18 in the cytosol [199, 200]. Priming can be independent of transcriptional expression whereby posttranslational modifications (i.e. phosphorylation and deubiquitination) are essential to "license" inflammasome activation [201]. The activation step (i.e. Signal 2) involves stimulation of cytosolic inflammasome receptors/ sensors that can be triggered by various DAMPs and/or disturbances in the cellular microenvironment, resulting in assembly and activation of the canonical inflammasome complex to facilitate activation of effectors caspase- 1 and -8 [194, 202]. The NLRP3 complex is arguably the best characterized inflammasome, and along with the NLRP1, NLRC4 and AIM2 inflammasome complexes facilitates the self-cleavage of total caspase- 1 and -8 into biologically active cleaved caspase- 1 and -8 , respectively [194, 195, 203, 204]. Both cleaved caspase-1 and -8 can cleave precursors of both IL- $1 \beta$ and IL-18 into mature proinflammatory cytokines that can then amplify downstream inflammation [205, 206]. Cleaved caspase- 1 and -8 are also implicated in the activation of programmed cell death pathways such apoptosis and pyroptosis [207-209], and will be discussed below.

The non-canonical inflammasome signaling pathway leads to the activation of the mouse homolog caspase11, with the corresponding human homologs being caspase- 4 and -5 (Fig. 2). It shares some similarities to the canonical activation of caspase-1, although the non- canonical pathway possesses some unique characteristics. Transcriptional priming is also present for caspase11 in the non-canonical inflammasome signaling pathway, mediated by extracellular PRRs, including Toll-Like Receptors (TLRs) (i.e. TLR2, TLR4), RAGE and IL-1R1 [195, 197]. Total caspase-11 can detect cytosolic lipopolysaccharides (LPS) from gram-negative bacteria, and oligomerize to form a macromolecular complex of full length caspase-11 components. Subsequently, full length caspase-11 undergoes autoproteolytic cleavage via proximity-induced activation and conversion to its active cleaved form. Cleaved caspase-11 can induce pyroptosis and also indirect maturation of IL-1 $\beta$ and IL-18, in a caspase-1-dependent manner via induction of $\mathrm{K}^{+}$efflux $[210,211]$. Low intracellular $\mathrm{K}^{+}$levels can activate NLRP1 and NLRP3 inflammasomes, thereby linking the non-canonical pathway to the canonical inflammasome pathway $[212,213]$. Caspase-11 can also be activated by a class of DAMPs known as oxidized 1-palmitoyl-2-arachidonyl-sn-glycero-3-phosphorylcholine (oxPAPC), although oxPAPC upregulates the production and secretion of IL-1 $\beta$, but does not induce pyroptosis [214].

\section{Molecular structure of Inflammasome components}

A canonical inflammasome complex is typically comprised of three distinct components: a receptor/sensor, an adapter and effector (Fig. 3). The sensor is usually a cytosolic PRR that detects perturbations in the intracellular microenvironment that serve as the activation signal to initiate inflammasome assembly. The inflammasome complexes are named after their respective intracellular PRR, which are from two major families: the nucleotide-binding oligomerization domain-like receptor (NLR) family and the pyrin and hematopoietic expression, interferon-inducible, nuclear localization (HIN) domain-containing (PYHIN) family [38, 194]. Members of the NLR family share similar structural domains such as the NLR apoptosis inhibitory protein (NAIP), MHC class II transcription activator (CIITA), incompatibility locus protein from Podospora anserina (HET-E), and telomerase-associated protein (TP1), collectively known as NACHT, and a leucine-rich repeat (LRR) $[215,216]$. The NACHT domain is responsible for NLR oligomerization, while LRR is the inhibitory unit folded onto the NACHT domain, keeping the receptor in its inactive state. The two other critical domains are the Pyrin (PYD) domain and the caspase activation and recruitment domain (CARD), which interact with other components with similar domains to form the inflammasome complex [38, 194, 217, 218]. Molecular structures of the AIM2, NLRP1, NLRP3, and NAIPNLRC4 receptor complexes are discussed below (Fig. 3).

The NLR-pyrin domain containing 1 (NLRP1) belongs to the NLR family of PRRs, with only a single variant of 


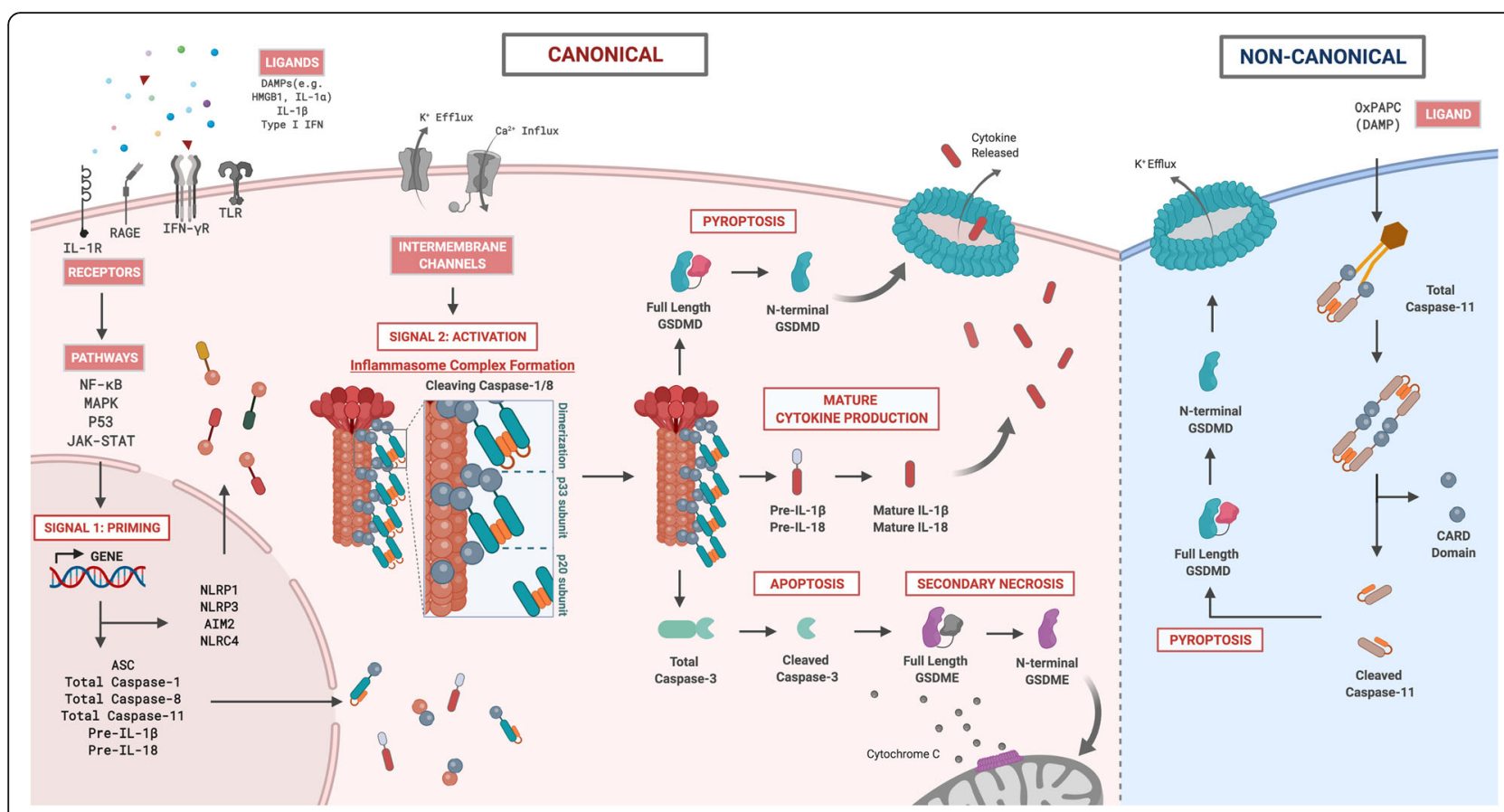

Fig. 2 A schematic diagram illustrating the canonical and non-canonical inflammasome signaling pathways in the brain during chronic cerebral hypoperfusion. In the canonical inflammasome pathway, two signals - priming and activation are involved. The first signal is the priming step whereby endogenous extracellular ligands (DAMPs) are able to bind onto its respective pattern recognition receptors (i.e. TLR, RAGE, IFN- $\gamma$ R, IL-1R) on neighbouring cells, activating several downstream regulatory pathways (i.e. NF-KB, MAPK, P53 and JAK-STAT), leading to increased gene expression of inflammasome components (i.e. receptors, adaptor and effector proteins) and both precursor IL-1 $\beta$ and IL-18 in the cytosol. Following priming, a second signal is required to activate the inflammasome receptor(s) to form a macromolecular platform that recruits the adaptor protein (i.e. ASC) and effector proteins (i.e. total caspase-1 and -8) to form a multi-protein complex termed an inflammasome. In the inflammasome complex, total caspase- 1 and -8 undergo proximity-induced activation to form active cleaved caspase-1 and -8 that initiates several catalytic functions. First, cleaved caspase- 1 and -8 induces mature cytokine production by cleaving precursors IL-1 $1 \beta$ and IL-18 into active mature IL-1 $\beta$ and IL-18 proinflammatory cytokines. Second, cleaved caspase-1 and -8 are able to initiate an inflammatory form of cell death by cleaving GSDMD-FL into GSDMD-NT. As more GSDMD-NTs are produced in the cytosol, these fragments self-oligomerize onto the plasma membrane to form a pore to facilitate the influx of water molecules to induce a lytic form of cell death known as pyroptosis. Third, cleaved caspase- 1 and -8 can trigger apoptosis by cleaving total caspase-3 into active cleaved caspase-3. Moreover, active cleaved caspase-3 can also initiate another form of cell death known as secondary necrosis by cleaving GSDME-FL into GSDME-NT. Similar to GSDMD-NT, GSDME-NT can self-oligomerize to form pores on the plasma membrane; in addition to forming pores on the mitochondrial membrane, which results in cytochrome $\mathrm{c}$ release, further exacerbating apoptosis. In the non-canonical inflammasome pathway, total caspase-11 can be activated by binding to an endogenous ligand (i.e. OxPAPC) that allows oligomerization of total caspase-11. Such oligomerization initiates the proximity-induced activation of total caspase-11 to form active cleaved caspase-11. The non-canonical effector protein, cleaved caspase-11, can also directly cleave GSDMD-FL into GSDMD-NT to cause pore formation. It has been shown that $\mathrm{K}^{+}$efflux resulting from pore formation can serve as an activation signal for canonical NLRP3 receptor activation, indicating cross-talk between the canonical and non-canonical inflammasome signalling pathways. Abbreviations: DAMPs, damage associated molecular patterns; HMGB1, high mobility group box protein 1; IL, interleukin; IFN, interferon; TLR, tolllike receptor; RAGE, receptor for advanced glycation end products; NF-KB, nuclear factor kappa-light-chain enhancer of activated B cells; MAPK, mitogen activated protein kinase; JAK/STAT, janus kinase-signal transducer and activator of transcription; Pre, precursor; GSDMD, gasdermin D; GSDME, gasdermin E

NLRP1 found in humans [194, 219]. The NLRP1 receptor consists of an N-terminal PYD, NACHT, LRR, function-to-find domain (FIND) and a C-terminal CARD domain. The FIIND domain is unique to NLRP1 in the NLR family, and may play an autoinhibitory role [219, 220] (Fig. 3). The NLR-pyrin domain containing 3 (NLRP3) belongs to the NLR family of PRRs and is perhaps the most studied of all inflammasomes. The NLRP3 receptor consists of an N-terminal PYD, NACHT and LRR domain [194, 221] (Fig. 3). The NLR apoptosis inhibitory protein (NAIP) and the NLR-CARD containing
4 (NLRC4) belong to the NLR family as they both contain NACHT and LRR domains. NAIP is distinct from other NLR proteins as they contain three baculovirus inhibitor-of-apoptosis repeats (BIR) at the N-terminal domain. Unlike the previously mentioned PRRs of the NLR family, NLRC4 contains an N-terminal CARD rather than a PYD domain, in addition to the NACHT and LRR domains [194, 222] (Fig. 3). The absent in melanoma 2 (AIM2) belongs to the PYHIN family of PRRs, and together with four other members forms the AIM2like receptor (ALR) family of inflammasomes. AIM2 is a 


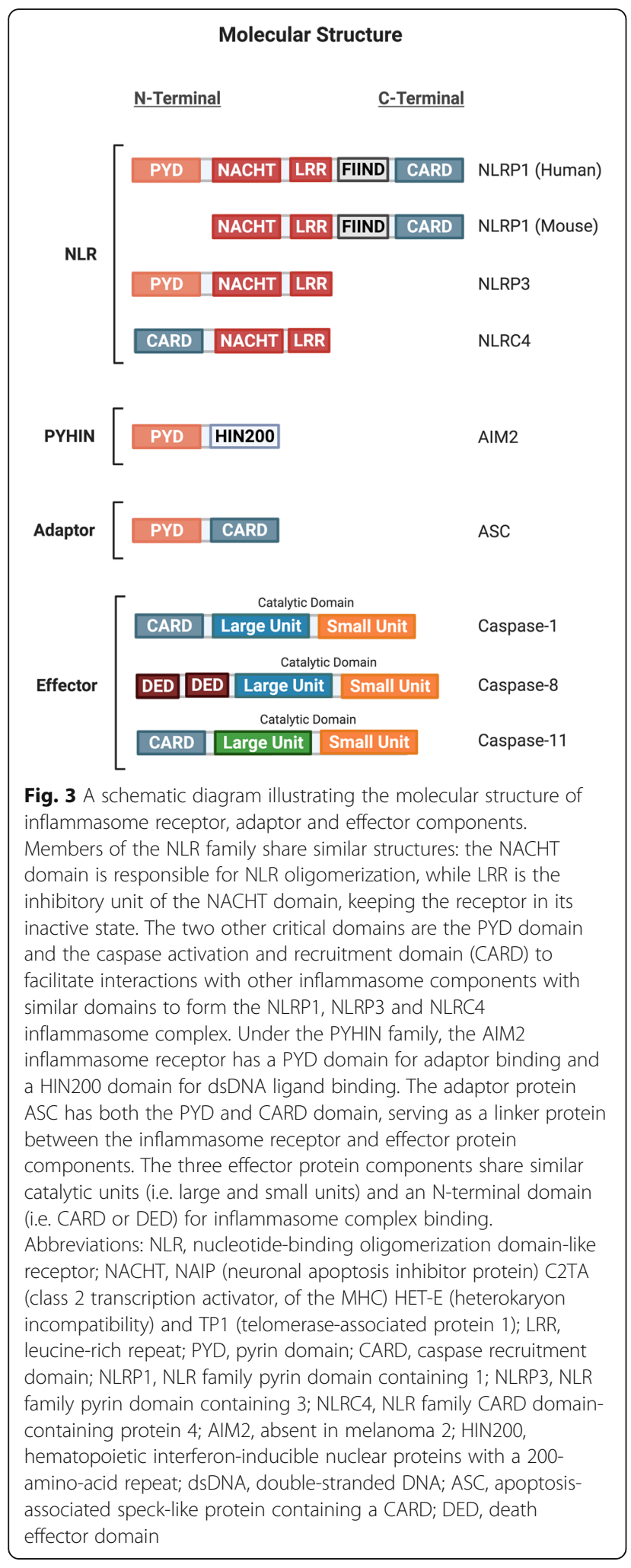

bipartite protein, consisting of an N-terminal PYD and a 200-amino-acid HIN domain with two oligonucleotide/ oligosaccharide-binding folds [218, 223]. The HIN domain can bind to double-stranded DNA (dsDNA) independent of its sequence, and during the absence of ligand binding can interact in an intramolecular manner with the PYD to result in autoinhibition [218] (Fig. 3).

The adapter, known as apoptosis-associated speck-like protein containing a CARD (ASC), is a protein responsible for the interactions between various inflammasome components, such as a scaffold protein that connects the PRR to the effector components. ASC contains both an $\mathrm{N}$-terminal PYD domain and a C-terminal CARD domain [217, 224] (Fig. 3).

The effector protein components are a group of inflammatory caspases that catalyze a broad spectrum of substrates upon activation. Caspase- $1,-8$ and -11 play a significant role as the effectors in the inflammasome signaling pathway. Both caspase- 1 and -11 contain an $\mathrm{N}$ terminal CARD domain and C-terminal catalytic domain (composed of large p20 and small p10 subunits). Caspase- 8 contains two death effector domains (DED) at its $\mathrm{N}$-terminal and the catalytic domain at the Cterminal $[225,226]$. Although these caspases are similar in structure, they differ in their domain linkers and residues in their catalytic pocket, contributing to their differential role in the inflammasome signaling pathway [227-229] (Fig. 3).

\section{Possible Inflammasome-inducing stimuli in VCI}

During the pathogenesis of VCI, a multitude of stress signals and DAMPs are produced in the cytosol, released and detected by various PRRs, resulting in their eventual activation and formation of inflammasome complexes $[194,200]$. This section discusses stimuli that potentially activate the NLRP1, NLRP3, NAIP-NLRC4 and AIM2 inflammasome receptors during $\mathrm{CCH}$ (Fig. 4).

The exact function of NLRP1 in innate immunity is not yet fully elucidated, but it is believed to be activated via autolytic proteolysis within the FIIND domain in response to severe bacterial infections [220]. NLRP1 levels are upregulated in ischemic conditions, and although the responsible activation signals are unclear, they are likely to be from aberrations in the cellular microenvironment such as depletion of intracellular ATP and reduction of intracellular $\mathrm{K}^{+}$levels arising from $\mathrm{K}^{+}$efflux during bioenergetic impairment $[38,212,230]$. The NLRP3 receptor can be activated by a multitude of intracellular signals including decreased $\mathrm{K}^{+}$, increased $\mathrm{Ca}^{2+}$ and oxidative stress during $\mathrm{CCH}[212,231,232]$. Given that NLRP3 can respond to a diverse range of signals, it is likely to be responding to a common cellular event caused by these activators rather than directly to the activators themselves. Moreover, increased levels of hyaluronic acid was observed in the cerebrospinal fluid of $\mathrm{VaD}$ patients that appeared to serve as a potential NLRP3 stimuli [233]. 


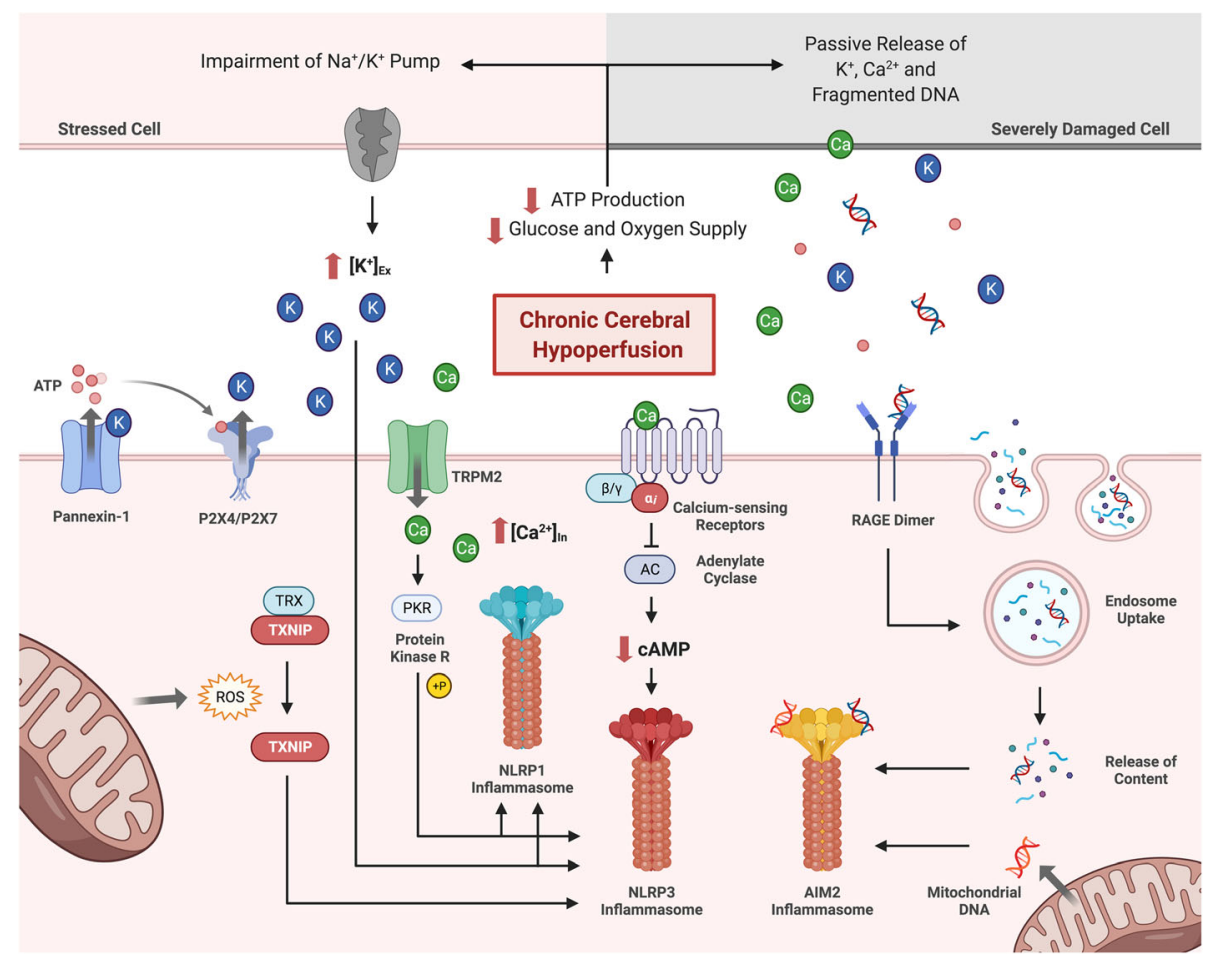

Fig. 4 A schematic diagram illustrating potential stimuli involved in inflammasome receptor activation during CCH. The precise molecular and cellular mechanisms of inflammasome receptor activation during CCH are unknown. However, relevant studies suggest several plausible mechanisms including - decreased intracellular $\mathrm{K}^{+}$concentration, increased intracellular $\mathrm{Ca}^{2+}$ concentration, ROS production, DNA fragmentation and oxidized mitochondrial DNA. During CCH, lower cerebral blood flow reduces ATP production, and impairs ATP-dependent transporters such as the $\mathrm{Na}^{+} / \mathrm{K}^{+}$-ATPase pump, leading to $\mathrm{K}^{+}$accumulation in the extracellular space. Alternatively, ATP released by damaged cells can bind to the P2X4 and P2X7 receptors on neighbouring cells, leading to the receptor opening and efflux of $\mathrm{K}^{+}$. In addition, damaged cells can also passively release $\mathrm{K}^{+}$into the extracellular environment. Extracellular $\mathrm{K}^{+}$can activate Pannexin-1 channels on the plasma membrane through a mechanism independent of the membrane potential. This further promotes the release of ATP into the extracellular space, creating a positive feedback loop for $\mathrm{K}^{+}$efflux. Consequently, the accumulation of extracellular $\mathrm{K}^{+}$and decrease in intracellular $\mathrm{K}^{+}$levels can activate the NLRP3 receptor by inducing a conformational change that promotes oligomerization. During $\mathrm{CCH}$, severely damaged necrotic cells may also release $\mathrm{Ca}^{2+}$ into the extracellular space, activating calcium-sensing receptors (CaSRs) on neighbouring cells. Activated CaSRs inhibit the activity of adenylate cyclase, reducing the conversion of ATP to CAMP. As CAMP is an inhibitor for NLRP3, a reduction in CAMP levels in the cytosol can promote NLRP3 inflammasome activity. $\mathrm{Ca}^{2+}$ can also promote inflammasome activation through the TRPM2 $\mathrm{Ca}^{2+}$ channel during $\mathrm{CCH}$. As $\mathrm{Ca}^{2+}$ enters the cell via the TRPM2 channel, it enables protein kinase R (PKR) in the cytoplasm to phosphorylate NLRP1 and NLRP3 receptors resulting in inflammasome activation. CCH also caused a substantial degree of oxidative stress and the production of ROS in the cell. ROS can interact with the TXNIP-TRX complex to release TXNIP from TRX, allowing it to bind to the NLRP3 receptor for subsequent inflammasome activation. CCH induces AIM2 inflammasome activation via the production and release of fragmented dsDNA. Severely damaged cells and mitochondria are the source of fragmented dsDNA during $\mathrm{CCH}$. While intracellular mitochondrial dsDNA interacts directly with the AIM2 receptor in the cytosol, extracellular dsDNA enters the cell via the facilitation of RAGE. When RAGE detects the presence of dsDNA in extracellular space, it promotes endosomal DNA uptake of the cell. The dsDNA will then bind onto the HIN-domain of the AIM2 receptor, releasing the receptor from its autoinhibitory state. This allows the AIM2 receptor to oligomerize and initiate inflammasome activation. Abbreviations: CCH, chronic cerebral hypoperfusion; ROS, reactive oxygen species; ATP, adenosine triphosphate; P2X4, P2X purinoceptor 4; P2X7, P2X purinoceptor 7; NLR, nucleotide-binding oligomerization domain-like receptor; NLRP1, NLR family pyrin domain containing 1; NLRP3, NLR family pyrin domain containing 3; cAMP, cyclic adenosine monophosphate; TRPM2, transient receptor potential melastatin 2; TXNIP, thioredoxin-interacting protein; TRX, thioredoxin; AIM2, absent in melanoma 2; HIN200, hematopoietic interferon-inducible nuclear proteins; dsDNA, double-stranded DNA; RAGE, receptor for advanced glycation end-products

While no study to date has directly investigated the effect of $\mathrm{CCH}$ to cause bioenergetic deficits, blood flow reduction during ischemia is known to induce $\mathrm{K}^{+}$efflux $[46,234]$. This is a possible mechanism by which $\mathrm{CCH}$ activates the NLRP inflammasome receptors. Lower cerebral blood flow reduces ATP production and impairs ATP-dependent transporters such as the $\mathrm{Na}^{+} / \mathrm{K}^{+}$-
ATPase pump leading to $\mathrm{K}^{+}$accumulation in the extracellular space during ischemia [46, 234]. Alternatively, ATP released by damaged cells can bind to the P2X purinoceptor 4 (P2X4) and P2X purinoceptor 7 (P2X7) on neighboring cells, leading to opening of the ligand-gated ion channel and $\mathrm{K}^{+}$efflux. In addition, $\mathrm{K}^{+}$can be passively released into the extracellular environment due to 
increased permeability of the plasma membrane from damaged cells [38, 235]. Elevated levels of extracellular $\mathrm{K}^{+}$can activate Pannexin-1 channels on the plasma membrane through a mechanism independent of the membrane potential, to further promote release of ATP, creating a positive feedback loop for $\mathrm{K}^{+}$efflux [38, 236, 237]. $\mathrm{K}^{+}$efflux has been identified as a key step for NLRP1 and NLRP3 inflammasome activation, although there is no clear understanding of the precise mechanism linking $\mathrm{K}^{+}$efflux and NLRP receptor activation [232, 238]. However, a recent study showed that low intracellular $\mathrm{K}^{+}$concentrations can open the inactive structure of NLRP3 by altering a domain in between the PYD and NACHT domains, resulting in a stable structure that promotes the functional oligomerization of NLRP3 into active oligomers [239] (Fig. 4).

Other than $\mathrm{K}^{+}$efflux, a reduced intracellular cyclic adenosine monophosphate (cAMP) concentration during $\mathrm{CCH}$ may activate the NLRP3 inflammasome [235, 240]. Binding of cAMP to the NLRP3 receptor inhibits its ability for inflammasome assembly. When cAMP is reduced upon CCH, NLRP3 activation is promoted [231, $235,240]$. While the underlying cause of cAMP reduction is unknown, evidence from mechanistic studies from ischemic models suggest an involvement of $\mathrm{Ca}^{2+}$. When $\mathrm{Ca}^{2+}$ is released by damaged cells, it activates Gprotein coupled calcium-sensing receptors (CaSRs) on the plasma membrane, allowing it to interact with Goi and inhibit adenylate cyclase, reducing the conversion of ATP to cAMP in neighboring cells [38, 231, 235]. The involvement of $\mathrm{Ca}^{2+}$ in mediating NLRP3 inflammasome activation is highly plausible as the $\mathrm{Ca}^{2+}$-permeable channel, transient receptor potential melastatin 2 (TRPM2), plays a significant role in regulating the production of IL-1 $\beta$ upon $\mathrm{CCH}$ [70]. One possible explanation for this is that it allows influx of $\mathrm{Ca}^{2+}$, which activates protein kinase $\mathrm{R}$ (PKR) in the cytoplasm. Upon activation, PKR can phosphorylate NLRP1 or NLRP3 receptors for inflammasome activation, leading to production of IL-1 3 [38, 241, 242] (Fig. 4).

Numerous lines of evidence have shown that NLRP3 inflammasome activation is closely linked to increased levels of ROS in neurological diseases [243, 244]. Several studies have already demonstrated a close association between ROS, thioredoxin-interacting protein (TXNIP) and NLRP3 [243-245]. The generation of ROS facilitates the uncoupling of TXNIP from thioredoxin (TRX), allowing TXNIP to bind to the NLRP3 receptor for inflammasome activation [244-246]. Due to increased oxidative stress observed in $\mathrm{CCH}$ mouse models of $\mathrm{VCI}$ [39, 55, 247], one study demonstrated that decreased TXNIP-associated oxidative stress was associated with reduced NLRP3 and IL-1 $\beta$ expression, in conjunction with better cognitive performance [248]. Another major source of ROS is from the mitochondria as increased hydrogen peroxide production induced oxidative stress that were observed in rodent models of $\mathrm{CCH}$ [39] (Fig. 4).

NAIP-NLRC4 is generally activated by pathogenic bacteria, with NAIP as a direct receptor to these bacterial signals [249] However, activation of NAIP-NLRC4 has been shown to be associated with lysophosphatidylcholine (LPC), which are lipids arising from the hydrolytic activity of phospholipase A2 ( $\left.\mathrm{PLA}_{2}\right)$ under stressed conditions [250, 251]. Although LPC has been found to activate NLRC4 and NLRP3 inflammasomes in neuroinflammatory disease mouse models [250, 252], it is unlikely to be involved in VCI as the levels of LPC do not differ significantly upon $\mathrm{CCH}$ [253]. Nucleotidederived metabolites, including adenine and N4acetylcytidine (N4A), can both prime and activate the NAIP-NLRC4 inflammasome [254], and could be relevant given that oxidative DNA damage has been described in VCI patients [60]. However, no evidence to date have investigated the effect of $\mathrm{CCH}$ on nucleotidederived metabolites.

AIM2 is activated by the binding of dsDNA to the HIN domain, thereby removing the autoinhibitory effect of the intramolecular interaction between the PYD-HIN domains. This ligand binding is achieved via electrostatic attractions between the positively-charged HIN domain and negatively-charged dsDNA [218, 223, 255]. The dsDNA is required to be at least 80 base pairs in length and is conventionally from viral or bacterial origins [256]. Given the sterile nature of VCI, it is likely that AIM2 is activated by host dsDNA instead because ischemic conditions produce anoxic depolarization and release of mitochondrial DNA into the cytosol due to ATP-induced mitochondrial apoptosis. Coupled with the extracellular release of nuclear and mitochondrial DNA by injured neurons and glial cells, this provides the appropriate activation signals in the form of dsDNA to AIM2 [257, 258]. During CCH, DNA fragmentation has been observed to occur in astrocytes and oligodendrocytes [130, 259]. Furthermore, it was recently shown that $\mathrm{CCH}$ increases plasma levels of double-stranded DNA, and induces AIM2 inflammasome-mediated neuropathology and cognitive impairment in a mouse model of $\mathrm{VaD}$ [71]. Moreover, $\mathrm{CCH}$-induced receptor for advanced glycation end-products (RAGE) upregulation can also promote DNA uptake into the cell via the action of endosomes, hence providing a mechanism through which extracellular DNA can interact with cytosolic AIM2 [260, 261] (Fig. 4).

\section{Formation of the Inflammasome complex}

In general, stimulation of the inflammasome receptor causes the LRR inhibitory unit to unfold from the 
NACHT domain $[38,216]$. Consequently, the inflammasome receptor reconfigures into an "open" structure to allow homo-oligomerization with neighbouring inflammasome receptors. As more inflammasome receptors converge, they form a macro-molecular platform with their N-terminal PYD domains pointing towards each other $[224,262]$. A PYD domain attracts other PYD domains via homotypic interactions. One of them is the adaptor protein, ASC, which facilitates inflammasome complex formation by binding to the PYD domain of the inflammasome receptor platform using its N-terminal PYD domain through homo-oligomerization [38, 224]. Many ASC proteins will come together during this process, forming a filamentous structure from the inflammasome receptor platform. These filamentous macromolecular aggregates are known as ASC specks [263]. As such, the CARD domain on the C-terminal of ASC is made available to bind with full-length caspases.
These caspases bind with their N-terminal CARD domain to the ASC specks via CARD-CARD domain interactions [217, 263], and therefore directly interact with CARD domains on inflammasome receptors in the absence of the ASC adaptor. NLRP1 and NLRC4 receptors can mediate ASC-independent inflammasome activation $[249,264]$. The structural formation of each major inflammasome complex is explained below (Fig. 5).

Following stimulation of the NLRP1 inflammasome receptor, the FIIND domain undergoes autolytic proteolysis to facilitate activation and oligomerization to form the inflammasome core [220]. NLRP1 oligomers appear to interact with ASC via homotypic PYD-PYD interactions [220]. After ASC speck formation, the ASC speck can recruit multiple effector inflammatory caspases via homotypic CARD-CARD interactions [219]. Despite being able to mediate ASC-independent NLRP1 inflammasome activation, NLRP1 activity level is higher in the

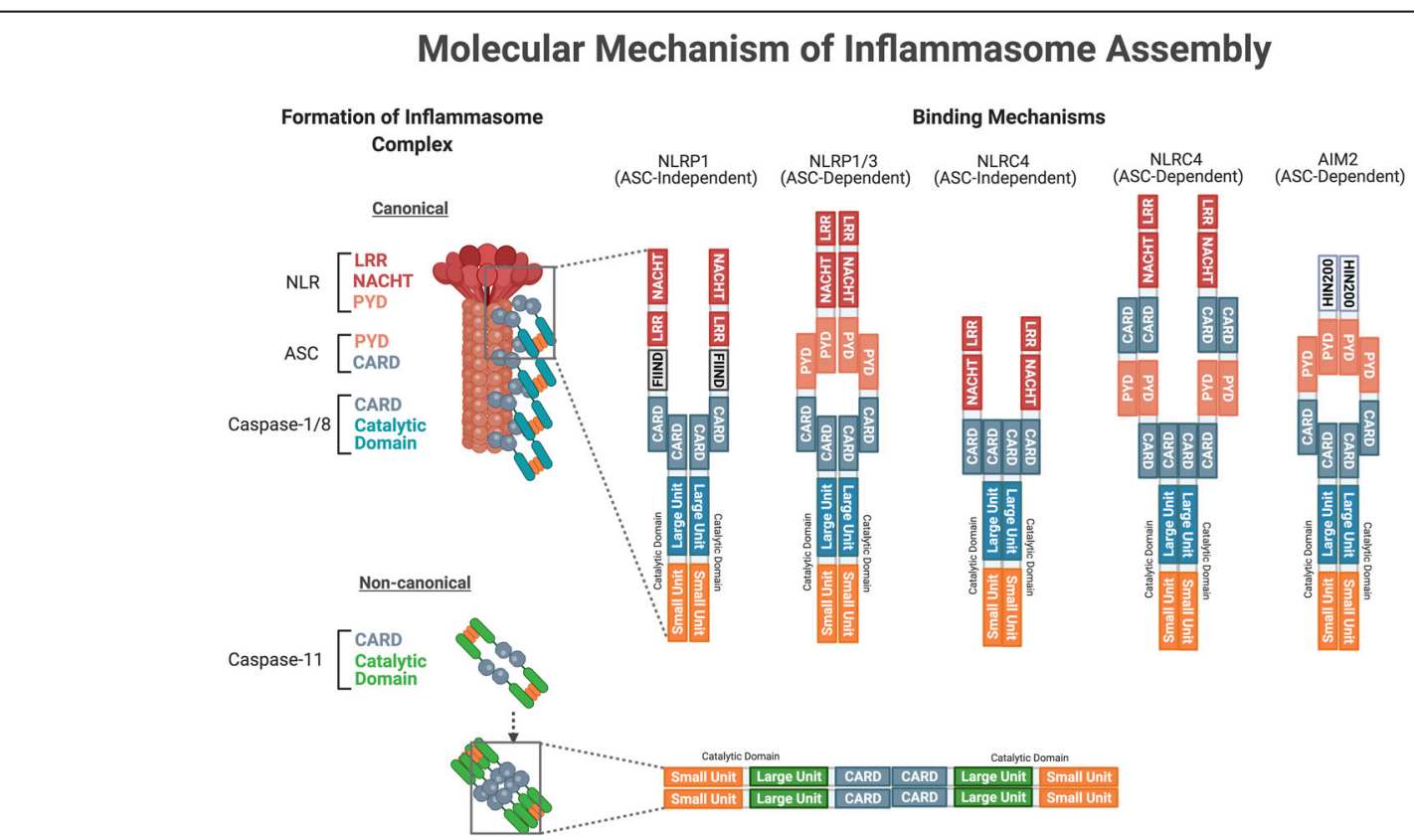

Fig. 5 A schematic diagram illustrating the assembly of the canonical and non-canonical inflammasome complexes. The formation of the canonical inflammasome complex requires the activation of inflammasome receptors from the second signal. As the LRR inhibitory unit unfolds from the NACHT domain, the receptors are in an "open" structure for homotypic oligomerization through their NACHT domain. Subsequently, the PYD domain recruits the adaptor protein via the PYD domain on ASC. As numerous ASC adaptor proteins comes together, they will form a filamentous structure with their CARD domain exposed. Consequently, effector proteins with their CARD domain can bind to the filamentous structure via CARD-CARD interactions. Such protein aggregation triggers proximity-induced activation of total caspase-1, and -8 , leading to cleavage of the inter-domain linker between the large and small units, producing active cleaved caspase- 1 and -8 . The above mentioned ASCdependent binding mechanism generally applies to all inflammasome complexes. However, NLRP1 can form an inflammasome complex without the adaptor ASC. Using its C-terminal CARD domain, NLRP1 binds to the effector protein via the CARD-CARD domain. NLRC4 can also adopt the same ASC-independent binding mechanisms with the CARD domain on the receptor. In the non-canonical inflammasome pathway, caspase-11 can undergo homo-oligomerization in the absence of a receptor and adaptor protein component via the CARD-CARD domain interaction. Similar to the activation of total caspase- 1 and -8, cleaved caspase-11 is produced upon proximity-induced activation. Abbreviations: NLR, nucleotidebinding oligomerization domain-like receptor; NACHT, NAIP (neuronal apoptosis inhibitor protein) C2TA (class 2 transcription activator, of the MHC) HET-E (heterokaryon incompatibility) and TP1 (telomerase-associated protein 1); LRR, leucine-rich repeat; PYD, pyrin domain; CARD, caspase recruitment domain; NLRP1, NLR family pyrin domain containing 1; NLRP3, NLR family pyrin domain containing 3; NLRC4, NLR family CARD domain-containing protein 4; AIM2, absent in melanoma 2; HIN200, hematopoietic interferon-inducible nuclear proteins with a 200-amino-acid repeat; dsDNA, double-stranded DNA; ASC, apoptosis-associated speck-like protein containing a CARD; DED, death effector domain 
presence of an ASC speck [220] (Fig. 5). Prior to NLRP3 activation, priming must occur in the form of increased expression and de-ubiquitination of NLRP3 [199, 201]. Assembly of the NLRP3 inflammasome also requires ASC to be linearly ubiquitinated [265]. The NLRP3 receptor binds to ASC via homotypic PYD-PYD interactions, and through the resulting ASC speck recruits effector inflammatory caspases via homotypic CARDCARD interactions [221, 224] (Fig. 5). Upon binding of NAIP to the ligand, a single NAIP oligomerizes with multiple NLRC4 receptors. Phosphorylation of a single evolutionarily conserved serine 533 residue in NLRC4 is necessary for the assembly of the NAIP-NLRC4 inflammasome [266]. NAIP-NLRC4 then interacts with ASC likely through homotypic CARD-CARD interactions, given the absence of a PYD domain in the NAIP-NLRC4 receptor. ASC speck formation ensues and is accompanied by recruitment of multiple effector inflammatory caspases through homotypic CARD-CARD interactions. NLRC4, however, possesses an innate CARD domain, and so can recruit the effector inflammatory caspases independent of ASC, although the presence of ASC can enhance the assembly of the NAIP-NLRC4 inflammasome complex [222, 249, 263] (Fig. 5). The PYD domain of AIM2 possesses an intrinsic tendency to selfaggregate, resulting in homo-oligomerization of several AIM2 receptors after activation via dsDNA binding to the HIN domain. The AIM2 receptor complex then recruits ASC concomitant with ASC speck formation via homotypic PYD-PYD interactions. AIM2 recruits multiple effector inflammatory caspases via homotypic CARD-CARD interactions in an ASC-dependent manner, due to the absence of CARD in the AIM2 receptor [255, 267] (Fig. 5).

The molecular assembly of different inflammasome complexes can vary between inflammasome receptors in the canonical pathway. The ultimate purpose of inflammasome assembly is to bring together the effector caspases in close proximity. Increasing the local concentration of effector caspase-1 around the complex facilitates dimerization of caspase- 1 monomers, and enables autoproteolytic activation [255, 267]. Subsequently, a transient activity hub of cleaved caspase- 1 p33/p10 is produced for substrate catalysis. Different cell types and inflammasome sizes influence the kinetics of p33/p10 processing. Therefore, the final product of cleaved caspase-1 p20/p10 serves as a classic hallmark of caspase-1 activation as it indicates termination of protease activity [226, 268] (Figs. 2, 3 \& 5). Unlike caspase-1, which binds to the inflammasome complex via CARDCARD interactions, caspase- 8 relies on its DED domain to carry out heterotypic interactions with the adaptor ASC. This is possibly due to the similarities with its selfassociation between DEDs and PYDs domains. As such, caspase- 8 is similarly able to undergo proximity-induced activation, producing cleaved caspase- 8 for substrate processing $[224,269,270]$. Nonetheless, caspase- 8 is capable of cleaving inflammasome substrates (IL-1 $\beta$ ) directly via the complex formation of caspase recruitment domain-containing protein-9 (CARD9), B-cell lymphoma/leukemia-10 (BCL10), Mucosa-associated lymphoid tissue lymphoma translocation protein-1 (MALT1), ASC and caspase-8. Caspase-8 can also interact with receptor-interacting serine/threonine kinase 1 (RIPK1) directly cleaving caspase- 1 leading to caspase- 1 activation $[205,206]$.

Organization of the canonical inflammasome complex usually involves a receptor, adaptor and effector caspases-1 and -8. However, in the non-canonical inflammasome pathway, caspase-11 can undergo homooligomerization in the absence of a receptor and adaptor protein component. Upon binding of a stimuli such as oxPAPC or LPS to the N-terminal CARD domain on caspase-11, the CARD domain interacts with the same domain on another caspase-11 to form a dimer [271, 272]. The dimer then interacts with others to form a homo-tetramer, which then oligomerizes to induces auto-proteolysis. As caspase-11 undergoes self-cleavage, it releases the pro-domain from the catalytic domain of caspase-11, producing biologically active cleaved caspase-11 [271, 272] (Figs. 2, 3 \& 5).

\section{Impact of the Inflammasome signaling pathway}

Upon the activation of the inflammasome signaling pathway, the mature cytokines IL-1 $\beta$ and IL-18, are produced leading to the downstream inflammatory response. Simultaneously, these effector proteins also initiate a wide variety of cell death pathways such as apoptosis, pyroptosis and secondary necrosis [38] (Fig. 2).

\section{Proinflammatory effect of IL-1 $\beta$ and IL-18}

The proinflammatory cytokines, IL- $1 \beta$ and IL-18, are both transcriptionally upregulated during inflammasome priming [199]. They are produced in the form of precursor cytosolic proteins activated by canonical cleaved caspase- 1 and -8 , while cleaved caspase- 11 aids in the release of these cytokines into the extracellular environment by inducing gasdermin pores [214, 268] (Fig. 2).

Following their production and release into the extracellular environment, mature IL-1 $\beta$ and IL-18 serve as ligands towards the IL-1R1 and IL-18R on the plasma membrane to facilitate an autocrine or paracrine effect. Consequently, this activates the NF- $\kappa B$ and MAPK(s) pathways to upregulate gene expression of several types of inflammatory mediators $[38,198,273,274]$. The first type is proinflammatory cytokines (i.e. TNF, IL-1 $\beta$, IL-6 and IL-8) that further propagate the inflammatory signal. 
The second is chemotactic cytokines (e.g. CXCchemokine ligand 8 and CX3C-chemokine ligand 1), which attract peripheral immune cells such as neutrophils and macrophages to the damaged region. The third type is adhesion molecules (e.g. E-selectin and ICAM-1) that facilitate leukocyte infiltration into the brain parenchyma $[275,276]$. These recruited peripheral immune cells can initiate a similar inflammatory response, and contribute to the pool of inflammatory mediators released from microglia and astrocytes [277, 278].

\section{Effect of Caspase-1, - 8 and -11 on cell death pathways}

Apoptosis is a form of programmed cell death that encompasses the intrinsic and extrinsic apoptotic pathways. Activation of both pathways ultimately converge to activate executioner caspase-3, leading to apoptosis characterized by membrane blebbing, cell shrinkage, nuclear fragmentation, chromatin condensation, chromosomal DNA fragmentation and global mRNA decay $[279,280]$. Inflammasomes induce apoptosis via recruitment and activation of caspase- 8 . Moreover, caspase- 1 is also implicated in apoptosis through caspase- 1 mediated cleavage of caspase-7 or caspase-3, both of which are involved in the execution of apoptosis [207, 281]. Caspase11 can also activate caspase- 3 to induce apoptosis in a caspase-1 independent manner [282]. Besides its apoptotic function, cleaved caspase- 3 can induce secondary necrosis by cleaving the hallmark protein, gasdermin $\mathrm{E}$ to produce the N-terminal fragment (NT-GSDME). Secondary necrosis involves the oligomerization of these $\mathrm{N}$ terminal fragments, leading to pore formation in the mitochondrial membrane and cellular surface [283] (Fig. 2 ), thus allowing cytochrome c to be released into the cytosol, further promoting apoptotic cell death [284].

Pyroptosis is an inflammasome-driven programmed cell death pathway that is initiated by the activation of caspase-1 and -11 resulting in cellular lysis $[208,210$, 211]. Gasdermin D is an integral pyroptotic protein comprised of an $\mathrm{N}$-terminal domain capable of forming a pore in the plasma membrane, and a $\mathrm{C}$-terminal domain which represses the activity of the $\mathrm{N}$-terminal gasdermin D domain (Fig. 2). Proteolytic cleavage of gasdermin $\mathrm{D}$ by either caspase- 1 or -11 relieves the inhibitory effect of the C-terminal gasdermin D domain on the $\mathrm{N}$-terminal gasdermin $\mathrm{D}$ domain, allowing for translocation of $\mathrm{N}$-terminal gasdermin $\mathrm{D}$ to the plasma membrane where it integrates and oligomerizes to form a gasdermin D pore $[208,210,211]$. Pore formation results in $\mathrm{K}^{+}$efflux and influx of both $\mathrm{Na}^{+}$and water molecules, resulting in cell swelling and lysis if there is a sufficient number of gasdermin D pores [208, 210, 211]. Pyroptosis is regarded as a proinflammatory form of cell death whereby proinflammatory cytokines such as IL-1 $\beta$ and IL-18 are usually restricted to the cytosol due to the lack of a secretory system but, along with other DAMPs and inflammatory mediators, they can be released into the extracellular environment after gasdermin pore formation [208, 210, 211]. Recently, caspase-8 was also demonstrated to cleave gasdermin $\mathrm{D}$ to induce pyroptosis [209]. In the absence of caspase- 1 or gasdermin D, NAIP-NLRC4 can recruit and activate caspase- 8 to induce a pyroptotic-like cell death involving the formation of membrane pores in a gasdermin D-independent manner [285].

\section{Inflammasomes in Glial activation}

As mentioned, microglia and astrocytes are key players in mediating neuroinflammation and tissue damage. Microglial cells are equipped with different PRRs that screen the microenvironment in the resting state [286, 287]. In an RNA-sequencing transcriptome study using mouse brain, gene expression of NLRP1, NLRP3, NLRC4 and AIM2 in the microglia was highest among all brain cell types. Moreover, microglial expression of caspase- 1 and IL-1 $\beta$ was around four and thirty fold higher than neurons, respectively [288]. This primes microglia for rapid activation when $\mathrm{CCH}$ induces ionic imbalance, oxidative stress and inflammation. Canonical classification of activated microglia is broadly described as either proinflammatory M1-like or anti-inflammatory M2-like phenotypes. M1-polarised microglia produce proinflammatory cytokines such as IL- $1 \beta$ and TNF- $\alpha$ that serve to activate more microglia cells in a paracrine manner [289]. However, emerging transcriptomic studies revealed more disease-associated subtypes of microglia such as Keratan sulfate proteoglycan (KSPG)-microglia (associated with amyotrophic lateral sclerosis), highly active "dark microglia" which interact with blood vessels and synapses (associated with Alzheimer's disease) and CD11c-microglia which interact with oligodendrocytes (associated with demyelination) [290]. Based on current evidence, microglia are likely to promote inflammatory and non-inflammatory responses via an involvement of NLRP3 and AIM2 inflammasomes during VCI [71, 291]. In fact, a study showed reduced proinflammatory microglia signatures in the hippocampus of mice with AIM2 deficiency upon $\mathrm{CCH}$ [71]. Attenuating NLRP3 inflammasome activity via pharmacological inhibitors during $\mathrm{CCH}$ also reduces microglial overactivation, possibly due to lower production of ROS during drug treatment [291].

Astrocytes are another immune effector cell type in the brain. Similar to microglial polarization states, activated astrocytes exist in two phenotypes based on traditional understanding: neurotoxic A1 and neuroprotective A2 astrocytes [292, 293]. Beyond this binary classification, reactive astrocytes were found to be more heterogeneous in terms of their morphology, 
locality, cellular interaction, and molecular expression. Therefore, the status of reactive astrocytes varies in a context-, time- and stimulus-specific manner [294]. In the context of neurodegenerative diseases, reactive astrocytes are consistently being identified with hypertrophied morphology and reduced expression of essential ion and neurotransmitter channels and receptors such as ATP-sensitive inward rectifier potassium channel 10 (Kir4.1), glial glutamate transporter 1 (GLT1), and increased expression of the glial fibrillary acidic protein (GFAP). This state of reactive astrocytes is commonly observed in A1 astrocytes that release proinflammatory and toxic mediators [294-297]. Both A1 and A2 phenotypes were present in conjunction with inflammasome activation following $\mathrm{CCH}$.

Astrocytes have been shown to express NLRP1, NLRP3, AIM2 and NLRC4 receptors under different conditions. However, genetic deletion of the AIM2 receptor did not affect the expression of GFAP in either the cortex or hippocampus of mice during $\mathrm{CCH}$, suggesting potential involvement of other inflammasome receptors [71, 257, 298, 299]. We recently collected unpublished data that the inflammasome signaling pathway is activated in fibrous and protoplasmic astrocytes under in vitro ischemic conditions, resulting in mature cytokine production, and apoptotic and pyroptotic cell death. Hence, we postulate that inflammasome activation may serve as a signal for astrocyte polarization.

\section{Inflammasomes in BBB dysfunction}

BBB disruption can arise from neuroinflammation, primarily through degradation of various tight junction proteins (TJPs). Matrix metalloproteinases (MMPs) released by glial cells can break down the extracellular matrix [300] and have been implicated in the disruption of the BBB under ischemic conditions [104]. MMP-2 and MMP-9 are known to be involved in BBB disruption and primarily localized to ischemic regions of astrocytic foot processes, during which TJPs undergo degradation over time [301]. Inflammasome signaling contributes to BBB dysfunction via the action of IL- $1 \beta$, which can upregulate the expression and release of MMPs from glial cells [302, 303]. Application of exogenous IL-1 $\beta$ elicits BBB dysfunction in rat and human brain microvascular endothelium [94, 304]. In addition, both IL-1 $\beta$ and IL-18 can upregulate expression of various chemokines in the extracellular space and cell adhesion molecules on the endothelium [276, 305]. Cell adhesion molecules, such as ICAM-1 and VCAM, attract and facilitate immune cell infiltration into the brain during neuroinflammation. These peripheral cells can also release active MMP-9, further exacerbating BBB dysfunction [306, 307]. A recent study showed that an interleukin-1 receptor antagonist preserved $\mathrm{BBB}$ integrity, attenuated changes in expression and localization of TJPs and MMPs in a rat model of ischemia-reperfusion [308]. Inhibition of caspase-1 enzymatic activity in a similar model further revealed caspase- 1 to induce $\mathrm{BBB}$ dysfunction through the activation of pyroptosis [309]. Therefore, a number of studies support a critical role of inflammasomes in BBB disruption, especially following disruption to CBF.

As an essential component of the BBB, the endothelial cell expresses a wide range of inflammasome receptors such as NLRP1, NLRP3 and NLRC4 [310]. Studies showed endothelial NLRP3 in modulating the BBB during different disease conditions, but evidence for $\mathrm{CCH}$ is still lacking [311-313]. NLRP3 may mediate BBB dysfunction for $\mathrm{CCH}$ based on in vitro and in vivo evidence from studies focusing on ischemic brain injury. Pharmacological inhibition of NLRP3 inflammasome activity has been shown to attenuate cerebral ischemia-induced $\mathrm{BBB}$ dysfunction by reducing its permeability and upregulating TJPs [313]. In addition, the study confirmed that reduced NLRP3 activity in endothelial cells increased expression of TJPs, cell viability and reduced barrier leakage [313]. This mechanism observed may explain the $\mathrm{BBB}$ dysfunction that is observed during $\mathrm{CCH}$.

Pericytes also express the NLRP3 receptor along with other NLRP and NLRC inflammasome receptors [314]. Upon stimulation of pericytes by oxidative stress and proinflammatory mediators, in vitro cerebral pericytes demonstrated upregulation of NLRP3 and NLRC4 mRNA expression [314]. Despite an increase in inflammasome receptor mRNA expression, activation of the inflammasome complex was not detected in cerebral pericytes following exposure with a wide range of DAMPs [314]. However, as pericytes are increasingly implicated in $\mathrm{BBB}$ dysfunction during $\mathrm{CCH}[91,100,101]$, additional studies are needed to establish the role of inflammasomes in pericytes during VCI.

\section{Inflammasome mediated cell death and neuronal loss} Inflammation is closely linked to cell death at the molecular level. The cell death pathway can be triggered by various proinflammatory mediators [315]. As DAMPs initiate the inflammasome signaling pathway via the NLR family and interferon-inducible protein, it activates key effector proteins such as caspase- 1 and caspase- 8 to cleave caspase-3, resulting in apoptosis and secondary necrosis [206, 283]. Together with the non-canonical caspase-11, these effector proteins catalyze pyroptosis via cleavage of gasdermin-D (GSDMD) [203, 208, 210]. Inhibition of caspase- 1 reduces inflammasome activation and cell death in primary cortical neurons and murine microglial cells subjected to ischemia-like conditions $[200,203]$. The NLRP3 inhibitor, MCC950, decreases apoptotic cell death and brain infarct size in a mouse model of ischemic stroke [316]. In a mouse model of 
VCI, AIM2 knockout mice expressed reduced inflammasome activity as well as apoptotic and pyroptotic cell death in neurons and microglia in the cortex and hippocampus. Similarly, a higher neuronal count was observed in the CA2 and CA3 area of the hippocampus in AIM2 knockout mice during $\mathrm{CCH}$ [71]. Therefore, the AIM2 inflammasome is involved in $\mathrm{CCH}$-induced neuroinflammation by mediating cell death and neuronal loss during VCI disease progression.

\section{Role of Inflammasomes in demyelination and WMLs}

Numerous studies have indicated a close association of inflammasome activity with the formation of WMLs that often occur together with activated microglia [77, 203, 317]. As mentioned, activated microglia release numerous inflammatory mediators that contribute to demyelination, including IL-1 $\beta$ and IL-18 that are produced during inflammasome activation. IL- $1 \beta$ was shown to impede oligodendrocyte migration and white matter repair in mouse models of VCI [69]. Conversely, reduced secretion of IL-1 $\beta$ preserved myelin integrity and attenuated the formation of WMLs under $\mathrm{CCH}$ [71]. Antiinflammatory pharmaceutical interventions and transgenic animal models have attenuated WML formation via suppressing microglial activation, and preventing caspase- 1 and IL-1 $\beta$ production [70, 318, 319]. Other than in microglia, inflammasomes are also activated during $\mathrm{CCH}$ in oligodendrocytes. Our recent study found increased levels of cleaved caspase- 1 in oligodendrocytes of mice after 30 days of BCAS [71]. Similar observations of inflammasome-mediated apoptotic and pyroptotic cell death markers were also found within oligodendrocytes. The evidence suggests that the inflammasome signaling pathway likely plays a causative role upstream of $\mathrm{CCH}$ induced WML formation.

\section{Evidence of inflammasome activity in $\mathrm{VCl}$ in humans}

An involvement of inflammasome activation and cytokine production is related to the risk factors that drives the early disease state of VCI. In tissue samples from patients with atherosclerosis, IL-1 $\beta$ is detected within endothelial cells of plaque microvessels [320]. Similarly, high levels of NLRP3, ASC, caspase-1, IL- $1 \beta$, and IL-18 mRNA expression was observed in carotid artery plaques of patients with cerebrovascular disease [321]. Studies of polymorphisms of IL-1 $\beta$ among small vessel disease patients, there was a higher frequency of the IL$1 \beta$ allele in comparison to controls [322], suggesting that elevated levels of IL-1 $\beta$ may contribute to the progression of small vessel disease leading to VCI. Genetic investigation of coronary artery disease patients also found that patients carrying the G allele of NLRP3 rs10754558 had more severe coronary artery stenosis and higher levels of serum IL-1 $\beta$ [323]. With the G allele of NLRP3 rs10754558 enhancing the mRNA stability of NLRP3, it increases the mRNA expression of this inflammasome receptor, potentially contributing to the pathophysiology of coronary artery stenosis [323, 324]. Besides chronic vascular conditions, inflammasome activity has also been identified in VCI-associated acute conditions such as stroke [38]. By preventing binding of IL-1 $\beta$ with its receptor, a clinical trial showed that acute stroke patients experienced a better outcome following the administration of an interleukin-1 receptor antagonist (i.e. anakinra) [274]. This was shown by a reduction in inflammation due to lower levels of neutrophils and Creactive proteins in the systemic circulation following a cerebral infarction. Among patients with cortical infarction, the use of an interleukin-1 receptor antagonist significantly reduced long-term disability after three months following cerebral ischemia; demonstrating the beneficial effect of reducing inflammasome activation and IL-1 $\beta$ secretion in cerebral vascular disease [274]. Similarly, IL-18 was shown to be more commonly associated with peripheral arterial occlusive disease, and cerebrovascular events [325], whereby an elevated level of IL-18 was shown to be evident in the plasma of acute coronary syndrome patients [326].

As the disease progresses to late-stage VCI, the actions of inflammasomes persist. In post-mortem samples from $\mathrm{VaD}$ patients, increases in the concentration of IL- $1 \beta$ was observed in the frontal cortex and hippocampus [66, 193]. Through cytokine profiling, studies of serum and plasma of $\mathrm{VaD}$ patients showed levels of IL- $1 \beta$ to be higher than in healthy controls. The relative increase in IL-1 $\beta$ was higher than other proinflammatory cytokines such as TNF- $\alpha$ and IL-6 [64, 65]. Nonetheless, some studies face challenges in detecting IL-1 $\beta$ in their patient samples $[183,184,187]$. For example, Mulugeta et al. did not detect any IL- $1 \beta$ in their patient brain tissues using ELISA kits [184]. Paganelli et al. found detectable levels of IL-1 $\beta$ only in $13 \%$ of all their serum samples through the same method [187]. Thus there is substantial variability in the interpretations of IL- $1 \beta$ in VCI because the levels present are near the limits of precise measurement by ELISA.

In addition to the presence of inflammasome-mediated proinflammatory cytokine production, immunostaining of inflammasome receptors, NLRP3 and AIM2, was greater in white matter lesions of patients with cerebral infarction [317]. Together these studies provide evidence of inflammasome activation in a severe state of VCI, highlighting the prominence of inflammasome signaling in the disease progression of VCI.

\section{Conclusions}

This review illustrates the mechanisms of inflammasome-mediated neuroinflammation under $\mathrm{CCH}$ 
in VCI. By providing direct evidence of inflammasome activation in VCI animal models and patients, we suggest that the critical involvement of the inflammasome signaling pathway in the pathogenesis of VCI may be mediated through CCH [64-66, 71, 118, 119, 193, 317]. Most importantly, inflammasome-mediated inflammatory mechanisms are early events that persist till the late stage of VCI; this sheds light on the inflammasome signaling pathway as a potential therapeutic target [64-66, $71,118,119,193,317]$. By reducing inflammasome activity levels, we can attenuate its influence on various pathogenic cellular mechanisms and structural damage observed during the disease progression of VCI [119, 291]. There are clinically approved therapeutic agents that can effectively target the actions of IL-1 $1 \beta$ : anakinra, canakinumab, and rilonacept. Moreover, agents that neutralize the effects of IL-18, Tadekinig alfa and GSK1070806 are also undergoing clinical trials [327]. It is essential to keep in mind that the inflammasome signaling pathway is a significant player within our innate immune system and physiologically guards against infectious agents [328]. Hence, there is a challenge to maintain an equilibrium in reducing inflammasome activity while maintaining our defense against infectious agents. Thus, the search for therapeutic interventions that selectively target specific types of inflammasome complexes may offer a greater safety and efficacy profile in the long term, especially for chronic diseases such as VCI.

\footnotetext{
Abbreviations

ACAS: Asymmetric Common Carotid Artery Stenosis; AD: Alzheimer's Disease; AlM2: Absent in Melanoma 2; AP-1: Activator Protein-1; ASC: Apoptosisassociated Speck-like protein containing CARD; ATP: Adenosine Triphosphate; BBB: Blood-Brain Barrier; BCAS: Bilateral Common Carotid Artery Stenosis; Bcl2: B-cell Lymphoma-2; C5a: Complement Factor 5a; CAA: Cerebral Amyloid Angiopathy; CADASIL: Cerebral Autosomal Dominant Arteriopathy with Subcortical Infarcts and Leukoencephalopathy; CAMP: Cyclic Adenosine Monophosphate; CaSRs: Calcium-sensing receptors; CARD: Caspase Activation and Recruitment Domain; CBF: Cerebral Blood Flow; CCH: Chronic Cerebral Hypoperfusion; CIITA: MHC class II Transcription Activator; CRP: Creactive protein; DAMPs: Damage-Associated Molecular Patterns; DED: Death Effector Domains; dsDNA: Double-stranded DNA; FIIND: Function-to-Find Domain; GFAP: Glial Fibrillary Acidic Protein; GLT1: Glial Glutamate Transporter 1; GSDMD: Gasdermin D; GSDME: Gasdermin E; $\mathrm{H}_{2} \mathrm{O}_{2}$ : Hydrogen Peroxide; HIF-1: Hypoxia-Inducible Factor-1; HRP: Horseradish Peroxidase; ICAM: Intercellular Adhesion Molecule; IFN: Type I interferon; IL1ß: Interleukin-1 B; IL-6: Interleukin-6; Kir4.1: ATP-sensitive Inward Rectifier Potassium Channel 10; LPC: Lysophosphatidylcholine;

LPS: Lipopolysaccharides; LRR: Leucine-Rich Repeat; MALT1: MucosaAssociated Lymphoid tissue lymphoma Translocation protein-1; MAPKs: Mitogen-Activated Protein Kinases; MID: Multi-Infarct Dementia; MMPs: Matrix Metalloproteinases; MPB: Myelin Basic Protein; mtROS: Mitochondrial ROS; NADPH: Nicotinamide Adenine Dinucleotide Phosphate; NAIP: NLR Apoptosis Inhibitory Protein; NAIP: NLR Apoptosis Inhibitory Protein; NF-kB: Nuclear Factor Kappa B; NLR: Nod-Like Receptor; NLR: Nucleotide-binding ligomerization domain-like receptor; NLRC4: NLRCARD Containing 4; NT-GSDMD: N-terminal fragment GSDMD; NT-GSDME: Nterminal fragment GSDME; OH: Hydroxyl Radical; oxPAPC: Oxidized 1palmitoyl-2-arachidonyl-sn-glycero-3-phosphorylcholine; P2X4: P2X purinoceptor 4; P2X7: P2X purinoceptor 7; PAMPs: Pathogen-Associated Molecular Patterns; PLA2: Phospholipase A2; PKR: Protein kinase R;
}

PRRs: Pattern Recognition Receptors; PYD: Pyrin; PYHIN: Nuclear localization (HIN) domain-containing; RAGE: Receptor for Advanced Glycation Endproducts; RIPK1: Receptor-Interacting serine/threonine Kinase 1; ROS: Reactive Oxygen Species; SVD: Small Vessel Disease; TJPs: Tight Junction Proteins; TLRs: Toll-Like Receptors; TNF: Tumor Necrosis Factor; TP1: Telomeraseassociated Protein; TRPM2: Transient receptor potential melastatin 2; TXNIP: Thioredoxin-interacting protein; TRX: Thioredoxin; UCCAO: Unilateral Common Carotid Artery Occlusion; VaD: Vascular Dementia; VCAM: Vascular Cell Adhesion Molecule; VCl: Vascular Cognitive Impairment; WML: White Matter Lesion

\section{Acknowledgements}

All figures in this article were created using BioRender.

\section{Authors' contributions}

LP, WLS, DYF led the writing of the manuscript and devised all the figures. DGJ, QND, GRD, CGS and MKPL edited the manuscript. TVA and CLHC supervised the writing and co-edited the manuscript. All authors read and approved the final manuscript.

\section{Funding}

This work was supported by the National Medical Research Council Research Grants (NMRC-CBRG-0102/2016; NMRC/CSA-SI/007/2016 and NMRC/OFIRG/ 0036/2017), Singapore.

\section{Availability of data and materials \\ Not applicable.}

\section{Declarations}

Ethics approval and consent to participate

Not applicable.

\section{Consent for publication}

Not applicable.

\section{Competing interests}

Not applicable.

\section{Author details}

'Department of Physiology, Yong Loo Lin School of Medicine, National University of Singapore, Singapore, Singapore. ${ }^{2}$ School of Pharmacy, Sungkyunkwan University, Suwon, Republic of Korea. ${ }^{3}$ Centre for Cardiovascular Biology and Disease Research, Department of Physiology, Anatomy and Microbiology, La Trobe University, Bundoora, VIC, Australia. ${ }^{4}$ Memory Aging and Cognition Centre, Department of Pharmacology, Yong Loo Lin School of Medicine, National University of Singapore, Singapore, Singapore. ${ }^{5}$ Department of Psychological Medicine, Yong Loo Lin School of Medicine, National University of Singapore, Singapore, Singapore.

${ }^{6}$ Department of Biochemistry, Yong Loo Lin School of Medicine, National University of Singapore, Singapore, Singapore. ${ }^{7}$ Healthy Longevity Translational Research Program, Yong Loo Lin School of Medicine, National University of Singapore, Singapore, Singapore. ${ }^{8}$ Centre for Healthy Longevity, National University Health System (NUHS), Singapore, Singapore.

Received: 12 June 2021 Accepted: 2 December 2021

Published online: 09 January 2022

\section{References}

1. World Health Organization, Alzheimer's disease international. Dementia: a public health priority. 2012 [cited 2021 Jan 24]. Available from: https://www. who.int/news-room/fact-sheets/detail/dementia.

2. Prince $M$, Bryce R, Albanese E, Wimo A, Ribeiro W, Ferri CP. The global prevalence of dementia: a systematic review and metaanalysis. Alzheimers Dement. 2013;9(1):63-75.e2 [cited 2018 Sep 13] Available from: http://www. ncbi.nlm.nih.gov/pubmed/23305823.

3. Lobo A, Launer LJ, Fratiglioni L, Andersen K, Di Carlo A, Breteler MMB, et al. Prevalence of dementia and major subtypes in Europe: a collaborative study of population-based cohorts. Neurology. 2000;54(11 SUPPL. 5):S4-9.

4. Di Carlo A, Baldereschi M, Amaducci L, Lepore V, Bracco L, Maggi S, et al. Incidence of dementia, Alzheimer's disease, and vascular dementia in Italy. 
The ILSA study. J Am Geriatr Soc. 2002;50(1):41-8 [cited 2020 Aug 26] Available from: https://pubmed.ncbi.nlm.nih.gov/12028245/.

5. Fujihara S, Brucki SMD, Rocha MSG, Carvalho AA, Piccolo AC. Prevalence of presenile dementia in a tertiary outpatient clinic. Arq Neuropsiquiatr. 2004; 62(3 A):592-5 [cited 2020 Aug 26] Available from: http://www.scielo.br/ scielo.php?script=sci_arttext\&pid=S0004-282X2004000400005\&lng=en\&nrm= iso\&tlng=en

6. Kalaria RN, Maestre GE, Arizaga R, Friedland RP, Galasko D, Hall K, et al. Alzheimer's disease and vascular dementia in developing countries: prevalence, management, and risk factors. Lancet Neurol. 2008:7:812-26 Lancet Publishing Group [cited 2020 Aug 26] Available from: https:/www. ncbi.nlm.nih.gov/pmc/articles/PMC2860610/.

7. Chan KY, Wu JJ, Liu L, Theodoratou E, Car J, Middleton L, et al. Epidemiology of alzheimer's disease and other forms of dementia in China, 1990-2010: a systematic review and analysis. Lancet. 2013;381(9882):2016-23 [cited 2020 Aug 26] Available from: https://pubmed.ncbi.nlm.nih.gov/2374 6902/.

8. Gorelick PB, Scuteri A, Black SE, Decarli C, Greenberg SM, ladecola C, et al. Vascular contributions to cognitive impairment and dementia: a statement for healthcare professionals from the American Heart Association/American Stroke Association. Stroke. 2011:42:2672-713.

9. Sweeney MD, Montagne A, Sagare AP, Nation DA, Schneider LS, Chui HC, et al. Vascular dysfunction - the disregarded partner of Alzheimer's disease. Alzheimers Dement. 2019;15:158-67 [cited 2021 Jan 24] Available from: https://pubmed.ncbi.nlm.nih.gov/30642436/.

10. Schneider JA, Arvanitakis Z, Bang W, Bennett DA. Mixed brain pathologies account for most dementia cases in community-dwelling older persons. Neurology. 2007;69(24):2197-204 [cited 2020 Aug 26] Available from: https://pubmed.ncbi.nlm.nih.gov/17568013/.

11. Toledo JB, Arnold SE, Raible K, Brettschneider J, Xie SX, Grossman M, et al. Contribution of cerebrovascular disease in autopsy confirmed neurodegenerative disease cases in the National Alzheimer's coordinating Centre. Brain. 2013;136(9):2697-706 [cited 2020 Aug 26] Available from: https://pubmed.ncbi.nlm.nih.gov/23842566/.

12. O'Brien JT, Erkinjuntti T, Reisberg B, Roman G, Sawada T, Pantoni L, et al. Vascular cognitive impairment. Lancet Neurol. 2003;2(2):89-98.

13. Van Der Flier WM, Skoog I, Schneider JA, Pantoni L, Mok V, Chen CLH, et al. Vascular cognitive impairment. Nat Rev Dis Prim. 2018;4:18003.

14. Román GC, Erkinjuntti T, Wallin A, Pantoni L, Chui HC. Subcortical ischaemic vascular dementia. Lancet Neurol. 2002;1 (7):426-36 [cited 2018 Oct 6] Available from: http://www.ncbi.nlm.nih.gov/pubmed/12849365.

15. Sachdev P, Kalaria R, O'Brien J, Skoog I, Alladi S, Black SE, et al. Diagnostic Criteria for Vascular Cognitive Disorders. Alzheimer Dis Assoc Disord. 2014; 28(3):206-18.

16. Pantoni L. Cerebral small vessel disease: from pathogenesis and clinical characteristics to therapeutic challenges. Lancet Neurol. 2010;9:689-701 [cited 2020 Aug 22] Available from: https://pubmed.ncbi.nlm.nih.gov/2061 0345/.

17. Cosentino F, Battista R, Scuteri A, De Sensi F, De Siati L, Di Russo C, et al. Impact of fasting glycemia and regional cerebral perfusion in diabetic subjects: a study with technetium-99m-ethyl cysteinate dimer single photon emission computed tomography. Stroke. 2009;40(1):306-8 [cited 2020 Dec 13] Available from: https://www.ahajournals.org/doi/10.1161/STROKEAHA.1 08.520627 .

18. Chen JJ, Rosas HD, Salat DH. Age-associated reductions in cerebral blood flow are independent from regional atrophy. Neuroimage. 2011;55(2):46878 [cited 2020 Dec 13] Available from: https:/www.ncbi.nlm.nih.gov/pmc/a rticles/PMC3435846/

19. Muller M, van der Graaf Y, Visseren FL, WPTM M, Geerlings MI. Hypertension and longitudinal changes in cerebral blood flow: the SMART-MR study. Ann Neurol. 2012;71(6):825-33 [cited 2020 Dec 13] Available from: http://doi. wiley.com/10.1002/ana.23554

20. Román GC. Brain hypoperfusion: a critical factor in vascular dementia. Neurol Res. 2004;26(5):454-8 [cited 2018 Sep 6] Available from: http://www. ncbi.nIm.nih.gov/pubmed/15265263.

21. Hilal S, Xu X, Ikram MK, Vrooman H, Venketasubramanian N, Chen C. Intracranial stenosis in cognitive impairment and dementia. J Cereb Blood Flow Metab. 2017;37(6):2262-9 [cited 2021 Jan 19] Available from: http:// journals.sagepub.com/doi/10.1177/0271678X16663752.

22. Ferro DA, Mutsaerts HJJM, Hilal S, Kuijf HJ, Petersen ET, Petr J, et al. Cortical microinfarcts in memory clinic patients are associated with reduced cerebral perfusion. J Cereb Blood Flow Metab. 2020;40(9):1869-78 [cited 2021 Jan 19] Available from: https://pubmed.ncbi.nlm.nih.gov/31558107/.

23. Schuff N, Matsumoto S, Kmiecik J, Studholme C, Du A, Ezekiel F, et al. Cerebral blood flow in ischemic vascular dementia and Alzheimer's disease, measured by arterial spin-labeling magnetic resonance imaging. Alzheimers Dement. 2009;5(6):454-62 [cited 2018 Sep 27] Available from: http://www. ncbi.nlm.nih.gov/pubmed/19896584.

24. Ciacciarelli A, Sette G, Giubilei F, Orzi F. Chronic cerebral hypoperfusion: an undefined, relevant entity. J Clin Neurosci Churchill Livingstone. 2020;73:812 [cited 2021 Mar 11] Available from: https://pubmed.ncbi.nlm.nih.gov/31 948882/.

25. Duncombe J, Kitamura A, Hase Y, Ihara M, Kalaria RN, Horsburgh K. Chronic cerebral hypoperfusion: a key mechanism leading to vascular cognitive impairment and dementia. Closing the translational gap between rodent models and human vascular cognitive impairment and dementia. Clin Sci. 2017;131(19):2451-68 [cited 2020 Jun 7] Available from: https://portla ndpress.com/clinsci/article/131/19/2451/71528/Chronic-cerebralhypoperfusion-a-key-mechanism.

26. Wolters FJ, Zonneveld HI, Hofman A, van der Lugt A, Koudstaal PJ, Vernooij MW, et al. Cerebral perfusion and the risk of dementia. Circulation. 2017; 136(8):719-28 [cited 2019 Jul 18] Available from: http://www.ncbi.nIm.nih. gov/pubmed/28588075

27. Kawamura J, Meyer JS, Terayama Y, Weathers S. Leukoaraiosis correlates with cerebral hypoperfusion in vascular dementia. Stroke. 1991;22(5):609-14 [cited 2019 Jul 18] Available from: http://www.ncbi.nlm.nih.gov/pubmed/2 028490.

28. APA A, Van Der Graaf Y, Vincken KL, WPTM M, Geerlings MI. Combined effect of cerebral hypoperfusion and white matter lesions on executive functioning - the SMART-MR study. Dement Geriatr Cogn Disord. 2010;29(3): 240-7 [cited 2020 Dec 13] Available from: https://pubmed.ncbi.nlm.nih. gov/20375504/.

29. Moskowitz MA, Lo EH, ladecola C. The science of stroke: Mechanisms in search of treatments. Neuron. NIH Public Access. 2010;67:181-98 [cited 2020 Dec 13] Available from: https://www.ncbi.nlm.nih.gov/pmc/articles/PMC2 957363/.

30. Wallin A, Blennow K, Fredman P, Gottfries CG, Karlsson I, Svenner-holm L. Blood brain barrier function in vascular dementia. Acta Neurol Scand. 2009; 81(4):318-22 [cited 2019 Aug 22] Available from: http://www.ncbi.nlm.nih. gov/pubmed/2360399.

31. Bouhrara M, Reiter DA, Bergeron CM, Zukley LM, Ferrucci L, Resnick SM, et al. Evidence of demyelination in mild cognitive impairment and dementia using a direct and specific magnetic resonance imaging measure of myelin content. Alzheimer's Dement. 2018;14(8):998-1004 [cited 2020 Dec 13] Available from: https://pubmed.ncbi.nlm.nih.gov/2 9679574/.

32. Low A, Mak E, Malpetti M, Passamonti L, Nicastro N, Stefaniak JD, et al. In vivo neuroinflammation and cerebral small vessel disease in mild cognitive impairment and Alzheimer's disease. J Neurol Neurosurg Psychiatry. 2021; 92(1):45-52. [cited 2020 Dec 13] Available from:. https://doi.org/10.1136/ jnnp-2020-323894.

33. Venkat $\mathrm{P}$, Chopp M, Chen J. Models and mechanisms of vascular dementia. Exp Neurol. 2015;272:97-108 [cited 2018 Oct 8] Available from: http://www. ncbi.nlm.nih.gov/pubmed/25987538.

34. Washida K, Hattori Y, Ihara M. Animal models of chronic cerebral hypoperfusion: From mouse to primate. Int J Mol Sci. MDPI AG. 2019;20: 6176 [cited 2020 Dec 13]. Available from: https://www.ncbi.nlm.nih.gov/ pmc/articles/PMC6941004/.

35. Li W, Liu H, Jiang H, Wang C, Guo Y, Sun Y, et al. (S)-Oxiracetam is the Active Ingredient in Oxiracetam that Alleviates the Cognitive Impairment Induced by Chronic Cerebral Hypoperfusion in Rats. Sci Rep. 2017;7(1):10052 [cited 2021 Nov 2] Available from: https://www.ncbi.nlm.nih.gov/pmc/a rticles/PMC5577264/

36. Hertz L. Bioenergetics of cerebral ischemia: A cellular perspective. Neuropharmacology. 2008;55(3):289-309 [cited 2020 Dec 24] Available from: https://pubmed.ncbi.nlm.nih.gov/18639906/.

37. Matute C, Alberdi E, Ibarretxe G, Sánchez-Gómez MV. Excitotoxicity in glial cells. Eur J Pharmacol. 2002;447(2-3):239-46.

38. Fann DY-W, Lee S-Y, Manzanero S, Chunduri P, Sobey CG, Arumugam TV. Pathogenesis of acute stroke and the role of inflammasomes. Ageing Res Rev. 2013;12(4):941-66 [cited 2016 Jan 22] Available from: http://www.ncbi. nlm.nih.gov/pubmed/24103368. 
39. Du J, Ma M, Zhao Q, Fang L, Chang J, Wang Y, et al. Mitochondrial bioenergetic deficits in the hippocampi of rats with chronic ischemiainduced vascular dementia. Neuroscience. 2013;231:345-52 [cited 2020 Dec 24] Available from: https://pubmed.ncbi.nlm.nih.gov/23232258/.

40. Plaschke K, Weigand MA, Michel A, Martin E, Bardenheuer HJ. Permanent cerebral hypoperfusion: 'Preconditioning-like' effects on rat energy metabolism towards acute systemic hypotension. Brain Res. 2000;858(2): 363-70 [cited 2021 Oct 31] Available from: https://pubmed.ncbi.nlm.nih. gov/10708688/.

41. Aliev G, Smith MA, Obrenovich ME, De La Torre JC, Perry G. Role of vascular hypoperfusion-induced oxidative stress and mitochondria failure in the pathogenesis of Alzheimer disease. Neurotox Res. 2003;5:491-504 [cited 2021 Nov 15] Available from: https://pubmed.ncbi.nlm.nih.gov/14715433/.

42. Liu L, Li CJ, Lu Y, Zong XG, Luo C, Sun J, et al. Baclofen mediates neuroprotection on hippocampal CA1 pyramidal cells through the regulation of autophagy under chronic cerebral hypoperfusion. Sci Rep. 2015:5(1):14474 [cited 2021 Mar 12] Available from: www.nature.com/ scientificreports.

43. Sheng $N$, Zheng $H$, Li M, Li M, Wang Z, Peng $Y$, et al. 4,5 caffeoylquinic acid and scutellarin, identified by integrated metabolomics and proteomics approach as the active ingredients of Dengzhan Shengmai, act against chronic cerebral hypoperfusion by regulating glutamatergic and GABAergic synapses. Pharmacol Res. 2020;152:104636 [cited 2021 Nov 2] Available from: https://pubmed.ncbi.nlm.nih.gov/31926275/.

44. Huang J, Li J, Feng C, Huang X, Wong L, Liu X, et al. Blood-Brain Barrier Damage as the Starting Point of Leukoaraiosis Caused by Cerebral Chronic Hypoperfusion and Its Involved Mechanisms: Effect of Agrin and Aquaporin4. Biomed Res Int. 2018;2018:2321797 [cited 2021 3] Available from: https:// www.ncbi.n/m.nih.gov/pmc/articles/PMC5846350/.

45. Jayant S, Sharma B. Selective Modulator of Cannabinoid Receptor Type 2 Reduces Memory Impairment and Infarct Size During Cerebral Hypoperfusion and Vascular Dementia. Curr Neurovasc Res. 2016;13(4):289302 [cited 2021 Nov 3] Available from: https://pubmed.ncbi.nlm.nih.gov/2 7586843/.

46. Mongin AA. Disruption of ionic and cell volume homeostasis in cerebral ischemia: The perfect storm. Pathophysiology. 2007;14(3-4):18393 [cited 2020 Dec 24] Available from: https://pubmed.ncbi.nlm.nih. gov/17961999/.

47. Yanpallewar SU, Hota D, Rai S, Kumar M, Acharya SB. Nimodipine attenuates biochemical, behavioral and histopathological alterations induced by acute transient and long-term bilateral common carotid occlusion in rats. Pharmacol Res. 2004;49(2):143-50 [cited 2021 Nov 3] Available from: https:// pubmed.ncbi.nlm.nih.gov/14643694/.

48. Nimmrich V, Eckert A. Calcium channel blockers and dementia. Br J Pharmacol. 2013;169:1203-10 [cited 2021 Nov 3] Available from: https:// pubmed.ncbi.nlm.nih.gov/23638877/.

49. Orgogozo J-M, Rigaud A-S, Stöffler A, Möbius H-J, Forette F. Efficacy and safety of Memantine in patients with mild to moderate vascular dementia. Stroke. 2002;33(7):1834-9.

50. Ganzella M, De Oliveira EDA, Comassetto DD, Cechetti F, Cereser VH, Moreira JD, et al. Effects of chronic guanosine treatment on hippocampal damage and cognitive impairment of rats submitted to chronic cerebral hypoperfusion. Neurol Sci. 2012;33(5):985-97 [cited 2021 Nov 15] Available from: https://pubmed.ncbi.nlm.nih.gov/22167652/.

51. Solenski NJ, DiPierro CG, Trimmer PA, Kwan AL, Helms GA. Ultrastructural changes of neuronal mitochondria after transient and permanent cerebral ischemia. Stroke. 2002;33(3):816-24 [cited 2021 Feb 19] Available from: https://www.ahajournals.org/doi/10.1161/hs0302.104541.

52. De La Torre JC, Aliev G. Inhibition of vascular nitric oxide after rat chronic brain hypoperfusion: Spatial memory and immunocytochemical changes. J Cereb Blood Flow Metab. 2005;25(6):663-72 [cited 2021 Feb 19] Available from: https://pubmed.ncbi.nlm.nih.gov/15703700/.

53. Abramov AY, Scorziello A, Duchen MR. Three distinct mechanisms generate oxygen free radicals in neurons and contribute to cell death during anoxia and reoxygenation. J Neurosci. 2007;27(5):1129-38 [cited 2021 Feb 19] Available from: https://pubmed.ncbi.nlm.nih.gov/17267568/.

54. Ono T, Tsuruta R, Fujita M, Aki HS, Kutsuna S, Kawamura Y, et al. Xanthine oxidase is one of the major sources of superoxide anion radicals in blood after reperfusion in rats with forebrain ischemia/reperfusion. Brain Res. 2009; 1305:158-67 [cited 2021 Feb 19] Available from: https://pubmed.ncbi.nlm. nih.gov/19781528/.
55. Choi DH, Lee KH, Kim JH, Seo JH, Kim HY, Shin CY, et al. NADPH oxidase 1, a novel molecular source of ROS in hippocampal neuronal death in vascular dementia. Antioxidants Redox Signal. 2014;21(4):533-50 [cited 2020 Dec 24] Available from: https://pubmed.ncbi.nlm.nih.gov/24294978/.

56. McCord JM, Roy RS. The pathophysiology of superoxide: Roles in inflammation and ischemia. Can J Physiol Pharmacol. 1982;60(11):1346-52 [cited 2021 Feb 19] Available from: https://pubmed.ncbi.nlm.nih.gov/62 95573/.

57. Radi R. Oxygen radicals, nitric oxide, and peroxynitrite: Redox pathways in molecular medicine. Proc Natl Acad Sci U S A. 2018;115(23):5839-48 [cited 2021 Feb 19] Available from: www.pnas.org/cgi/doi/10.1073/pnas.1804 932115

58. Yamagishi S, Nakamura K, Matsui T. Role of Oxidative Stress in the Development of Vascular Injury and its Therapeutic Intervention by Nifedipine. Curr Med Chem. 2008;15(2):172-7 [cited 2020 Dec 29] Available from: https://pubmed.ncbi.nlm.nih.gov/18220772/.

59. Gustaw-Rothenberg K, Kowalczuk K, Stryjecka-Zimmer M. Lipids peroxidation markers in Alzheimer's disease and vascular dementia. Geriatr Gerontol Int. 2010;10(2):161-6 [cited 2020 Dec 24] Available from: https:// pubmed.ncbi.nlm.nih.gov/20446930/.

60. Gackowski D, Rozalski R, Siomek A, Dziaman T, Nicpon K, Klimarczyk M, et al. Oxidative stress and oxidative DNA damage is characteristic for mixed Alzheimer disease/vascular dementia. J Neurol Sci. 2008;266(1-2):57-62 [cited 2021 May 17] Available from: https://pubmed.ncbi.nlm.nih.gov/1 7888453/.

61. Ryglewicz D, Rodo M, Kunicki PK, Bednarska-Makaruk M, Graban A, Lojkowska W, et al. Plasma antioxidant activity and vascular dementia. J Neurol Sci. 2002;203(204):195-7 [cited 2021 Sep 15] Available from: https:// pubmed.ncbi.nlm.nih.gov/12417383/.

62. Chen GY, Nuñez G. Sterile inflammation: Sensing and reacting to damage. Nat Rev Immunol. 2010;10:826-37 [cited 2020 Dec 27] Available from: https://pubmed.ncbi.nlm.nih.gov/21088683/.

63. Newton K, Dixit VM. Signaling in innate immunity and inflammation. Cold Spring Harb Perspect Biol. 2012;4(3) [cited 2020 Dec 27] Available from: https://www.ncbi.nlm.nih.gov/pmc/articles/PMC3282411/.

64. Zuliani G, Ranzini M, Guerra G, Rossi L, Munari MR, Zurlo A, et al. Plasma cytokines profile in older subjects with late onset Alzheimer's disease or vascular dementia. J Psychiatr Res. 2007;41(8):686-93 [cited 2018 Oct 12] Available from: http://www.ncbi.nlm.nih.gov/pubmed/16600299.

65. Schmitz M, Hermann P, Oikonomou P, Stoeck K, Ebert E, Poliakova T, et al. Cytokine profiles and the role of cellular prion protein in patients with vascular dementia and vascular encephalopathy. Neurobiol Aging. 2015; 36(9):2597-606 [cited 2018 Oct 12] Available from: http://www.ncbi.nlm.nih. gov/pubmed/26170132.

66. Belkhelfa M, Beder N, Mouhoub D, Amri M, Hayet R, Tighilt N, et al. The involvement of neuroinflammation and necroptosis in the hippocampus during vascular dementia. J Neuroimmunol. 2018;320:48-57 [cited 2018 Oct 12] Available from: http://www.ncbi.nlm.nih.gov/pubmed/29759140.

67. Engelhart MJ, Geerlings MI, Meijer J, Kiliaan A, Ruitenberg A, van Swieten JC, et al. Inflammatory Proteins in Plasma and the Risk of Dementia. Arch Neurol. 2004;61(5):668 [cited 2018 Oct 12] Available from: http://archneur.ja manetwork.com/article.aspx?doi=10.1001/archneur.61.5.668.

68. Basu A, Krady JK, Levison SW. Interleukin-1: a master regulator of neuroinflammation. J Neurosci Res. 2004;78(2):151-6 [cited 2020 Jun 6] Available from: http://www.ncbi.nlm.nih.gov/pubmed/15378607.

69. Zhou Y, Zhang J, Wang L, Chen Y, Wan Y, He Y, et al. Interleukin-1 $\beta$ impedes oligodendrocyte progenitor cell recruitment and white matter repair following chronic cerebral hypoperfusion. Brain Behav Immun. 2017; 60:93-105 [cited 2018 Oct 13] Available from: http://www.ncbi.nlm.nih.gov/ pubmed/27663285.

70. Miyanohara J, Kakae M, Nagayasu K, Nakagawa T, Mori Y, Arai K, et al. TRPM2 channel aggravates CNS inflammation and cognitive impairment via activation of Microglia in Chronic cerebral Hypoperfusion. J Neurosci. 2018; 38(14):3520-33.

71. Poh L, Fann DY, Wong P, Lim HM, Foo SL, Kang S-W, et al. AIM2 inflammasome mediates hallmark neuropathological alterations and cognitive impairment in a mouse model of vascular dementia. Mol Psychiatry. 2020; [cited 2020 Dec 27]; Available from: http://www.nature. com/articles/s41380-020-00971-5.

72. Liu Q, He S, Groysman L, Shaked D, Russin J, Cen S, et al. White matter injury due to experimental chronic cerebral hypoperfusion is associated 
with C5 deposition. Stover CM, editor. PLoS One. 2013;8(12):e84802 [cited 2020 Jun 7] Available from: https://journals.plos.org/plosone/article?id=10.13 71/journal.pone.0094516.

73. Gülke E, Gelderblom M, Magnus T. Danger signals in stroke and their role on microglia activation after ischemia. Ther Adv Neurol Dis. SAGE Publications Ltd. 2018;11:1756286418774254 [cited 2021 Feb 19]. Available from: https://www.ncbi.n/m.nih.gov/pmc/articles/PMC5968660/.

74. Pascual O, Ben AS, Rostaing P, Triller A, Bessis A. Microglia activation triggers astrocyte-mediated modulation of excitatory neurotransmission. Proc Natl Acad Sci U S A. 2012;109(4):E197-205 [cited 2018 Oct 12] Available from: www.pnas.org/cgi/doi/10.1073/pnas.1111098109.

75. Tomimoto H, Akiguchi I, Suenaga T, Nishimura M, Wakita H, Nakamura S, et al. Alterations of the blood-brain barrier and glial cells in white-matter lesions in cerebrovascular and Alzheimer's disease patients. Stroke. 1996; 27(11):2069-74 [cited 2018 Oct 12] Available from: http://www.ncbi.nlm.nih. gov/pubmed/8898818.

76. Fernando MS, Simpson JE, Matthews F, Brayne C, Lewis CE, Barber R, et al. White matter lesions in an unselected cohort of the elderly: Molecular pathology suggests origin from chronic hypoperfusion injury. Stroke. 2006; 37(6):1391-8 [cited 2018 Oct 12] Available from: https://www.ahajournals. org/doi/10.1161/01.STR.0000221308.94473.14.

77. Simpson JE, Fernando MS, Clark L, Ince PG, Matthews F, Forster G, et al. White matter lesions in an unselected cohort of the elderly: Astrocytic, microglial and oligodendrocyte precursor cell responses. Neuropathol Appl Neurobiol. 2007;33(4):410-9 [cited 2019 Jul 18] Available from: http://www. ncbi.nlm.nih.gov/pubmed/17442062.

78. Häußler V, Daehn T, Rissiek B, Roth V, Gerloff C, Arumugam TV, et al. Intravenous Immunoglobulin (IVIg) Induce a Protective Phenotype in Microglia Preventing Neuronal Cell Death in Ischaemic Stroke. NeuroMolecular Med. 2020;22(1):121-32 [cited 2021 May 17] Available from: https://pubmed.ncbi.nlm.nih.gov/31559534/.

79. Marín-Teva JL, Cuadros MA, Martín-Oliva D, Navascués J. Microglia and neuronal cell death. Neuron Glia Biol. 2011;7(1):25-40 [cited 2019 Jul 18] Available from: https://www.cambridge.org/core/product/identifier/S174092 5X12000014/type/journal_article.

80. Grammas P. Neurovascular dysfunction, inflammation and endothelial activation: Implications for the pathogenesis of Alzheimer's disease. J Neuroinflammation. BioMed Central. 2011:8:26 [cited 2020 Dec 27] Available from: https://www.ncbi.n/m.nih.gov/pmc/articles/PMC3072921/.

81. Zegeye MM, Andersson B, Sirsjö A, Ljungberg LU. IL-6 trans-Signaling Impairs Sprouting Angiogenesis by Inhibiting Migration, Proliferation and Tube Formation of Human Endothelial Cells. Cells. 2020;9(6):1414 [cited 2020 Dec 27] Available from: https://pubmed.ncbi.nlm.nih.gov/32517159/.

82. Dimitrijevic OB, Stamatovic SM, Keep RF, Andjelkovic AV. Effects of the Chemokine CCL2 on Blood-Brain Barrier Permeability during IschemiaReperfusion Injury. J Cereb Blood Flow Metab. 2006;26(6):797-810 [cited 2019 Jul 18] Available from: http://www.ncbi.nlm.nih.gov/pubmed/16192 992.

83. Sumi N, Nishioku T, Takata F, Matsumoto J, Watanabe T, Shuto H, et al. Lipopolysaccharide-activated microglia induce dysfunction of the bloodbrain barrier in rat microvascular endothelial cells co-cultured with microglia. Cell Mol Neurobiol. 2010;30(2):247-53 [cited 2020 Dec 27] Available from: https://pubmed.ncbi.nlm.nih.gov/19728078/.

84. Preston M, Gong X, Su W, Matsumoto SG, Banine F, Winkler C, et al. Digestion products of the $\mathrm{PH} 20$ hyaluronidase inhibit remyelination. Ann Neurol. 2013;73(2):266-80 [cited 2019 Jul 18] Available from: http://www. ncbi.nlm.nih.gov/pubmed/23463525.

85. Bazzoni G, Dejana E. Endothelial cell-to-cell junctions: molecular organization and role in vascular homeostasis. Physiol Rev. 2004;84(3):869-901.

86. Hill J, Rom S, Ramirez SH, Persidsky Y. Emerging Roles of Pericytes in the Regulation of the Neurovascular Unit in Health and Disease. $J$ Neuroimmune Pharmacol. NIH Public Access. 2014;9:591-605 [cited 2021 Sep 15] Available from: https://www.ncbi.nlm.nih.gov/pmc/articles/PMC42 09199/.

87. Chai Q, He WQ, Zhou M, Lu H, Fu ZF. Enhancement of Blood-Brain Barrier Permeability and Reduction of Tight Junction Protein Expression Are Modulated by Chemokines/Cytokines Induced by Rabies Virus Infection. J Virol. 2014;88(9):4698-710 [cited 2021 Mar 13] Available from: https:// www.ncbi.n/m.nih.gov/pmc/articles/PMC3993813/.

88. Komarova YA, Kruse K, Mehta D, Malik AB. Protein Interactions at Endothelial Junctions and Signaling Mechanisms Regulating Endothelial Permeability.
Circ Res. Lippincott Williams and Wilkins. 2017;120:179-206 [cited 2021 Mar 13] Available from: https://www.ncbi.nlm.nih.gov/pmc/articles/PMC522 5667/.

89. Rao R. Oxidative stress-induced disruption of epithelial and endothelial tight junctions. Front Biosci. 2008;13(18):7210-26 [cited 2021 Feb 19] Available from: https://www.ncbi.nlm.nih.gov/pmc/articles/PMC6261932/.

90. De Vries HE, Blom-Roosemalen MCM, Van Oosten M, De Boer AG, Van Berkel TJC, Breimer DD, et al. The influence of cytokines on the integrity of the blood-brain barrier in vitro. J Neuroimmunol. 1996;64(1):37-43 [cited 2021 Feb 19] Available from: https://pubmed.ncbi.nlm.nih.gov/8598388/.

91. Liu Q, Radwanski R, Babadjouni R, Patel A, Hodis DM, Baumbacher P, et al. Experimental chronic cerebral hypoperfusion results in decreased pericyte coverage and increased blood-brain barrier permeability in the corpus callosum. J Cereb Blood Flow Metab. 2019;39(2):240-50 [cited 2021 Jan 8] Available from: https://pubmed.ncbi.nlm.nih.gov/29192539/.

92. Lopez-Ramirez MA, Fischer R, Torres-Badillo CC, Davies HA, Logan K, Pfizenmaier $\mathrm{K}$, et al. Role of Caspases in Cytokine-Induced Barrier Breakdown in Human Brain Endothelial Cells. J Immunol. 2012;189(6):3130-9 [cited 2021 Feb 19] Available from: https://pubmed.ncbi.nlm.nih.gov/22896632/.

93. Takeshita Y, Ransohoff RM. Inflammatory cell trafficking across the bloodbrain barrier: chemokine regulation and in vitro models. Immunol Rev. 2012; 248(1):228-39 [cited 2020 Jun 6] Available from: http://www.ncbi.nlm.nih. gov/pubmed/22725965.

94. Blamire AM, Anthony DC, Rajagopalan B, Sibson NR, Perry VH, Styles P. Interleukin-1 $\beta$-induced changes in blood-brain barrier permeability, apparent diffusion coefficient, and cerebral blood volume in the rat brain: A magnetic resonance study. J Neurosci. 2000;20(21):8153-9 [cited 2021 Jan 8] Available from: https://www.jneurosci.org/content/20/21/8153.

95. Ihara $\mathrm{M}$, Tomimoto $\mathrm{H}$, Kinoshita M, Oh J, Noda M, Wakita H, et al. Chronic cerebral Hypoperfusion induces MMP-2 but not MMP-9 expression in the Microglia and vascular endothelium of White matter. J Cereb Blood Flow Metab. 2001;21(7):828-34.

96. Wardlaw JM, Sandercock PAG, Dennis MS, Starr J. Is breakdown of the blood-brain barrier responsible for lacunar stroke, leukoaraiosis, and dementia? Stroke. 2003;34(3):806-12.

97. Wardlaw JM, Doubal F, Armitage P, Chappell F, Carpenter T, Muñoz Maniega S, et al. Lacunar stroke is associated with diffuse Blood-Brain barrier dysfunction. Ann Neurol. 2009;65(2):194-202.

98. Ueno M, Tomimoto H, Akiguchi I, Wakita H, Sakamoto H. Blood-Brain barrier disruption in White matter Lesions in a rat model of Chronic cerebral Hypoperfusion. J Cereb Blood Flow Metab. 2002;22(1):97-104.

99. Huang J, Li J, Feng C, Huang X, Wong L, Liu X, et al. Blood-Brain Barrier Damage as the Starting Point of Leukoaraiosis Caused by Cerebral Chronic Hypoperfusion and Its Involved Mechanisms: Effect of Agrin and Aquaporin4. Biomed Res Int. 2018;2018:1-10 [cited 2020 Jun 10] Available from: https://www.hindawi.com/journals/bmri/2018/2321797/.

100. Lee JM, Lee JH, Song MK, Kim YJ. Nxp031 improves cognitive impairment in a chronic cerebral hypoperfusion-induced vascular dementia rat model through nrf2 signaling. Int J Mol Sci. 2021;22(12):6285 [cited 2021 Sep 15] Available from: https://www.mdpi.com/1422-0067/22/12/6285/htm.

101. Sun Z, Gao C, Gao D, Sun R, Li W, Wang F, et al. Reduction in pericyte coverage leads to blood-brain barrier dysfunction via endothelial transcytosis following chronic cerebral hypoperfusion. Fluids Barriers CNS. 2021;18(1):1-18 [cited 2021 Sep 15] Available from: https://fluidsbarrierscns. biomedcentral.com/articles/10.1186/s12987-021-00255-2.

102. Wallin A, Sjögren M, Edman $\AA$, Blennow K, Regland B. Symptoms, vascular risk factors and Blood-Brain barrier function in relation to $C T$ White-matter changes in dementia. Eur Neurol. 2000;44(4):229-35.

103. Janyou A, Wicha P, Jittiwat J, Suksamrarn A, Tocharus C, Tocharus J. Dihydrocapsaicin Attenuates Blood Brain Barrier and Cerebral Damage in Focal Cerebral Ischemia/Reperfusion via Oxidative Stress and Inflammatory. Sci Rep. 2017;7(1):10556 [cited 2020 Dec 27] Available from: https://pubmed. ncbi.nlm.nih.gov/28874782/.

104. Varatharaj A, Galea I. The blood-brain barrier in systemic inflammation. Brain Behav Immunity Feb. 2017;1:1-12 Availaeble from: https://www. sciencedirect.com/science/article/pii/S0889159116300551.

105. Ankarcrona M, Dypbukt JM, Bonfoco E, Zhivotovsky B, Orrenius S, Lipton SA, et al. Glutamate-induced neuronal death: a succession of necrosis or apoptosis depending on mitochondrial function. Neuron. 1995;15(4):961-73.

106. Yamashima T. Ca2+-dependent proteases in ischemic neuronal death. A conserved 'calpain-cathepsin cascade' from nematodes to primates. Cell 
Calcium. 2004;36(3-4):285-93 [cited 2020 Dec 24] Available from: https:// pubmed.ncbi.nlm.nih.gov/15261484/.

107. Lee BI, Lee DJ, Cho KJ, Kim GW. Early nuclear translocation of endonuclease $\mathrm{G}$ and subsequent DNA fragmentation after transient focal cerebral ischemia in mice. Neurosci Lett. 2005;386(1):23-7 [cited 2020 Dec 24] Available from: https://pubmed.ncbi.nlm.nih.gov/15979239/.

108. Xu Y, Bradham C, Brenner DA, Czaja MJ. Hydrogen peroxide-induced liver cell necrosis is dependent on AP-1 activation. Am J Physiol Liver Physiol. 1997;273(4):G795-803 [cited 2021 Feb 19] Available from: https:/www. physiology.org/doi/10.1152/ajpgi.1997.273.4.G795.

109. Lee JE, Sohn J, Lee JH, Lee KC, Son CS, Tockgo YC. Regulation of bcl-2 family in hydrogen peroxide-induced apoptosis in human leukemia $\mathrm{HL}-60$ cells. Exp Mol Med. 2000;32(1):42-6 [cited 2021 Feb 19] Available from: https://www.nature.com/articles/emm20008.

110. Micheau O, Tschopp J. Induction of TNF receptor I-mediated apoptosis via two sequential signaling complexes. Cell. 2003;114(2):181-90 [cited 2021 Jan 5] Available from: https://pubmed.ncbi.nlm.nih.gov/12887920/.

111. Fisher CM. Lacunar strokes and infarcts: A review. Neurology. 1982;32(8): 871-6 [cited 2020 Sep 26] Available from: https://pubmed.ncbi.nlm.nih.gov/ 7048128/.

112. Rami A, Kögel D. Apoptosis meets autophagy-like cell death in the ischemic penumbra: Two sides of the same coin? Autophagy. Taylor and Francis Inc. 2008;4:422-6 [cited 2020 Dec 29] Available from: https:/pubmed.ncbi.nlm. nih.gov/18319639/.

113. Kerr JFR, Wyllie AH, Currie AR. Apoptosis: A basic biological phenomenon with wide-ranging implications in tissue kinetics. Br J Cancer. 1972;26(4): 239-57 [cited 2020 Dec 29] Available from: https://www.ncbi.nlm.nih.gov/ pmc/articles/PMC2008650/.

114. Creagh EM, Conroy H, Martin SJ. Caspase-activation pathways in apoptosis and immunity. Immunol Rev. 2003;193:10-21 [cited 2020 Dec 29] Available from: https://pubmed.ncbi.nlm.nih.gov/12752666/.

115. Gray F, Polivka M, Viswanathan A, Baudrimont M, Bousser M-G, Chabriat H. Apoptosis in cerebral autosomal-dominant arteriopathy with subcortical infarcts and leukoencephalopathy. J Neuropathol Exp Neurol. 2007;66(7): 597-607 [cited 2020 Jun 8] Available from: https:/academic.oup.com/jnen/a rticle-lookup/doi/10.1097/nen.0b013e318093e574.

116. Sun ZK, Ma XR, Jia YJ, Liu YR, Zhang JW, Zhang BA. Effects of resveratrol on apoptosis in a rat model of vascular dementia. Exp Ther Med. 2014;7(4):8438

117. Guo L, Wang D, Xu Y, Cui K. Effects of IL-1ß on Hippocampus Cell Apoptosis and Learning Ability of Vascular Dementia Rats. Eur Rev Med Pharmacol Sci. 2018;22(18):6042-8 [cited 2020 Jun 8] Available from: https://pubmed.ncbi. nlm.nih.gov/30280789/.

118. Poh L, Razak SMBA, Lim HM, Lai MKP, Chen CL-H, Lim LHK, et al. AIM2 inflammasome mediates apoptotic and pyroptotic death in the cerebellum following chronic hypoperfusion. Exp Neurol. 2021;346:113856 [cited 2021 Sep 8] Available from: https://linkinghub.elsevier.com/retrieve/pii/S00144 88621002648.

119. Poh L, Rajeev V, Selvaraji S, Lai MKP, Chen CLH, Arumugam TV, et al, Intermittent fasting attenuates inflammasome-associated apoptotic and pyroptotic death in the brain following chronic hypoperfusion. Neurochem Int. 2021;148:105109 [cited 2021 Jul 28] Available from: https://pubmed.ncbi. nlm.nih.gov/34174333/.

120. Kövari E, Gold G, Herrmann FR, Canuto A, Hof PR, Michel JP, et al. Cortical Microinfarcts and Demyelination Significantly Affect Cognition in Brain Aging. Stroke. 2004;35(2):410-4 [cited 2021 Jan 2] Available from: https:// www.ahajournals.org/doi/10.1161/01.STR.0000110791.51378.4E.

121. Rosenberg GA. Inflammation and white matter damage in vascular cognitive impairment. In: Stroke. Stroke. 2009;40:S20-3 [cited 2021 Jan 2] Available from: https://pubmed.ncbi.nlm.nih.gov/19064797/.

122. Love S. Demyelinating diseases. J Clin Pathol. BMJ Publishing Group. 2006; 59:1151-9 [cited 2021 Jan 2] Available from: https://www.ncbi.nlm.nih.gov/ pmc/articles/PMC1860500/.

123. Krick S, Eul BG, Hänze J, Savai R, Grimminger F, Seeger W, et al. Role of hypoxia-inducible factor-1a in hypoxia-induced apoptosis of primary alveolar epithelial type II cells. Am J Respir Cell Mol Biol. 2005;32(5):395-403 [cited 2021 Jan 2] Available from: https://pubmed.ncbinlm.nih.gov/15695738/.

124. Chandler S, Coates R, Gearing A, Lury J, Wells G, Bone E. Matrix metalloproteinases degrade myelin basic protein. Neurosci Lett. 1995;201(3): 223-6.
125. Akassoglou K, Bauer J, Kassiotis G, Pasparakis M, Lassmann H, Kollias G, et al. Oligodendrocyte apoptosis and primary demyelination induced by local TNF/p55TNF receptor signaling in the central nervous system of transgenic mice: Models for multiple sclerosis with primary oligodendrogliopathy. Am J Pathol. 1998;153(3):801-13 [cited 2021 Jan 2] Available from: https:// pubmed.ncbi.nlm.nih.gov/9736029/.

126. Márquez-Martín A, Jiménez-Altayó F, Dantas AP, Caracuel L, Planas AM, Vila E. Middle cerebral artery alterations in a rat chronic hypoperfusion model. J Appl Physiol. 2012;112(3):511-8 [cited 2021 Feb 21] Available from: https:// pubmed.ncbi.nlm.nih.gov/22096118/.

127. Skrobot OA, Black SE, Chen C, DeCarli C, Erkinjuntti T, Ford GA, et al. Progress toward standardized diagnosis of vascular cognitive impairment: Guidelines from the Vascular Impairment of Cognition Classification Consensus Study. Alzheimers Dement. 2018;14(3):280-92 [cited 2021 Jun 16] Available from: https://alz-journals.onlinelibrary.wiley.com/doi/full/10.1016/j. jalz.2017.09.007.

128. Wardlaw JM, Smith EE, Biessels GJ, Cordonnier C, Fazekas F, Frayne R, et al. Neuroimaging standards for research into small vessel disease and its contribution to ageing and neurodegeneration. Lancet Neurol. 2013;12:82238 [cited 2020 Sep 15] Available from: https://pubmed.ncbi.nlm.nih.gov/23 867200\%.

129. Barker R, Wellington D, Esiri MM, Love S. Assessing White matter ischemic damage in dementia patients by measurement of myelin proteins. J Cereb Blood Flow Metab. 2013;33(7):1050-7.

130. Masumura M, Hata R, Nagai Y, Sawada T. Oligodendroglial cell death with DNA fragmentation in the white matter under chronic cerebral hypoperfusion: comparison between normotensive and spontaneously hypertensive rats. Neurosci Res. 2001;39(4):401-12.

131. Holland PR, Searcy JL, Salvadores N, Scullion G, Chen G, Lawson G, et al. Gliovascular disruption and cognitive deficits in a mouse model with features of small vessel disease. J Cereb Blood Flow Metab. 2015;35(6):100514 [cited 2021 May 17] Available from: https://pubmed.ncbi.nlm.nih.gov/2 $5669904 \%$

132. Shibata M, Ohtani R, Ihara M, White TH, Lesions M. Glial Activation in a Novel Mouse Model of Chronic Cerebral Hypoperfusion. Stroke. 2004;35(11): 2598-603 [cited 2018 Sep 6] Available from: http://www.ncbi.nlm.nih.gov/ pubmed/15472111.

133. Reimer MM, McQueen J, Searcy L, Scullion G, Zonta B, Desmazieres A, et al. Rapid disruption of axon-glial integrity in response to mild cerebral hypoperfusion. J Neurosci. 2011;31(49):18185-94.

134. Barber R, Scheltens P, Gholkar A, Ballard C, McKeith I, Ince P, et al. White matter lesions on magnetic resonance imaging in dementia with Lewy bodies, Alzheimer's disease, vascular dementia, and normal aging. J Neurol Neurosurg Psychiatry. 1999;67(1):66-72 [cited 2018 Sep 6] Available from: http://www.ncbi.nlm.nih.gov/pubmed/10369824.

135. Gootjes L, Teipel SJ, Zebuhr Y, Schwarz R, Leinsinger G, Scheltens P, et al. Regional Distribution of White Matter Hyperintensities in Vascular Dementia, Alzheimer's Disease and Healthy Aging. Dement Geriatr Cogn Disord. 2004; 18(2):180-8 [cited 2018 Oct 7] Available from: http://www.ncbi.nlm.nih.gov/ pubmed/15211074.

136. Palesi F, De Rinaldis A, Vitali P, Castellazzi G, Casiraghi L, Germani G, et al. Specific patterns of white matter alterations help distinguishing Alzheimer's and vascular dementia. Front Neurosci. 2018;12(APR):274.

137. Longstreth WT, Manolio TA, Arnold A, Burke GL, Bryan N, Jungreis CA, et al. Clinical correlates of white matter findings on cranial magnetic resonance imaging of 3301 elderly people: The cardiovascular health study. Stroke. 1996;27(8):1274-82 [cited 2020 Sep 8] Available from: https://pubmed.ncbi. nlm.nih.gov/8711786/.

138. Krishnan MS, O'Brien JT, Firbank MJ, Pantoni L, Carlucci G, Erkinjuntti T, et al. Relationship between periventricular and deep white matter lesions and depressive symptoms in older people. The LADIS Study. Int J Geriatr Psychiatry. 2006;21(10):983-9 [cited 2020 Sep 8] Available from: https:// pubmed.ncbinlm.nih.gov/16955428/.

139. Román GC, Kalaria RN. Vascular determinants of cholinergic deficits in Alzheimer disease and vascular dementia. Neurobiol Aging. Elsevier. 2006; 27:1769-85.

140. Gray F, Dubas F, Roullet E, Escourolle R. Leukoencephalopathy in diffuse hemorrhagic cerebral amyloid angiopathy. Ann Neurol. 1985;18(1):54-9 [cited 2020 Sep 8] Available from: https:/pubmed.ncbi.nlm.nih.gov/403 7751\%. 
141. Kim S, Choi SH, Lee YM, Kim MJ, Kim YD, Kim JY, et al. Periventricular white matter hyperintensities and the risk of dementia: a CREDOS study. Int Psychogeriatrics. 2015;27(12):2069-77 [cited 2020 Jun 11] Available from: https://www.cambridge.org/core/product/identifier/S1041610215001076/ type/journal_article.

142. Sulkava R, Erkinjuntti T. Vascular dementia due to cardiac arrhythmias and systemic hypotension. Acta Neurol Scand. 1987;76(2):123-8 [cited 2020 Aug 22] Available from: http://doi.wiley.com/10.1111/j.1600-0404.1987.tb03555.x.

143. Bernbaum M, Menon BK, Fick G, Smith EE, Goyal M, Frayne R, et al. Reduced blood flow in normal white matter predicts development of leukoaraiosis. J Cereb Blood Flow Metab. 2015;35(10):1610-5 [cited 2019 Jul 18] Available from: http://www.ncbi.n/m.nih.gov/pubmed/25966951.

144. Kalaria RN. Neuropathological diagnosis of vascular cognitive impairment and vascular dementia with implications for Alzheimer's disease. Acta Neuropathologica. Springer Berlin Heidelberg. 2016;131:659-85 [cited 2019 Nov 26] Available from: http://link.springer.com/10.1007/s00401-016-1571-z.

145. Smith EE, Schneider JA, Wardlaw JM, Greenberg SM. Cerebral microinfarcts: The invisible lesions. The Lancet Neurology. NIH Public Access. 2012;11:27282 [cited 2020 Oct 26]Available from: https://www.ncbi.nlm.nih.gov/pmc/a rticles/PMC3359329/.

146. Westover MB, Bianchi MT, Yang C, Schneider JA, Greenberg SM. Estimating cerebral microinfarct burden from autopsy samples. Neurology. 2013;80(15): 1365-9 [cited 2020 Oct 26] Available from: https://pubmed.ncbi.nlm.nih. gov/23486880/.

147. Voskuhl RR, Peterson RS, Song B, Ao Y, Morales LBJ, Tiwari-Woodruff S, et al. Reactive astrocytes form scar-like perivascular barriers to leukocytes during adaptive immune inflammation of the CNS. J Neurosci. 2009;29(37):1151122 Available from: https://pubmed.ncbi.nlm.nih.gov/19759299/.

148. Brundel M, De Bresser J, Van Dillen JJ, Kappelle LJ, Biessels GJ. Cerebral microinfarcts: A systematic review of neuropathological studies. J Cereb Blood Flow Metab. 2012;32:425-36 [cited 2020 Oct 26] Available from: https://pubmed.ncbi.nlm.nih.gov/22234334/.

149. Suter OC, Sunthorn T, Kraftsik R, Straubel J, Darekar P, Khalili K, et al. Cerebral hypoperfusion generates cortical watershed microinfarcts in Alzheimer disease. Stroke. 2002;33(8):1986-92 [cited 2020 Oct 26] Available from: https://pubmed.ncbi.nlm.nih.gov/12154250/.

150. Okamoto Y, Yamamoto T, Kalaria RN, Senzaki H, Maki T, Hase Y, et al. Cerebral hypoperfusion accelerates cerebral amyloid angiopathy and promotes cortical microinfarcts. Acta Neuropathol. 2012;123(3):381-94 [cited 2020 Oct 26] Available from: https://pubmed.ncbi.nlm.nih.gov/22170742/.

151. Hilal S, Sikking E, Shaik MA, Chan QL, Van Veluw SJ, Vrooman H, et al. Cortical cerebral microinfarcts on 3T MRI: A novel marker of cerebrovascular disease. Neurology. 2016;87(15):1583-90 [cited 2020 Oct 26] Available from: https://n.neurology.org/content/87/15/1583.

152. Zhang L, Biessels GJ, Hilal S, Chong JSX, Liu S, Shim HY, et al. Cerebral microinfarcts affect brain structural network topology in cognitively impaired patients. J Cereb Blood Flow Metab. 2021;41(1):105-15 [cited 2021 Jan 19] Available from: https://pubmed.ncbi.nlm.nih.gov/31986957/.

153. Auriel E, Edlow BL, Reijmer YD, Fotiadis P, Ramirez-Martinez S, Ni J, et al. Microinfarct disruption of white matter structure: A longitudinal diffusion tensor analysis. Neurology. 2014:83(2):182-8 [cited 2020 Oct 26] Available from: https://www.ncbi.nlm.nih.gov/pmc/articles/PMC4117171/.

154. Hinman JD, Lee MD, Tung S, Vinters HV, Thomas Carmichael S. Molecular disorganization of axons adjacent to human lacunar infarcts. Brain. 2015; 138(3):736-45 [cited 2020 Oct 26] Available from: https://pubmed.ncbi.n/m. nih.gov/25614025/.

155. Hartmann DA, Hyacinth HI, Liao FF, Shih AY. Does pathology of small venules contribute to cerebral microinfarcts and dementia? J Neurochem. Blackwell Publishing Ltd. 2018;144:517-26 [cited 2020 Oct 26] Available from: https://pubmed.ncbi.nlm.nih.gov/28950410/.

156. Fein G, Di Sclafani V, Tanabe J, Cardenas V, Weiner MW, Jagust WJ, et al. Hippocampal and cortical atrophy predict dementia in subcortical ischemic vascular disease. Neurology. 2000;55(11):1626-35 [cited 2020 Oct 29] Available from: https://www.ncbi.nlm.nih.gov/pmc/articles/PMC2733356/.

157. van de Pol L, Gertz H-J, Scheltens P, Wolf H. Hippocampal Atrophy in Subcortical Vascular Dementia. Neurodegener Dis. 2011;8(6):465-9 [cited 2020 16] Available from: https://www.karger.com/Article/FullText/326695.

158. Vijayakumar A, Vijayakumar A. Comparison of Hippocampal Volume in Dementia Subtypes. ISRN. Radiol. 2013;2013:1-5 [cited 2020 Oct 29] Available from: https://www.ncbi.nlm.nih.gov/pmc/articles/PMC4045526/.
159. Kirino T, Tamura A, Sano K. Selective vulnerability of the Hippocampus to ischemia - reversible and irreversible types of ischemic cell damage. Prog Brain Res. 1985;63(C):39-58.

160. Hossmann K-A. The Hypoxic Brain. Boston, MA: In Springer; 1999. p. 155-69. [cited 2020 Oct 29] Available from: https://link.springer.com/chapter/10.1 007/978-1-4615-4711-2_14

161. Pulsinelli WA, Brierley JB. A new model of bilateral hemispheric ischemia in the unanesthetized rat. Stroke. 1979;10(3):267-72 [cited 2020 Oct 29] Available from: https://pubmed.ncbi.nlm.nih.gov/37614/.

162. Kirino T. Delayed neuronal death in the gerbil hippocampus following ischemia. Brain Res. 1982;239(1):57-69 [cited 2020 Oct 29] Available from: https://pubmed.ncbi.nlm.nih.gov/7093691/.

163. Beudel M, Leenders $\mathrm{KL}$, de Jong BM. Hippocampus activation related to 'real-time' processing of visuospatial change. Brain Res. 2016;1652:204-11.

164. Goukasian N, Porat S, Blanken A, Avila D, Zlatev D, Hurtz S, et al. Cognitive Correlates of Hippocampal Atrophy and Ventricular Enlargement in Adults with or without Mild Cognitive Impairment. Dement Geriatr Cogn Dis Extra. 2019;9(2):281-93 [cited 2020 Sep 16] Available from: https://www.karger. com/Article/FullText/490044

165. Laczó J, Andel R, Nedelska Z, Vyhnalek M, Vlcek K, Crutch S, et al. Exploring the contribution of spatial navigation to cognitive functioning in older adults. Neurobiol Aging. 2017;51:67-70 [cited 2020 Sep 16] Available from: https://pubmed.ncbi.nlm.nih.gov/28039765/.

166. Sinclair LI, Tayler HM, Love S. Synaptic protein levels altered in vascular dementia. Neuropathol Appl Neurobiol. 2015;41(4):533-43 [cited 2020 Oct 29] Available from: https://pubmed.ncbi.nlm.nih.gov/25559750/.

167. Hachinski V, ladecola C, Petersen RC, Breteler MM, Nyenhuis DL, Black SE, et al. National Institute of Neurological Disorders and Stroke-Canadian Stroke Network Vascular Cognitive Impairment Harmonization Standards. Stroke. 2006;37(9):2220-41 [cited 2019 Nov 26] Available from: http://www. ncbi.nlm.nih.gov/pubmed/16917086.

168. Voss SE, Bullock RA. Executive Function: The Core Feature of Dementia? Dement Geriatr Cogn Disord. 2004;18(2):207-16 [cited 2020 Nov 1] Available from: https://www.karger.com/Article/FullText/79202.

169. Moorhouse P, Song X, Rockwood K, Black S, Kertesz A, Gauthier S, et al. Executive dysfunction in vascular cognitive impairment in the consortium to investigate vascular impairment of cognition study. J Neurol Sci. 2010; 288(1-2):142-6.

170. Kramer JH, Reed BR, Mungas D, Weiner MW, Chui HC. Executive dysfunction in subcortical ischaemic vascular disease. J Neurol Neurosurg Psychiatry. 2002;72(2):217-20 [cited 2020 Nov 1] Available from: https://www.ncbi.nlm. nih.gov/pmc/articles/PMC1737728/.

171. Benjamin P, Lawrence AJ, Lambert C, Patel B, Chung AW, Mackinnon AD, et al. Strategic lacunes and their relationship to cognitive impairment in cerebral small vessel disease. Neurolmage Clin. 2014;4:828-37.

172. Salmon DP, Bondi MW. Neuropsychological assessment of dementia. Annual Review of Psychology. NIH Public Access. 2009;60:257-82 [cited 2020 Nov 7] Available from: https://www.ncbi.nlm.nih.gov/pmc/articles/ PMC2864104/.

173. Bentham PW, Jones S, Hodges JR. A comparison of semantic memory in vascular dementia and dementia of Alzheimer's type. Int J Geriatr Psychiatry. 1997;12(5):575-80 [cited 2020 Nov 7] Available from: https://onlinelibrary. wiley.com/doi/full/10.1002/\%28SICl\%291099-1166\%28199705\%2912\%3A5\%3 C575\%3A\%3AAID-GPS566\%3E3.0.CO\%3B2-N.

174. Graham NL, Emery T, Hodges JR. Distinctive cognitive profiles in Alzheimer's disease and subcortical vascular dementia. J Neurol Neurosurg Psychiatry. 2004;75(1):61-71 [cited 2020 Nov 7] Available from: https://www.ncbi.nlm. nih.gov/pmc/articles/PMC1757469/.

175. Vuorinen $\mathrm{E}$, Laine $\mathrm{M}$, Rinne J. Common pattern of language impairment in vascular dementia and in Alzheimer disease. Alzheimer Dis Assoc Disord. 2000;14(2):81-6 [cited 2020 Nov 7] Available from: https://pubmed.ncbi.nlm. nih.gov/10850746/.

176. Ricker JH, Keenan PA, Jacobson MW. Visuoperceptual-spatial ability and visual memory in vascular dementia and dementia of the Alzheimer type. Neuropsychologia. 1994;32(10):1287-96

177. Gyanwali B, Venketasubramanian N, Chen C, Hilal S. Effects of cerebral small vessels disease on brain perfusion in a memory clinic population. J Cereb Blood Flow Metab. 2019:39:135 [cited 2021 Jan 19] Available from: https:// research.vumc.nl/en/publications/effects-of-cerebral-small-vessels-diseaseon-brain-perfusion-in-a. 
178. Stefaniak J, O'brien J. Imaging of neuroinflammation in dementia: A review. J Neurol Neurosurg Psychiatry. BMJ Publishing Group Ltd. 2016;87:21-8 [cited $2021 \mathrm{Sep}$ 2] Available from: https://jnnp-bmj-com.libproxy1.nus.edu. $\mathrm{sg} /$ content/87/1/21.

179. Passamonti L, Tsvetanov KA, Jones PS, Bevan-Jones WR, Arnold R, Borchert $\mathrm{RJ}$, et al. Neuroinflammation and functional connectivity in Alzheimer's disease: Interactive influences on cognitive performance. J Neurosci. 2019; 39(36):7218-26 [cited 2021 Sep 2] Available from: https://www.jneurosci. org/content/39/36/7218.

180. Ng A, Tam WW, Zhang MW, Ho CS, Husain SF, Mclntyre RS, et al. IL-1ß, IL-6, TNF- $a$ and CRP in Elderly Patients with Depression or Alzheimer's disease: Systematic Review and Meta-Analysis. Sci Rep. 2018;8(1):1-12 [cited 2021 Sep 4] Available from: https://www.nature.com/articles/s41598-018-30487-6.

181. Schmidt R, Schmidt H, Curb JD, Masaki K, White LR, Launer LJ. Early inflammation and dementia: a 25-year follow-up of the Honolulu-Asia Aging Study. Ann Neurol. 2002;52(2):168-74 [cited 2020 Jun 6] Available from: http://www.ncbi.n/m.nih.gov/pubmed/12210786.

182. Ravaglia G, Forti P, Maioli F, Chiappelli M, Montesi F, Tumini E, et al. Blood inflammatory markers and risk of dementia: The Conselice Study of Brain Aging. Neurobiol Aging. 2007;28(12):1810-20 [cited 2020 Jun 6] Available from: http://www.ncbi.n/m.nih.gov/pubmed/17011077.

183. Chen A, Oakley AE, Monteiro M, Tuomela K, Allan LM, Mukaetova-Ladinska $E B$, et al. Multiplex analyte assays to characterize different dementias: Brain inflammatory cytokines in poststroke and other dementias. Neurobiol Aging. 2016;38:56-67 [cited 2021 Sep 4] Available from: https://www.ncbi. nlm.nih.gov/pmc/articles/PMC4759608/.

184. Mulugeta E, Molina-Holgado F, Elliott MS, Hortobagyi T, Perry R, Kalaria $\mathrm{RN}$, et al. Inflammatory mediators in the frontal lobe of patients with mixed and vascular dementia. Dement Geriatr Cogn Disord. 2008;25(3): 278-86 [cited 2021 Apr 28] Available from: https://pubmed.ncbi.nlm.nih. gov/18303264/.

185. Yamada K, Kono K, Umegaki H, Yamada K, Iguchi A, Fukatsu T, et al. Decreased interleukin-6 level in the cerebrospinal fluid of patients with Alzheimer-type dementia. Neurosci Lett. 1995;186(2-3):219-21 [cited 2021 Sep 4] Available from: https://pubmed.ncbi.nlm.nih.gov/7777201/.

186. Kim SM, Song J, Kim S, Han C, Park MH, Koh Y, et al. Identification of peripheral inflammatory markers between normal control and Alzheimer's disease. BMC Neurol. 2011;11:51 [cited 2021 Sep 4] Available from: https:// pubmed.ncbi.nlm.nih.gov/21569380/.

187. Paganelli R, Di lorio A, Patricelli L, Ripani F, Sparvieri E, Faricelli R, et al. Proinflammatory cytokines in sera of elderly patients with dementia: Levels in vascular injury are higher than those of mild-moderate Alzheimer's disease patients. Exp Gerontol. 2002;37(2-3):257-63 [cited 2021 Apr 28] Available from: https://pubmed.ncbi.nlm.nih.gov/11772511/.

188. Cuello AC. Early and Late CNS Inflammation in Alzheimer's Disease: Two Extremes of a Continuum? Trends Pharmacol Sci. 2017;38:956-66 [cited 2021 Sep 6] Available from: https://pubmed.ncbi.n/m.nih.gov/2 $8867259 /$.

189. Koelman L, Pivovarova-Ramich O, Pfeiffer AFH, Grune T, Aleksandrova K. Cytokines for evaluation of chronic inflammatory status in ageing research: Reliability and phenotypic characterisation. Immun Ageing. 2019;16(1):1-12 [cited 2021 Sep 6] Available from: https://immunityageing.biomedcentral. com/articles/10.1186/s12979-019-0151-1.

190. Gomez-Nicola D, Boche D. Post-mortem analysis of neuroinflammatory changes in human Alzheimer's disease. Alzheimer's Res Ther. 2015;7(1):42 [cited 2021 Sep 6] Available from: https://www.ncbi.n/m.nih.gov/pmc/a rticles/PMC4405851/.

191. Aziz N. Measurement of circulating cytokines and immune-activation markers by multiplex technology in the clinical setting: What are wereally measuring? For Immunopathol Dis Therap. 2015;6(1-2):19-22 [cited 2021 Sep 6] Available from: https://www.ncbi.nlm.nih.gov/pmc/articles/PMC5345938/.

192. Malaguarnera L, Motta M, Di Rosa M, Anzaldi M, Malaguarnera M. Interleukin18 and transforming growth factor-beta 1 plasma levels in Alzheimer's disease and vascular dementia. Neuropathology. 2006;26(4):307-12.

193. Cacabelos R, Alvarez XA, Fernandez-Novoa L, Franco A, Mangues R, Pellicer $A$, et al. Brain interleukin-1 $\beta$ in Alzheimer's disease and vascular dementia. Methods Find Exp Clin Pharmacol. 1994;16(2):141-51 [cited 2021 Sep 2] Available from: https://pubmed.ncbi.nlm.nih.gov/8007743/.

194. Lamkanfi M, Dixit VM. Mechanisms and functions of inflammasomes. Cell Cell Press. 2014;157:1013-22. [cited 2021 Jan 12] Available from:. https://doi. org/10.1016/j.cell.2014.04.007.
195. Patel MN, Carroll RG, Galván-Peña S, Mills EL, Olden R, Triantafilou M, et al. Inflammasome priming in sterile Inflammatory disease. Trends Mol Med. 2017;23(2):165-80

196. Kayagaki N, Warming S, Lamkanfi M, Vande Walle L, Louie S, Dong J, et al. Non-canonical inflammasome activation targets caspase-11. Nature. 2011; 479(7371):117-21 [cited 2016 Oct 8] Available from: http://www.ncbi.nlm. nih.gov/pubmed/22002608.

197. He Q, You H, Li X-M, Liu T-H, Wang P, Wang B-E. HMGB1 promotes the synthesis of pro-IL-1 $\beta$ and pro-IL-18 by activation of p38 MAPK and NF-KB through receptors for advanced Glycation end-products in macrophages. Asian Pacific J Cancer Prev. 2012;13(4):1365-70.

198. Fann DYW, Lim YA, Cheng YL, Lok KZ, Chunduri P, Baik SH, et al. Evidence that NF-KB and MAPK Signaling Promotes NLRP Inflammasome Activation in Neurons Following Ischemic Stroke. Mol Neurobiol. 2018;55(2):1082-96 [cited 2021 Jan 21] Available from: https://pubmed.ncbi.nlm.nih.gov/28092 085/.

199. Bauernfeind FG, Horvath G, Stutz A, Alnemri ES, MacDonald K, Speert D, et al. Cutting edge: NF-kappaB activating pattern recognition and cytokine receptors license NLRP3 inflammasome activation by regulating NLRP3 expression. J Immunol. 2009;183(2):787-91.

200. Fann DY-W, Lee SY, Manzanero S, Tang SC, Gelderblom M, Chunduri P, et al. Intravenous immunoglobulin suppresses NLRP1 and NLRP3 inflammasomemediated neuronal death in ischemic stroke. Cell Death Dis. 2013;4(9):e790.

201. Juliana C, Fernandes-Alnemri T, Kang S, Farias A, Qin F, Alnemri ES. Nontranscriptional priming and deubiquitination regulate NLRP3 inflammasome activation. J Biol Chem. 2012;287(43):36617-22.

202. Rubartelli A. DAMP-mediated activation of NLRP3-Inflammasome in Brain sterile inflammation: the fine line between healing and Neurodegeneration. Front Immunol. 2014;5:99.

203. Poh L, Kang SW, Baik SH, Ng GYQ, She DT, Balaganapathy P, et al. Evidence that NLRC4 inflammasome mediates apoptotic and pyroptotic microglial death following ischemic stroke. Brain Behav Immun. 2019;75:34-47 [cited 2018 Sep 13] Available from: http://www.ncbi.nlm.nih.gov/pubmed/30195027.

204. Hornung V, Ablasser A, Charrel-Dennis M, Bauernfeind F, Horvath G, Caffrey DR, et al. AIM2 recognizes cytosolic dsDNA and forms a caspase-1-activating inflammasome with ASC. Nature. 2009;458(7237):514-8 [cited 2021 Apr 28] Available from: https://pubmed.ncbi.nlm.nih.gov/19158675/.

205. Man SM, Tourlomousis P, Hopkins L, Monie TP, Fitzgerald KA, Bryant CE. Salmonella Infection Induces Recruitment of Caspase- 8 to the Inflammasome To Modulate IL-1ß Production. J Immunol. 2013;191(10): 5239-46 [cited 2021 Feb 26] Available from: https://pubmed.ncbi.nlm.nih. gov/24123685/.

206. Gurung P, Kanneganti T-D. Novel roles for caspase-8 in $\mathrm{L}-1 \beta$ and inflammasome regulation. Am J Pathol. 2015;185(1):17-25 [cited 2019 Jul 19] Available from: http://www.ncbi.nlm.nih.gov/pubmed/25451151.

207. Sagulenko V, Vitak N, Vajjhala PR, Vince JE, Stacey KJ. Caspase-1 is an apical Caspase leading to Caspase-3 cleavage in the AIM2 Inflammasome response, independent of Caspase-8. J Mol Biol. 2018;430(2):238-47.

208. Shi J, Zhao Y, Wang K, Shi X, Wang Y, Huang H, et al. Cleavage of GSDMD by inflammatory caspases determines pyroptotic cell death. Nature. 2015; 526(7575):660-5.

209. Sarhan J, Liu BC, Muendlein HI, Li P, Nilson R, Tang AY, et al. Caspase-8 induces cleavage of gasdermin D to elicit pyroptosis during Yersinia infection. Proc Natl Acad Sci. 2018;115(46):E10888-97.

210. Kayagaki N, Stowe IB, Lee BL, O'Rourke K, Anderson K, Warming S, et al. Caspase-11 cleaves gasdermin D for non-canonical inflammasome signalling. Nature. 2015;526(7575):666-71 [cited 2019 Jul 19] Available from: http://www.nature.com/articles/nature15541.

211. Liu X, Zhang Z, Ruan J, Pan Y, Magupalli VG, Wu H, et al. Inflammasomeactivated gasdermin $D$ causes pyroptosis by forming membrane pores. Nature. 2016;535(7610):153-8.

212. Pétrilli V, Papin S, Dostert C, Mayor A, Martinon F, Tschopp J. Activation of the NALP3 inflammasome is triggered by low intracellular potassium concentration. Cell Death Differ. 2007;14(9):1583-9 [cited 2021 Mar 11] Available from: https://pubmed.ncbi.nlm.nih.gov/17599094/.

213. Rühl S, Broz P. Caspase-11 activates a canonical NLRP3 inflammasome by promoting K + efflux. Eur J Immunol. 2015;45(10):2927-36 [cited 2019 Jul 18] Available from: http://www.ncbi.nlm.nih.gov/pubmed/26173909.

214. Zanoni I, Tan Y, Di Gioia M, Broggi A, Ruan J, Shi J, et al. An endogenous caspase-11 ligand elicits interleukin-1 release from living dendritic cells. Science. 2016;352(6290):1232-6. 
215. Ting JP-Y, Lovering RC, Alnemri ES, Bertin J, Boss JM, Davis BK, et al. The NLR gene family: a standard nomenclature. Immunity. 2008;28(3):285-7.

216. Jha S, Ting JP-Y. Inflammasome-associated nucleotide-binding domain, leucine-rich repeat proteins and inflammatory diseases. J Immunol. 2009; 183(12):7623-9 [cited 2016 Mar 11] Available from: https://www.ncbi.nlm. nih.gov/pmc/articles/PMC3666034/.

217. Proell M, Gerlic M, Mace PD, Reed JC, Riedl SJ. The CARD plays a critical role in ASC foci formation and inflammasome signalling. Biochem J. 2013;449(3): 613-21 [cited 2016 Feb 18] Available from: http://www.pubmedcentral.nih. gov/articlerender.fcgi?artid=3966062\&tool=pmcentrez\&rendertype=abstract.

218. Jin T, Perry A, Smith P, Jiang J, Xiao TS. Structure of the absent in melanoma 2 (AIM2) pyrin domain provides insights into the mechanisms of AIM2 autoinhibition and inflammasome assembly. J Biol Chem. 2013;288(19): 13225-35.

219. Gong Q, Robinson K, Xu C, Huynh PT, Chong KHC, Tan EYJ, et al. Structural basis for distinct inflammasome complex assembly by human NLRP1 and CARD8. Nat Commun. 2021;12(1):1-15. [cited 2021 Mar 20] Available from: https://doi.org/10.1038/s41467-020-20319-5.

220. Finger JN, Lich JD, Dare LC, Cook MN, Brown KK, Duraiswamis C, et al. Autolytic proteolysis within the function to find domain (FIIND) is required for NLRP1 inflammasome activity. J Biol Chem. 2012;287(30):25030-7 [cited 2021 Mar 20] Available from: https://pubmed.ncbi.nlm.nih.gov/22665479/.

221. Sharif H, Wang L, Wang WL, Magupalli VG, Andreeva L, Qiao Q, et al. Structural mechanism for NEK7-licensed activation of NLRP3 inflammasome. Nature. 2019;570(7761):338-43 [cited 2021 May 17] Available from: https:// www.ncbi.n/m.nih.gov/pmc/articles/PMC6774351/.

222. Matyszewski M, Zheng W, Lueck J, Antiochos B, Egelman EH, Sohn J. CryoEM structure of the NLRC4CARD filament provides insights into how symmetric and asymmetric supramolecular structures drive inflammasome assembly. J Biol Chem. 2018;293(52):20240-8 [cited 2021 May 17] Available from: https://www.ncbi.n/m.nih.gov/pmc/articles/PMC6311515/.

223. Roberts TL, Idris A, Dunn JA, Kelly GM, Burnton CM, Hodgson S, et al. HIN200 proteins regulate caspase activation in response to foreign cytoplasmic DNA. Science. 2009;323(5917):1057-60.

224. Lu A, Magupalli VG, Ruan J, Yin Q, Atianand MK, Vos MR, et al. Unified polymerization mechanism for the assembly of ASC-dependent inflammasomes. Cell. 2014;156(6):1193-206 [cited 2016 Jan 15] Available from: https://www.ncbi.n/m.nih.gov/pmc/articles/PMC4000066/.

225. Wang S, Miura M, Jung YK, Zhu H, Li E, Yuan J. Murine caspase-11, an ICEinteracting protease, is essential for the activation of ICE. Cell. 1998;92(4): 501-9 [cited 2016 Oct 8] Available from: http://www.ncbi.nlm.nih.gov/ pubmed/9491891.

226. Boucher D, Monteleone M, Coll RC, Chen KW, Ross CM, Teo JL, et al. Caspase-1 self-cleavage is an intrinsic mechanism to terminate inflammasome activity. J Exp Med. 2018;215(3):827-40 [cited 2019 Jul 19] Available from: http://www.ncbi.nlm.nih.gov/pubmed/29432122.

227. Blanchard H, Kodandapani L, Mittl PRE, Di Marco S, Krebs JF, Wu JC, et al. The three-dimensional structure of caspase-8: An initiator enzyme in apoptosis. Structure. 1999;7(9):1125-33 [cited 2021 Feb 24] Available from: https://pubmed.ncbi.nlm.nih.gov/10508784/.

228. Case CL, Kohler LJ, Lima JB, Strowig T, Zoete MRD, Flavell RA, et al. Caspase11 stimulates rapid flagellin-independent pyroptosis in response to Legionella pneumophila. Proc Natl Acad Sci U S A. 2013;110(5):1851-6 [cited 2021 Feb 24] Available from: https://pubmed.ncbi.nlm.nih.gov/23307811/.

229. Huang X, Feng Y, Xiong G, Whyte S, Duan J, Yang Y, et al. Caspase-11, a specific sensor for intracellular lipopolysaccharide recognition, mediates the non-canonical inflammatory pathway of pyroptosis. Cell Biosci BioMed Central Ltd. 2019;9:31 [cited 2021 Feb 24] Available from: https://cella ndbioscience.biomedcentral.com/articles/10.1186/s13578-019-0292-0.

230. Liao K-C, Mogridge J. Activation of the Nlrp1b inflammasome by reduction of cytosolic ATP. Infect Immun. 2013;81(2):570-9.

231. Lee G-S, Subramanian N, Kim Al, Aksentijevich I, Goldbach-Mansky R, Sacks $D B$, et al. The calcium-sensing receptor regulates the NLRP3 inflammasome through Ca2+ and CAMP. Nature. 2012;492(7427):123-7.

232. Muñoz-Planillo R, Kuffa P, Martínez-Colón G, Smith BL, Rajendiran TM, Núñez $\mathrm{G} . \mathrm{K}+$ efflux is the common trigger of NLRP3 Inflammasome activation by bacterial toxins and particulate matter. Immunity. 2013;38(6):1142-53.

233. Nägga K, Hansson O, Van Westen D, Minthon L, Wennström M. Increased levels of hyaluronic acid in cerebrospinal fluid in patients with vascular dementia. J Alzheimer's Dis. 2014;42(4):1435-41 [cited 2021 Feb 24] Available from: https://pubmed.ncbi.nlm.nih.gov/25024336/.
234. Markus HS. Cerebral perfusion and stroke. J Neurology, Neurosurgery and Psychiatry. BMJ Publishing Group Ltd. 2004;75:353-61 [cited 2021 Sep 9] Available from: https://jnnp.bmj.com/content/75/3/353.

235. Paik S, Kim JK, Silwal P, Sasakawa C, Jo EK. An update on the regulatory mechanisms of NLRP3 inflammasome activation. Cellular and Molecular Immunology. Nature Publishing Group. 2021;18:1141-60 [cited 2021 Sep 9] Available from: https://www.nature.com/articles/s41423-021-00670-3.

236. Whyte-Fagundes P, Zoidl G. Mechanisms of pannexin1 channel gating and regulation. Biochimica et Biophysica Acta - Biomembranes. Elsevier. 2018; 1860:65-71.

237. Silverman WR, de Rivero Vaccari JP, Locovei S, Qiu F, Carlsson SK, Scemes E, et al. The pannexin 1 channel activates the inflammasome in neurons and astrocytes. J Biol Chem. 2009;284(27):18143-51 [cited 2021 Sep 10] Available from: https://www.ncbi.nlm.nih.gov/pmc/articles/PMC2709345/.

238. Xu Z, Chen ZM, Wu X, Zhang L, Cao Y, Zhou P. Distinct Molecular Mechanisms Underlying Potassium Efflux for NLRP3 Inflammasome Activation. Front Immunol. Frontiers Media SA. 2020;11 [cited 2021 Sep 9] Available from: https://www.ncbi.nlm.nih.gov/pmc/articles/PMC7793832/.

239. Tapia-Abellan A, Angosto-Bazarra D, Alarcon-Vila C, Baños MC, HafnerBratkovič I, Oliva B, et al. Sensing low intracellular potassium by NLRP3 results in a stable open structure that promotes inflammasome activation. Sci Adv. 2021;7(38):4468-83 [cited 2021 Sep 17];in press Available from: https://www.science.org/doi/abs/10.1126/sciadv.abf4468.

240. Li H, Wang J, Wang P, Rao Y, Chen L. Resveratrol Reverses the Synaptic Plasticity Deficits in a Chronic Cerebral Hypoperfusion Rat Model. J Stroke Cerebrovasc Dis. 2016;25(1):122-8 [cited 2021 Sep 9] Available from: https:// pubmed.ncbi.nlm.nih.gov/26456198/.

241. Peng K, Liu L, Wei D, Lv Y, Wang G, Xiong W, et al. P2X7R is involved in the progression of atherosclerosis by promoting NLRP3 inflammasome activation. Int J Mol Med. 2015;35(5):1179-88 [cited 2021 Sep 11] Available from: https://www.ncbi.nlm.nih.gov/pmc/articles/PMC4380202/.

242. Lu B, Nakamura T, Inouye K, Li J, Tang Y, Lundbäck $P$, et al. Novel role of PKR in inflammasome activation and HMGB1 release. Nature. 2012; 488(7413):670-4 [cited 2021 Sep 11] Available from: https://pubmed.ncbi. nlm.nih.gov/22801494/.

243. Lane T, Flam B, Lockey R, Kolliputi N. TXNIP shuttling: missing link between oxidative stress and inflammasome activation, vol. 4. MAR: Frontiers in Physiology. Frontiers; 2013. p. 50

244. Ye X, Zuo D, Yu L, Zhang L, Tang J, Cui C, et al. ROS/TXNIP pathway contributes to thrombin induced NLRP3 inflammasome activation and cell apoptosis in microglia. Biochem Biophys Res Commun. 2017;485(2):499-505 [cited 2021 Sep 9] Available from: https:/pubmed.ncbi.nlm.nih.gov/28202418/.

245. Han Y, Xu X, Tang C, Gao P, Chen X, Xiong X, et al. Reactive oxygen species promote tubular injury in diabetic nephropathy: The role of the mitochondrial ros-txnip-nlrp3 biological axis. Redox Biol. 2018;16:32-46 [cited $2021 \mathrm{Sep} 9$ ] Available from: https://www.ncbi.n/m.nih.gov/pmc/a rticles/PMC5842313/.

246. Abais JM, Xia M, Li G, Chen Y, Conley SM, Gehr TWB, et al. Nod-like receptor protein 3 (NLRP3) inflammasome activation and podocyte injury via thioredoxin-interacting protein (TXNIP) during hyperhomocysteinemia. J Biol Chem. 2014;289(39):27159-68 [cited 2021 Sep 9] Available from: https:// www.ncbi.nlm.nih.gov/pmc/articles/PMC4175351/.

247. Saxena AK, Abdul-Majeed SS, Gurtu S, WMY M. Investigation of redox status in chronic cerebral hypoperfusion-induced neurodegeneration in rats. Appl Transl Genomics. 2015;5:30-2 [cited 2021 Sep 9] Available from: https:// www.ncbi.nlm.nih.gov/pmc/articles/PMC4745367/.

248. Du SQ, Wang XR, Zhu W, Ye Y, Yang JW, Ma SM, et al. Acupuncture inhibits TXNIP-associated oxidative stress and inflammation to attenuate cognitive impairment in vascular dementia rats. CNS Neurosci Ther. 2018;24(1):39-46 [cited 2021 Sep 9] Available from: https://www.ncbi.nlm.nih.gov/pmc/a rticles/PMC6489958/.

249. Zhang L, Chen S, Ruan J, Wu J, Tong AB, Yin Q, et al. Cryo-EM structure of the activated NAIP2-NLRC4 inflammasome reveals nucleated polymerization. Science. 2015;350(6259):404-9 [cited 2021 Feb 25] Available from: https:// pubmed.ncbi.nlm.nih.gov/26449474/.

250. Freeman L, Guo H, David CN, Brickey WJ, Jha S, Ting JP-Y. NLR members NLRC4 and NLRP3 mediate sterile inflammasome activation in microglia and astrocytes. J Exp Med. 2017;214(5):1351-70.

251. Scholz H, Eder C. Lysophosphatidylcholine activates caspase-1 in microglia via a novel pathway involving two inflammasomes. J Neuroimmunol. 2017; 310:107-10. 
252. Ismaeel S, Qadri A. ATP Release Drives Inflammation with Lysophosphatidylcholine. ImmunoHorizons. 2021;5(4):219-33 [cited 2021 Sep 10] Available from: https://www.immunohorizons.org/content/5/4/219.

253. Ying Y. Sphingosine kinase inhibition ameliorates chronic hypoperfusioninduced white matter lesions. [Singapore]: National University of Singapore; 2016.

254. Furman D, Chang J, Lartigue L, Bolen CR, Haddad F, Gaudilliere B, et al. Expression of specific inflammasome gene modules stratifies older individuals into two extreme clinical and immunological states. Nat Med. 2017:23(2):174-84.

255. Wang B, Yin Q. AIM2 inflammasome activation and regulation: a structural perspective. J Struct Biol. 2017;200(3):279-82

256. Jin T, Perry A, Jiang J, Smith P, Curry JA, Unterholzner L, et al. Structures of the HIN domain:DNA complexes reveal ligand binding and activation mechanisms of the AIM2 Inflammasome and IFI16 receptor. Immunity. 2012; 36(4):561-71.

257. Lénárt N, Brough D, Dénes Á. Inflammasomes link vascular disease with neuroinflammation and brain disorders. J Cereb Blood Flow Metab. SAGE Publications. 2016:36:1668-85 [cited 2019 Jan 9] Available from: http://www. ncbi.nlm.nih.gov/pubmed/27486046.

258. Bae JH, Jo SI, Kim SJ, Lee JM, Jeong JH, Kang JS, et al. Circulating cell-free mtDNA contributes to AIM2 Inflammasome-mediated Chronic inflammation in patients with type 2 diabetes. Cells. 2019;8(4):328.

259. Tomimoto $H$, Ihara M, Wakita H, Ohtani R, Lin J-X, Akiguchi I, et al. Chronic cerebral hypoperfusion induces white matter lesions and loss of oligodendroglia with DNA fragmentation in the rat. Acta Neuropathol. 2003; 106(6):527-34

260. Kim MS, Bang JH, Lee J, Han JS, Baik TG, Jeon WK. Ginkgo biloba L. extract protects against chronic cerebral hypoperfusion by modulating neuroinflammation and the cholinergic system. Phytomedicine. 2016;23(12): 1356-64 [cited 2021 Sep 10] Available from: https://pubmed.ncbi.nlm.nih. gov/27765355/.

261. Sirois CM, Jin T, Miller AL, Bertheloot D, Nakamura H, Horvath GL, et al. RAGE is a nucleic acid receptor that promotes inflammatory responses to DNA. J Exp Med. 2013;210(11):2447-63.

262. Lechtenberg BC, Mace PD, Riedl SJ. Structural mechanisms in NLR inflammasome signaling. Curr Opin Structl Biol. Elsevier Ltd. 2014;29:17-25 [cited 2021 May 8] Available from: https://www.ncbi.n/m.nih.gov/pmc/a rticles/PMC4268015/.

263. Hoss F, Rodriguez-Alcazar JF, Latz E. Assembly and regulation of ASC specks. Cell Mol Life Sci. 2017;74(7):1211-29.

264. Van Opdenbosch N, Gurung P, Vande Walle L, Fossoul A, Kanneganti TD, Lamkanfi M. Activation of the NLRP1b inflammasome independently of ASC-mediated caspase-1 autoproteolysis and speck formation. Nat Commun. 2014;5. [cited 2021 Feb 25] Available from: https://pubmed.ncbi. nlm.nih.gov/24492532/

265. Rodgers MA, Bowman JW, Fujita H, Orazio N, Shi M, Liang Q, et al. The linear ubiquitin assembly complex (LUBAC) is essential for NLRP3 inflammasome activation. J Exp Med. 2014;211(7):1333-47.

266. Qu Y, Misaghi S, Izrael-Tomasevic A, Newton K, Gilmour LL, Lamkanfi M, et al. Phosphorylation of NLRC4 is critical for inflammasome activation. Nature. 2012;490(7421):539-42.

267. Lu A, Li Y, Yin Q, Ruan J, Yu X, Egelman E, et al. Plasticity in PYD assembly revealed by cryo-EM structure of the PYD filament of AIM2. Cell Discov. 2015;1(1):1 [cited 2021 May 17] Available from: https://www.ncbi.nlm.nih. gov/pmc/articles/PMC4646227/.

268. Schroder K, Tschopp J. The Inflammasomes. Cell. 2010;140:821-32 [cited 2021 Feb 26] Available from: https://pubmed.ncbi.nlm.nih.gov/20303873/.

269. Antonopoulos C, Russo HM, El Sanadi C, Martin BN, Li X, Kaiser WJ, et al. Caspase-8 as an effector and regulator of NLRP3 inflammasome signaling. J Biol Chem. 2015;290(33):20167-84 [cited 2021 Feb 26] Available from: http://www.jbc.org/article/S002192582 042157X/fulltext.

270. Vajjhala PR, Lu A, Brown DL, Pang SW, Sagulenko V, Sester DP, et al. The inflammasome adaptor ASC induces procaspase-8 death effector domain filaments. J Biol Chem. 2015;290(49):29217-30 [cited 2021 Feb 26] Available from: https://www.ncbi.n/m.nih.gov/pmc/articles/PMC4705927/.

271. Chu LH, Indramohan M, Ratsimandresy RA, Gangopadhyay A, Morris EP Monack DM, et al. The oxidized phospholipid oxPAPC protects from septic shock by targeting the non-canonical inflammasome in macrophages. Nat Commun. 2018;9(1):1-16
272. Ross C, Chan AH, Von Pein J, Boucher D, Schroder K. Dimerization and autoprocessing induce caspase-11 protease activation within the non-canonical inflammasome. Life Sci Alliance. $2018 ; 1(6)$. [cited 2021 Feb 27] Available from: https://www.ncbi.nlm.nih.gov/pmc/articles/PMC6284101/

273. Bian ZM, Elner SG, Yoshida A, Kunkel SL, Su J, Elner VM. Activation of p38, ERK $1 / 2$ and NIK pathways is required for IL-1 $\beta$ and TNF-a-induced chemokine expression in human retinal pigment epithelial cells. Exp Eye Res. 2001;73(1):111-21.

274. Emsley HCA, Smith CJ, Georgiou RF, Vail A, Hopkins SJ, Rothwell NJ, et al. A randomised phase $\|$ study of interleukin-1 receptor antagonist in acute stroke patients. J Neurol Neurosurg Psychiatry. 2005;76(10):1366-72 [cited 2021 Jan 22] Available from: https://pubmed.ncbi.nlm.nih.gov/16170078/.

275. Bethea JR, Gillespie GY, Benveniste EN. Interleukin-1 $\beta$ induction of TNF-a gene expression: Involvement of protein kinase C. J Cell Physiol. 1992;152(2): 264-73 [cited 2021 Jan 21] Available from: https://pubmed.ncbi.nlm.nih. gov/1639861/.

276. Wang X, Feuerstein GZ, Gu JL, Lysko PG, Yue TL. Interleukin-1 $\beta$ induces expression of adhesion molecules in human vascular smooth muscle cells and enhances adhesion of leukocytes to smooth muscle cells. Atherosclerosis. 1995;115(1):89-98 [cited 2021 Jan 21] Available from: https://pubmed.ncbi.nlm.nih.gov/7545398/.

277. Yata K, Nishimura Y, Unekawa M, Tomita Y, Suzuki N, Tanaka T, et al. In vivo imaging of the mouse neurovascular unit under chronic cerebral hypoperfusion. Stroke. 2014;45(12):3698-703 [cited 2021 Nov 12] Available from: https://www.ahajournals.org/doi/abs/10.1161/strokeaha.114.005891.

278. Wakita H, Tomimoto H, Akiguchi I, Kimura J. Glial activation and white matter changes in the rat brain induced by chronic cerebral hypoperfusion: an immunohistochemical study. Acta Neuropathol. 1994;87(5):484-92 [cited 2019 Jul 18] Available from: http://www.ncbi.nlm.nih.gov/pubmed/8059601.

279. Man SM, Kanneganti T-D. Converging roles of caspases in inflammasome activation, cell death and innate immunity. Nat Rev Immunol. 2016;16(1):721.

280. Porter AG, Jänicke RU. Emerging roles of caspase-3 in apoptosis. Cell Death Differ. 1999;6(2):99-104 [cited 2016 Jan 28] Available from: http://www.ncbi. nlm.nih.gov/pubmed/10200555.

281. Lamkanfi M, Kanneganti T-D, Van Damme P, Vanden Berghe T, Vanoverberghe I, Vandekerckhove J, et al. Targeted peptidecentric proteomics reveals caspase-7 as a substrate of the caspase-1 inflammasomes. Mol Cell Proteomics. 2008;7(12):2350-63.

282. Kang SJ, Wang S, Hara H, Peterson EP, Namura S, Amin-Hanjani S, et al. Dual role of caspase-11 in mediating activation of caspase- 1 and caspase-3 under pathological conditions. J Cell Biol. 2000;149(3):613-22 [cited 2016 Oct 8] Available from: http://www.ncbi.nlm.nih.gov/pubmed/10791975.

283. Feng S, Fox D, Man SM. Mechanisms of Gasdermin Family Members in Inflammasome Signaling and Cell Death. J Mol Biol. 2018;430(18):3068-80 [cited 2019 Jul 18] Available from: http://www.ncbi.nlm.nih.gov/pubmed/2 9990470.

284. Garrido C, Galluzzi L, Brunet M, Puig PE, Didelot C, Kroemer G. Mechanisms of cytochrome $\mathrm{c}$ release from mitochondria. Vol. 13, Cell Death and Differentiation. Nature Publishing Group; 2006. p. 1423-33.

285. Mascarenhas DPA, Cerqueira DM, Pereira MSF, Castanheira FVS, Fernandes TD, Manin GZ, et al. Inhibition of caspase-1 or gasdermin-D enable caspase8 activation in the Naip5/NLRC4/ASC inflammasome. Seifert HS. PLOS Pathog. 2017;13(8):e1006502.

286. Kim SU, de Vellis J. Microglia in health and disease. J Neurosci Res. 2005; 81(3):302-13 [cited 2016 Jan 7] Available from: http://www.ncbi.n/m.nih.gov/ pubmed/15954124.

287. Barreto G, White RE, Ouyang Y, Xu L, Giffard RG. Astrocytes: targets for neuroprotection in stroke. Cent Nerv Syst Agents Med Chem. 2011;11(2): 164-73 [cited 2020 Jun 7] Available from: http://www.ncbi.nlm.nih.gov/ pubmed/21521168.

288. Zhang Y, Chen K, Sloan SA, Bennett ML, Scholze AR, O'Keeffe S, et al. An RNA-Sequencing Transcriptome and Splicing Database of Glia, Neurons, and Vascular Cells of the Cerebral Cortex. J Neurosci. 2014;34(36):11929 [cited 2020 Apr 30] Available from: https://www.ncbi.nlm.nih.gov/pmc/articles/ PMC4152602/.

289. Taylor RA, Sansing LH. Microglial responses after ischemic stroke and intracerebral hemorrhage. Clin Dev Immunol. 2013;2013:746068.

290. Stratoulias V, Venero JL, Tremblay M, Joseph B. Microglial subtypes: diversity within the microglial community. EMBO J. 2019;38(17) [cited 2021 Sep 13] Available from: https://www.ncbi.nlm.nih.gov/pmc/articles/PMC6717890/. 
291. Su S-H, Wu Y-F, Lin Q, Wang D-P, Hai J. URB597 protects against NLRP3 inflammasome activation by inhibiting autophagy dysfunction in a rat model of chronic cerebral hypoperfusion. J Neuroinflammation. 2019;16(1): 260 [cited 2020 Jun 6] Available from: http://www.ncbi.nlm.nih.gov/ pubmed/31815636.

292. Liddelow SA, Guttenplan KA, Clarke LE, Bennett FC, Bohlen CJ, Schirmer L, et al. Neurotoxic reactive astrocytes are induced by activated microglia. Nature. 2017;541(7638):481-7 [cited 2021 Feb 2] Available from: https:// www.ncbi.n/m.nih.gov/pmc/articles/PMC5404890/.

293. Liddelow SA, Barres BA. Reactive Astrocytes: Production, Function, and Therapeutic Potential. Immunity. 2017;46:957-67 [cited 2021 Sep 13] Available from: https://pubmed.ncbi.nlm.nih.gov/28636962/.

294. Sofroniew MV. Astrocyte Reactivity: Subtypes, States, and Functions in CNS Innate Immunity. Trends Immunol. 2020;41:758-70 [cited 2021 Sep 13] Available from: https://pubmed.ncbi.nlm.nih.gov/32819810/.

295. Rodríguez-Arellano JJ, Parpura V, Zorec R, Verkhratsky A. Astrocytes in physiological aging and Alzheimer's disease. Neuroscience. 2016;323:170-82 [cited 2021 Sep 13] Available from: https://pubmed.ncbi.nlm.nih.gov/2 5595973/.

296. Kaiser M, Maletzki I, Hülsmann S, Holtmann B, Schulz-Schaeffer W, Kirchhoff $F$, et al. Progressive loss of a glial potassium channel (KCNJ10) in the spinal cord of the SOD1 (G93A) transgenic mouse model of amyotrophic lateral sclerosis. J Neurochem. 2006;99(3):900-12 [cited 2021 Sep 13] Available from: https://pubmed.ncbi.nlm.nih.gov/16925593/.

297. Li K, Li J, Zheng J, Qin S. Reactive astrocytes in neurodegenerative diseases. Aging Dis. JKL International LLC. 2019;10:664-75 [cited 2021 Sep 13] Available from: https://www.ncbi.nlm.nih.gov/pmc/articles/PMC6538217/.

298. Zeis T, Allaman I, Gentner M, Schroder K, Tschopp J, Magistretti PJ, et al. Metabolic gene expression changes in astrocytes in Multiple Sclerosis cerebral cortex are indicative of immune-mediated signaling. Brain Behav Immun. 2015;48:313-25 [cited 2021 Sep 14] Available from: https://pubmed. ncbi.nlm.nih.gov/25937052/.

299. Lau LT, ACH Y. Astrocytes produce and release interleukin-1, interleukin-6, tumor necrosis factor alpha and interferon-gamma following traumatic and metabolic injury. J Neurotrauma. 2001;18(3):351-9 [cited 2021 Sep 14] Available from: https://pubmed.ncbi.nlm.nih.gov/11284554/.

300. Candelario-Jalil E, Yang Y, Rosenberg GA. Diverse roles of matrix metalloproteinases and tissue inhibitors of metalloproteinases in neuroinflammation and cerebral ischemia. Neuroscience. 2009;158(3):98394.

301. Yang Y, Estrada EY, Thompson JF, Liu W, Rosenberg GA. Matrix metalloproteinase-mediated disruption of tight junction proteins in cerebral vessels is reversed by synthetic matrix metalloproteinase inhibitor in focal ischemia in rat. J Cereb Blood Flow Metab. 2007;27(4):697-709 [cited 2021 May 17] Available from: https://pubmed.ncbi.nlm.nih.gov/16850029/.

302. Xie Z, Singh M, Singh K. Differential regulation of matrix metalloproteinase-2 and -9 expression and activity in adult rat cardiac fibroblasts in response to interleukin-1ß. J Biol Chem. 2004;279(38):39513-9 [cited 2021 Feb 1] Available from: https://pubmed.ncbi.nlm.nih.gov/15269222/.

303. Cheng CY, Kuo CT, Lin CC, Hsieh HL, Yang CM. IL-1 induces expression of matrix metalloproteinase-9 and cell migration via a c-Src-dependent, growth factor receptor transactivation in A549 cells. Br J Pharmacol. 2010; 160(7):1595-610 [cited 2021 Feb 1] Available from: https://www.ncbi.nlm. nih.gov/pmc/articles/PMC2936833/.

304. Rigor RR, Beard RS, Litovka OP, Yuan SY. Interleukin-1ß-induced barrier dysfunction is signaled through PKC- $\theta$ in human brain microvascular endothelium. Am J Physiol Physiol. 2012;302(10):C1513-22 [cited 2021 Jan 8] Available from: https://www.physiology.org/doi/10.1152/ajpcell.00371.2011.

305. Hayashi M, Luo Y, Laning J, Strieter RM, Dorf ME. Production and function of monocyte chemoattractant protein-1 and other beta-chemokines in murine glial cells. J Neuroimmunol. 1995;60(1-2):143-50 [cited 2020 Jun 6] Available from: http://www.ncbi.nlm.nih.gov/pubmed/7642742.

306. Gidday JM, Gasche YG, Copin JC, Shah AR, Perez RS, Shapiro SD, et al. Leukocyte-derived matrix metalloproteinase- 9 mediates blood-brain barrier breakdown and is proinflammatory after transient focal cerebral ischemia. Am J Physiol - Hear Circ Physiol. 2005;289(2 58-2):558-68 [cited 2021 Jan 8] Available from: https://journals.physiology.org/doi/full/10.1152/ajpheart.012 75.2004?rfr_dat=cr_pub++0pubmed\&url_ver=Z39.88-2003\&rfr_id=ori\%3A rid\%3Acrossref.org.

307. Turner RJ, Sharp FR. Implications of MMP9 for blood brain barrier disruption and hemorrhagic transformation following ischemic stroke. Vol. 10, Frontiers in Cellular Neuroscience. Frontiers Research Foundation; 2016 [cited 2021 Jan 8]. p. 56. Available from: https://www.ncbi.nlm.nih.gov/pmc/articles/ PMC4777722/

308. Zhang DD, Jin C, Zhang YT, Gan XD, Zou MJ, Wang YY, et al. A novel IL1RA-PEP fusion protein alleviates blood-brain barrier disruption after ischemia-reperfusion in male rats. J Neuroinflammation. 2018;15(1):16 [cited $2021 \mathrm{Jan}$ 8] Available from: https://jneuroinflammation.biomedcentral.com/a rticles/10.1186/s12974-018-1058-z.

309. Liang Y, Song P, Chen W, Xie X, Luo R, Su J, et al. Inhibition of Caspase-1 Ameliorates Ischemia-Associated Blood-Brain Barrier Dysfunction and Integrity by Suppressing Pyroptosis Activation. Front Cell Neurosci. 2021;14: 449 [cited 2021 Feb 1] Available from: https://www.frontiersin.org/articles/1 0.3389/fncel.2020.540669/full.

310. Nagyoszi P, Nyúl-Tõth Á, Fazakas C, Wilhelm I, Kozma M, Molnár J, et al. Regulation of NOD-like receptors and inflammasome activation in cerebral endothelial cells. J Neurochem. 2015;135(3):551-64 [cited 2021 Sep 15] Available from: https://onlinelibrary.wiley.com/doi/full/10.1111/jnc.13197.

311. Chen $Y$, Wang L, Pitzer AL, Li X, Li PL, Zhang Y. Contribution of redoxdependent activation of endothelial Nlrp3 inflammasomes to hyperglycemia-induced endothelial dysfunction. J Mol Med. 2016;94(12): 1335-47 [cited 2021 Sep 14] Available from: https://pubmed.ncbi.nlm.nih. gov/27783111/.

312. Zhang Y, Chen Y, Zhang Y, Li PL, Li X. Contribution of cathepsin Bdependent Nlrp3 inflammasome activation to nicotine-induced endothelial barrier dysfunction. Eur J Pharmacol. 2019;865:172795 [cited 2021 Sep 14] Available from: https://pubmed.ncbi.nlm.nih.gov/31733211/.

313. Cao G, Jiang N, Hu Y, Zhang Y, Wang G, Yin M, et al. Ruscogenin attenuates cerebral ischemia-induced blood-brain barrier dysfunction by suppressing TXNIP/NLRP3 inflammasome activation and the MAPK pathway. Int J Mol Sci. 2016;17(9) [cited 2021 Sep 15] Available from: https://www.ncbi.nlm.nih. gov/pmc/articles/PMC5037697/.

314. Nyúl-Tóth Á, Kozma M, Nagyőszi P, Nagy K, Fazakas C, Haskó J, et al. Expression of pattern recognition receptors and activation of the noncanonical inflammasome pathway in brain pericytes. Brain Behav Immun. 2017;64:220-31.

315. Rock KL, Kono H. The inflammatory response to cell death. Vol. 3, Annual Review of Pathology: Mechanisms of Disease. NIH Public Access; 2008 [cited 2021 Jan 4]. p. 99-126. Available from: https://www.ncbi.nlm.nih.gov/pmc/a rticles/PMC3094097/

316. Ismael S, Zhao L, Nasoohi S, Ishrat T. Inhibition of the NLRP3-inflammasome as a potential approach for neuroprotection after stroke. Sci Rep. 2018;8(1): 1-9 [cited 2021 Feb 1] Available from: https://www.nature.com/articles/s41 598-018-24350-x.

317. Matsuyama H, Shindo A, Shimada T, Yata K, Wakita H, Takahashi R, et al. Chronic cerebral hypoperfusion activates AIM2 and NLRP3 inflammasome. Brain Res. 2020;1736:146779 [cited 2020 Jun 6] Available from: http://www. ncbi.n/m.nih.gov/pubmed/32171704.

318. Lee KM, Bang J, Kim BY, Lee IS, Han J-S, Hwang BY, et al. Fructus mume alleviates chronic cerebral hypoperfusion-induced white matter and hippocampal damage via inhibition of inflammation and downregulation of TLR4 and p38 MAPK signaling. BMC Complement Altern Med. 2015;15(1): 125 [cited 2021 Mar 11] Available from: http://bmccomplementalternmed. biomedcentral.com/articles/10.1186/s12906-015-0652-1.

319. Manso Y, Holland PR, Kitamura A, Szymkowiak S, Duncombe J, Hennessy E, et al. Minocycline reduces microgliosis and improves subcortical white matter function in a model of cerebral vascular disease. Glia. 2018;66(1):34-46.

320. Frostegård J, Ulfgren AK, Nyberg P, Hedin U, Swedenborg J, Andersson U, et al. Cytokine expression in advanced human atherosclerotic plaques: Dominance of pro-inflammatory (Th1) and macrophage-stimulating cytokines. Atherosclerosis. 1999;145(1):33-43 [cited 2021 Jan 22];145(1):3343 Available from: https://pubmed.ncbi.nlm.nih.gov/10428293/.

321. Paramel Varghese G, Folkersen L, Strawbridge RJ, Halvorsen B, Yndestad A, Ranheim T, et al. NLRP3 Inflammasome Expression and Activation in Human Atherosclerosis. J Am Heart Assoc. 2016;5(5). [cited 2021 Sep 2] Available from: https://www.ncbi.nlm.nih.gov/pmc/articles/PMC4889178/

322. Dziedzic T, Slowik A, Pera J, Szczudlik A. Interleukin 1 Beta Polymorphism $(-511)$ and Risk of Stroke due to Small Vessel Disease. Cerebrovasc Dis. 2005;20(5):299-303 [cited 2021 Jan 22] Available from: https://www.karger. com/Article/FullText/87928.

323. Zhou D, Wang X, Chen T, Wen W, Liu Y, Wu Y, et al. The NLRP3 rs 10754558 polymorphism is associated with the occurrence and prognosis of coronary 
artery disease in the Chinese Han population. Biomed Res Int. 2016 [cited 2021 Sep 11];2016. Available from: https://doi.org/10.1155/2016/3185397.

324. Hitomi Y, Ebisawa M, Tomikawa M, Imai T, Komata T, Hirota T, et al. Associations of functional NLRP3 polymorphisms with susceptibility to foodinduced anaphylaxis and aspirin-induced asthma. J Allergy Clin Immunol. 2009;124(4):779-785.e6 [cited 2021 Sep 11] Available from: http://www.ja cionline.org/article/S0091674909011518/fulltext.

325. Trøseid M, Seljeflot I, Hjerkinn EM, Arnesen H. Interleukin-18 is a strong predictor of cardiovascular events in elderly men with the metabolic syndrome synergistic effect of inflammation and hyperglycemia. Diabetes Care. 2009;32(3):486-92 [cited 2021 Jan 22] Available from: https://www. ncbi.nlm.nih.gov/pmc/articles/PMC2646034/.

326. Ji Q, Zeng Q, Huang Y, Shi Y, Lin Y, Lu Z, et al. Elevated plasma IL-37, IL-18, and IL-18BP concentrations in patients with acute coronary syndrome. Mediat Inflamm. 2014:2014.

327. Chauhan D, Vande Walle L, Lamkanfi M. Therapeutic modulation of inflammasome pathways. Immunol Rev. 2020;297(1):123-38 [cited 2021 Jan 22] Available from: https://onlinelibrary.wiley.com/doi/abs/10.1111/imr.12 908.

328. Lamkanfi M, Dixit VM. Inflammasomes and their roles in health and disease. Annu Rev Cell Dev Biol. 2012;28:137-61 [cited 2016 Feb 18] Available from: http://www.annualreviews.org.libproxy1.nus.edu.sg/doi/full/10.1146/annurevcellbio-101011-155745.

\section{Publisher's Note}

Springer Nature remains neutral with regard to jurisdictional claims in published maps and institutional affiliations.

Ready to submit your research? Choose BMC and benefit from:

- fast, convenient online submission

- thorough peer review by experienced researchers in your field

- rapid publication on acceptance

- support for research data, including large and complex data types

- gold Open Access which fosters wider collaboration and increased citations

- maximum visibility for your research: over $100 \mathrm{M}$ website views per year

At $\mathrm{BMC}$, research is always in progress.

Learn more biomedcentral.com/submissions 